\title{
The evolutionary ecology of flash displays and other transiently visible anti-predation signals
}

by

Karl Loeffler-Henry

A thesis submitted to the Faculty of Graduate and Postdoctoral Affairs in partial fulfillment of the requirements for the degree of

Doctor of Philosophy

in

Biology

Carleton University Ottawa, Ontario

(C) 2021, Karl Loeffler-Henry 


\begin{abstract}
Hidden anti-predation signals describe signals that serve to prevent predation and are not consistently visible but only exposed transiently. These signals have evolved independently numerous times in taxa ranging from insects to mammals. In spite of the fact that hidden signals are both conspicuous and abundant, we know relatively little about their evolution and function. The aims of this study are to answer two fundamental questions, 1 . how do hidden signals generate a fitness benefit, and 2. what ecological circumstances precipitate their evolution? In order to address these questions, I have combined custom-built computer games and phylogenetic character analysis. The computer games use humans as model predators and allowed us to simulate the deployment of hidden signals while manipulating specific parameters. The phylogenetic character analysis has allowed us to test whether certain morphological and behavioural traits are correlated with the evolution of hidden signals. By combining these two independent approaches we have been able to comprehensively evaluate a variety of hypotheses regarding the evolution of hidden signals. Chapter 1 summarizes the current knowledge of hidden signals. Chapter 2 describes an experimental "proof of concept", to determine if flash displays can generate a survival benefit through one specific proposed mechanism, namely a "decoy" effect. Chapter 3 describes a phylogenetic analysis used to test whether body size (a well-known predictor of predation risk), is correlated with the evolution of hidden signals across a range of insect taxa. Chapter 4 describes an experimental test of the efficacy of startle signals in deterring an insect predator. Chapter 5 combines an experimental and phylogenetic evaluation of the implications of flight initiation distance on the anti-predation benefit of flash displays. Finally, in Chapter 6 I summarize my thoughts on the collective implications of my thesis work. Overall, I argue that hidden signals are an ecologically important adaptation that can prevent attacks through multiple mechanisms and may be selected for by a variety of predator taxa.
\end{abstract}




\section{Acknowledgments}

I am extremely grateful to my supervisor Dr. Tom Sherratt. Throughout my doctoral studies Tom has generously shared his knowledge, experience and expertise. I am very fortunate to have had a supervisor and mentor who is not only extremely competent, but also dedicated to providing the best possible opportunities for my development as a scientist. I would also like to extend my gratitude to Dr. Changku Kang. The skills and knowledge that Changku imparted to me during his time at the Sherratt Lab have been integral to the creation of this thesis. It has been a privilege to collaborate with Chankgu on many research projects. I would also like to thank Dr. Tim Caro and Yolanda Yip without whose collaboration Chapter 2 would not have been possible. I am grateful to the members of my advisory committee Dr. Andrew Simons and Dr. Howard Rundle for providing much insightful feedback during our many committee meetings. In addition to being on my advisory committee Andrew galvanized my interest in research as my undergraduate thesis supervisor. I am also very grateful to Professor Michael Runtz who allowed me to take his Natural History course while I was still in high school. Without that experience I would not have had the opportunity nor the inclination to pursue a career as a biologist. I would also like to thank my examiners Dr. Ullasa Kodandaramaiah and Dr. Michael Hildebrand for taking the time to read my thesis and the insightful feedback provided during my defense. Additionally, I would like to thank the Carleton community as a whole for making my time as a student here enjoyable and informative.

In addition to my academic mentors and colleagues I also very grateful to the people who have supported me in my personal life. Starting with my mother Beth Loeffler-Henry who provided me with a strong foundation early life by nurturing my curiosity. I have many fond memories of the days that my mother took me out of primary school and spent time with me going to museums, reading, and going for nature walks. I would also like to thank my stepfather David Cook who along with my mother has provided me with unwavering support and spent countless hours proofreading my work, discussing research topics and has always been available to lend an ear and offer kind words of encouragement. I would like to thank my father Richard LoefflerHenry whose aquarium hobby strongly contributed to my interest in the natural world early in life. Additionally, Richard frequently took time to tutor me in r during my PhD studies. Lastly, I 
would like to express my gratitude to the many pets that I have kept over the years who played a pivotal role in both the development of my interest in living things and my growth as a person. In particular my dog Bingo, who provided me unconditional love and support every day from the first grade of primary school to my second year as a PhD student. Thank you for the time we spent together. 


\section{Co-authorship Statements}

Several chapters in this thesis have been published in collaboration with other authors. Specifically, Dr. Changku Kang, Yolanda Yip, Dr. Tim Caro and Dr. Tom Sherratt are coauthors of Chapter 2. Chapter 3 and 5 were published in collaboration with Dr. Changku Kang and Dr. Tom Sherratt. When Chapter 4 is ready for submission it will be in collaboration with Dr. Tom Sherratt. See author contribution sections of the respective published papers. 


\section{Table of Contents}

Abstract

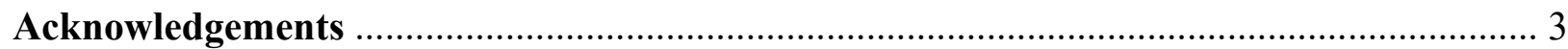

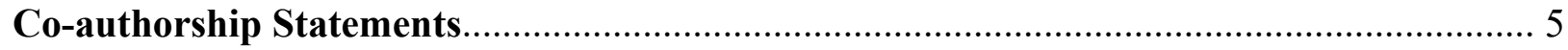

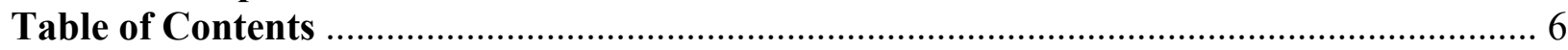

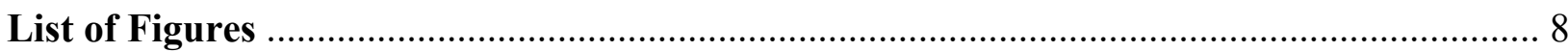

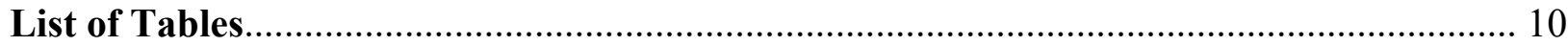

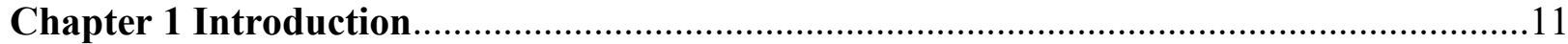

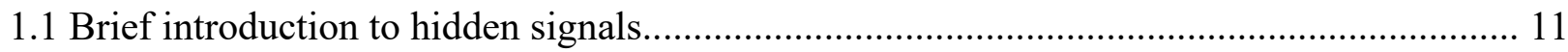

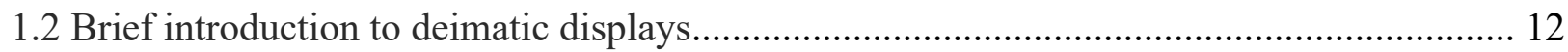

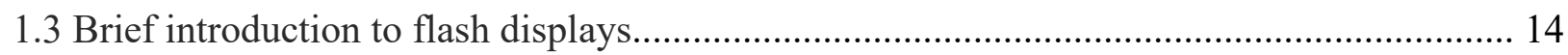

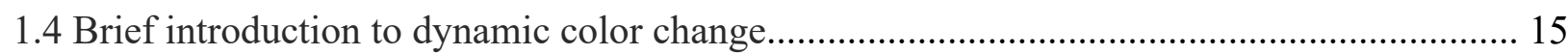

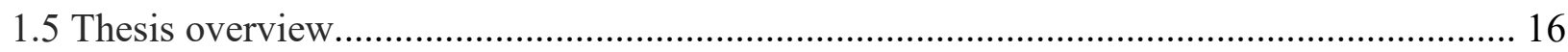

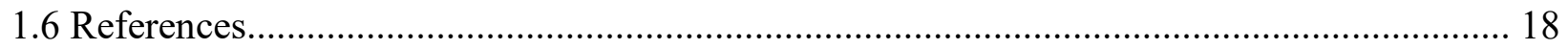

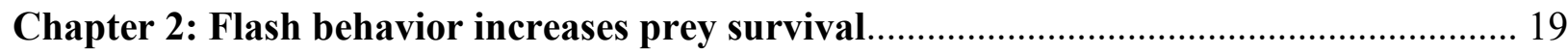

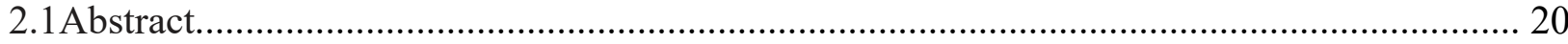

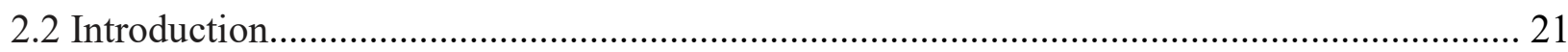

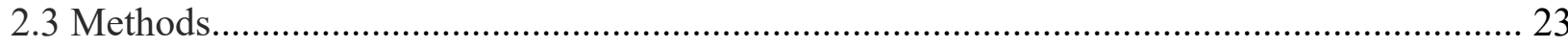

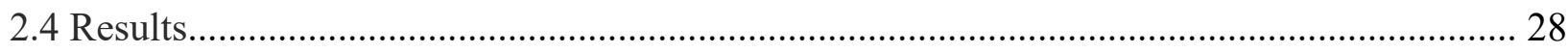

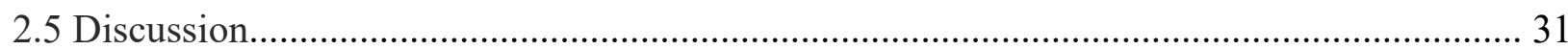

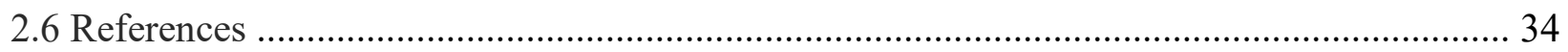

Chapter 3: Consistent Associations between Body Size and Hidden Contrasting Color

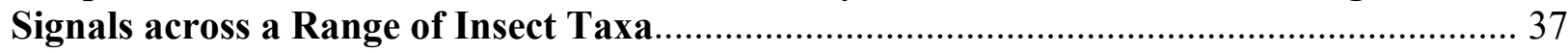

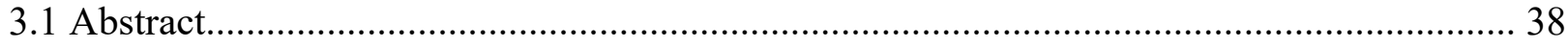

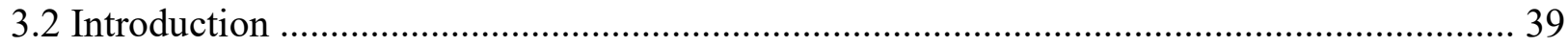

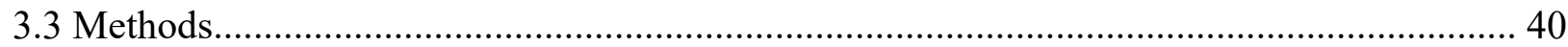

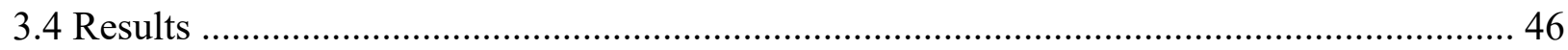

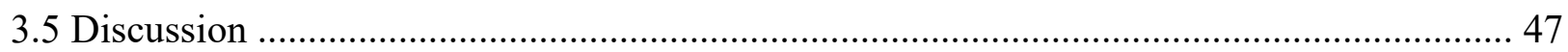

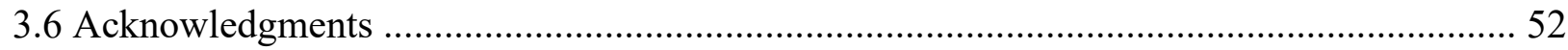

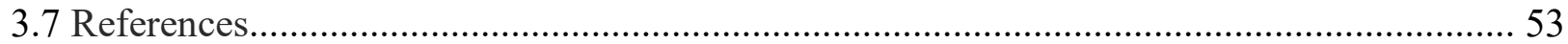

Chapter 4: Eyespots in large caterpillars deter insect predators ……………………....... 57

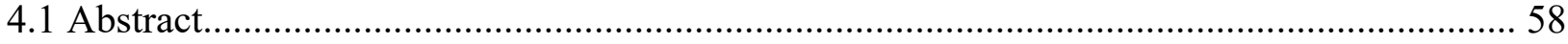

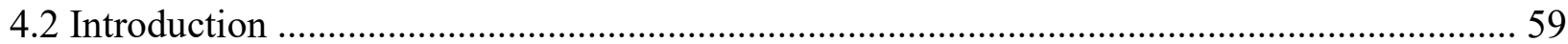

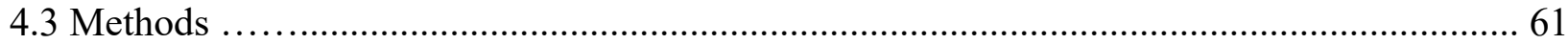

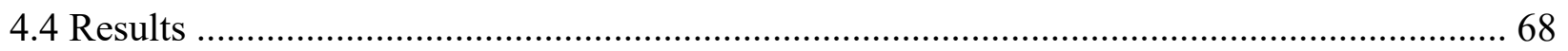

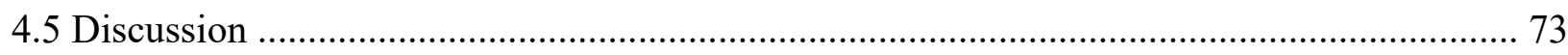

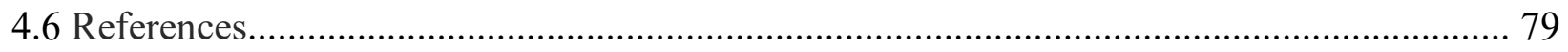


Chapter 5: The anti-predation benefit of flash displays is related to the distance at which

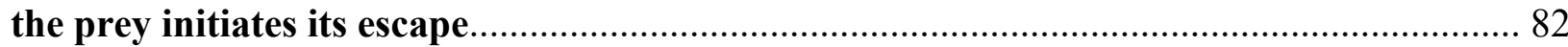

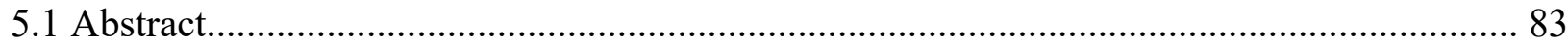

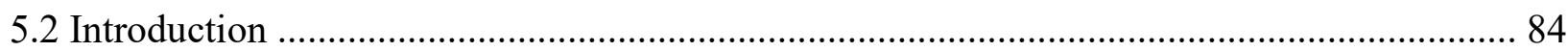

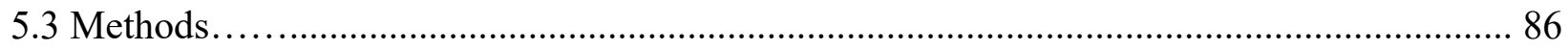

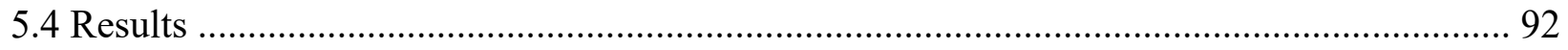

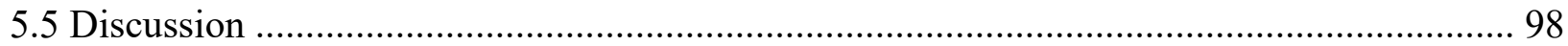

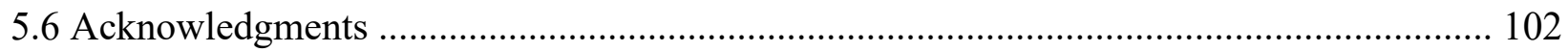

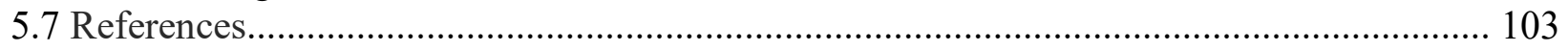

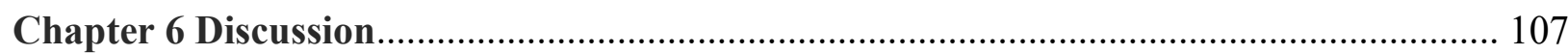

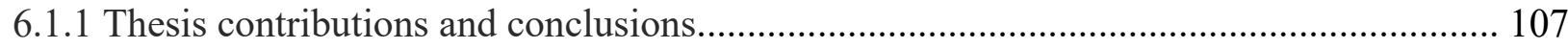

6.1.2 Remarks on the role of natural verses sexual selection in the evolution of hidden

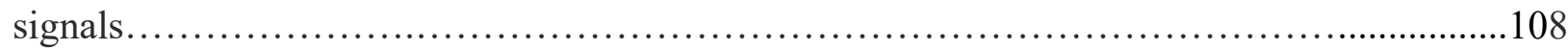

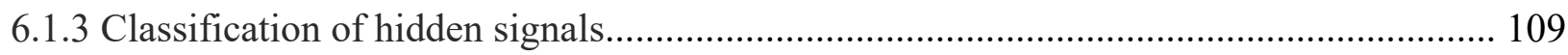

6.1.4 The role of non-avian predators in selecting for hidden signals................................... 110

6.1.5 The role of body size in the evolution of antipredation adaptation............................... 111

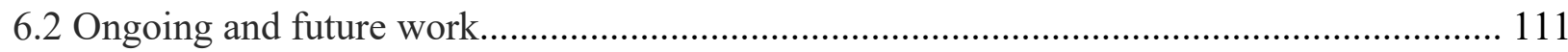

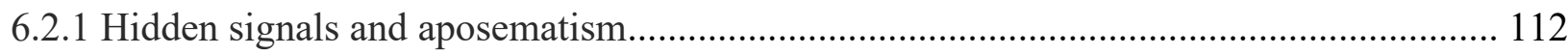

6.2.2 How insect predators contribute to the evolution of anti-predation signals globally....... 113

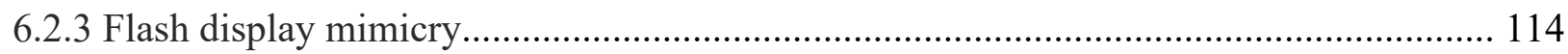

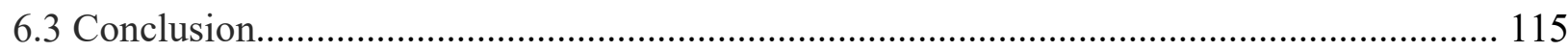

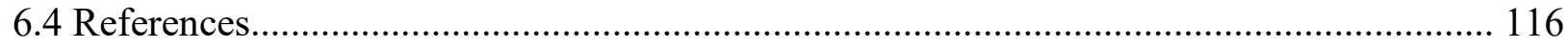

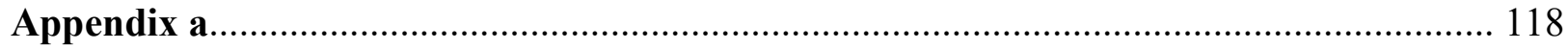

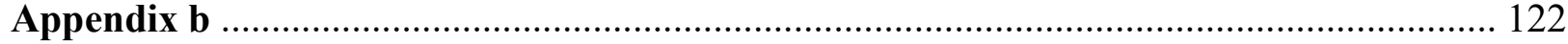

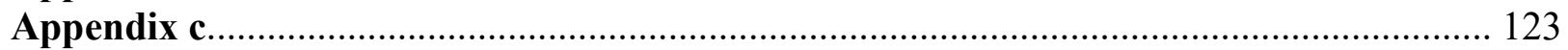




\section{List of Figure}

Figure 1.1 Examples of deimatic displays, Iris oratoria left, Arctia caja right............... 13

Figure 1.2 An example of a flash display Oedipoda caerulescens, cryptic resting appearance left,

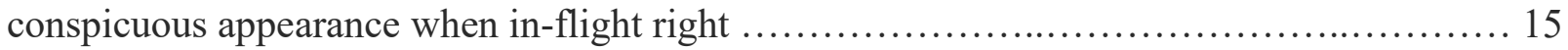

Figure 2.1 The prey (here shown together, although note that they were presented alone and in pseudo-random sequence to volunteers) displayed against the (a) grass and (b) sandy background. Individual prey were either cyan, magenta, blue, green, yellow, cryptic or red in color (left to right). Cryptic prey were presented only in the final 2 trials after presenting the prey with fixed conspicuous colors. These cryptic prey either kept their cryptic color when they moved, or they flashed red as they moved. Cryptic prey presented against the grass background had an red, green, blue values of each pixel (RGB) of $(73,151,19)$ and an RGB of $(192,156,111)$ when presented against a sand background....

Figure 2.2 Comparisons of the survivorship of cryptic prey and flashing prey when presented against 2 different backgrounds (grass and sand). (a) shows the comparison between cryptic prey and continuously flashing prey in Experiment 1 while (b) shows the comparison between cryptic prey and intermittently flashing prey in Experiment 2. Bars represent the mean survivorships and error bars represent Wilson binomial 95\% confidence intervals. $\mathrm{CR}=$ cryptic prey; $\mathrm{CF}=$ continuously flashing prey; IF = intermittently flashing prey....

Figure 2.3 The log transformed detection time (when the prey was found) and giving up time (when volunteers stopped looking, inferring the prey was not present in the scene) for cryptic prey and continuously flashing prey in Experiment 1. Bars and error bars represent mean and standard error of the mean. $\mathrm{CR}=$ cryptic prey; $\mathrm{CF}=$ continuously flashing prey ............. 30

Figure 3.1 Histograms of estimated color contrast values using image analysis for each group: Orthoptera (a), Mantidae (b), Phasmatidae (c), Saturniidae (d), and Sphingidae (e). The vertical line in each histogram shows the threshold above which the species were considered to possess hidden contrasting color signals determined by k-means clustering.

Figure 3.2 Each box-whisker plot shows the relationship between the presence of hidden contrasting color signals and body size for Orthoptera (a), Mantidae (b), Phasmatidae (c), Saturniidae (d), and Sphingidae (e) without controlling for phylogenetic relationships. Vertical lines in the middle indicate median values, boxes show interquartile ranges, whiskers show lowest/largest values, and dots show outliers. The numbers of species included in the analysis are

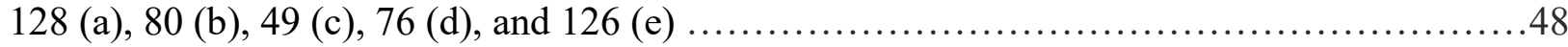

Figure 3.3 Coefficients and standard errors of the coefficients from the phylogenetic generalized least squares (PGLS) results. Positive values indicate that hidden contrasting color signals were associated with large size after controlling for phylogeny. See figure 3.2 for sample sizes. The photos show an example species in each group. From left to right, Phymateus morbillosus (photo credit: David Jackson), Deroplatys lobata (Edouard Hue), Phasma gigas (anonymous), Automeris io (upper, CBG Photography Group), Cautethia spuria (lower, Daniel H. Janzen).... 49 
Figure 4.1 Manipulated live five-spotted hawkmoth $M$. quinquemaculata larva used in this experiment (from left to right: small no eyespots, large no eyespots, small with eyespots, large

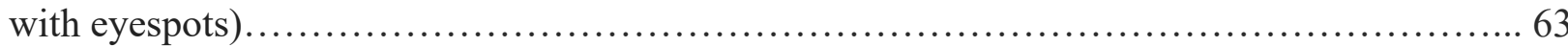

Figure 4.2 Survival plot of time taken for mantids to attack presented prey, following the fit of a Cox proportional hazards model. Small caterpillars with eyespots were most readily attacked while large caterpillars with eyespots were least readily attacked $\ldots \ldots \ldots \ldots \ldots \ldots \ldots \ldots \ldots \ldots . . .70$

Figure 4.3 Survival plot of time taken by mantids to reach "first base" following presentation of caterpillars. Large caterpillars with eyespots most readily attracted mantid attention, while small caterpillars without eyespots attracted least attention...................................... 71

Figure 4.4 Intra-specific comparison of eyespot size and body size of caterpillars across 10 ontogenetic stages. The red dots show the eye spot and body sizes of the manipulated caterpillars used in this experiment............................................................. 72

Figure 5.1 The mean proportion of each treatment prey type that survived once it had settled. The vertical error bars represent the $95 \%$ Wilson binomial confidence intervals for these means. FID: flight initiation distance................................................... 94

Figure 5.2 Distribution of the time taken by human volunteers to capture each of the four prey types. Those cases where the volunteer gave up searching were treated as censused at the time of giving up. Flashers with high flight initiation distances tended to survive the longest while nonflashers with high flight initiation distances tended to survive the shortest period of time.... 95

Figure 5.3 A scatterplot and density plots depicting the relationship between mean body mass, mean flight initiation distance (FID), and the presence of putative flashing signals in birds. We used the modal response of volunteers when classifying each species as having putative flashing signals or not ( $N=61$ species) for plotting. The trend lines represent the predictions from the PGLS models using the maximum clade credibility tree ................................ 96

Figure 5.4 Mean body mass, mean flight initiation distance (FID) [both logged] and the presence of putative flashing signals of each species and their phylogenetic positions on the maximum clade credibility tree

Figure 6.1, A putative example of the flash display mimicry, D. carolina left, $N$. antiopa right. 


\section{List of Figure Tables}

Table 3.1 Results of phylogenetically controlled analysis............................ 47

Table 4.1 Factorial design showing treatment combinations of large and small five-spotted hawkmoth caterpillars with and without eyespots. Treatment 0 involved a presentation of

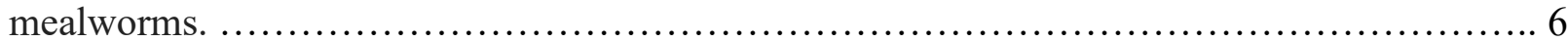

Table 4.2 Treatment order over the four test days arranged in the four separate temporal

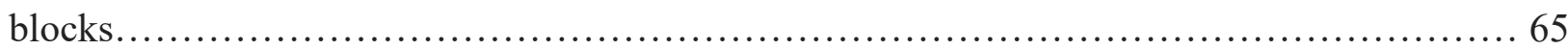

Table 5.1 Results of PGLS models (assuming a Brownian motion model of trait evolution) predicting the flight initiation distance of birds using the maximum clade credibility tree...... 98 


\section{Introduction}

\subsection{Brief introduction to hidden signals}

In evolutionary biology, a signal refers to a trait that has been selected for because it conveys information from one organism to another (Maynard-Smith \& Harper 2003). Conspicuous signals selected in prey to inform would-be predators of their unprofitability remain among the most celebrated examples of animal communication. These signals include aposematism (warning of a defence, Poulton 1890), Batesian mimicry (an undefended organism displaying the aposematic signal of a defended organism, Bates 1862) and Müllerian mimicry (multiple defended organisms converging on a common aposematic signal, Muller 1879). The vast majority of research that has so far been conducted on anti-predation signals has focused on signals that animals display continuously (Ruxton et al. 2018). However, there is another category of antipredation signals that has been relatively overlooked by evolutionary biologists, specifically antipredation signals that are only exposed transiently ("flash displays", Edmunds 1974). These transiently exposed signals can serve many of the same functions as consistently visible anti-predation signals. Additionally, their potential to be suddenly exposed when fleeing, lends them to a variety of other antipredation mechanisms. An investigation of the antipredation mechanisms specific to transiently exposed signals will be the focus of this thesis.

In this thesis, the umbrella term 'hidden signal' will be used to describe any anti-predation signal whose exposure can be modulated by an animal such that it is displayed transiently. In many flying insects (Lepidoptera, Orthoptera, Hemiptera, Phasmatodea and Mantodea), this may be accomplished by having a chromatic signal on the hindwings that is exposed during flight but is covered by forewings when the organism is at rest (Cott 1940, Edmunds 1974). Hidden signals can also take the form of contrasting and conspicuous bright patches on the inner thighs and undersides of frogs, and the conspicuous contrasting feathers of birds, that are only exposed in flight, as well as tail flags seen in lagomorphs and some ungulates (Caro et al. 2020, Edmunds 1974). 
Not all transiently hidden signals serve an antipredation function. Indeed, selection has favored transient visibility in numerous mate attraction signals throughout the animal kingdom. Examples of transiently visible mate attraction displays include the tail feathers of male peafowl (Phasianidae) and the conspicuous colors on the dorsal fins of male flasher wrasse (Labridae). Mate attraction signals may be distinguished from anti-predation signals by the following criteria. First, mate attraction signals are generally sexually dimorphic whereas antipredation signals tend not to be. Second, unlike mate attraction signals, anti-predation signals tend to be displayed in response to direct threat of predation, or at times of elevated predation risk (Edmunds 1974). In practice, distinguishing between signals that are the result of natural selection and those that are the result of sexual selection is often challenging and nuanced. In some cases, signals may function both to attract mates and deter predation, allowing both sexual and natural selection to operate synergistically in their evolution. One of the aims of this thesis is to test the extent to which natural selection has shaped the evolution of hidden signals. This will be accomplished by testing the degree to which the evolution of hidden signals is associated with predictors of predation pressure.

There have been three antipredation functions for hidden signals proposed in the literature. These are deimatic displays (e.g. Umbers et al 2017), flash displays (e.g. Edmunds 1974) and dynamic color change (e.g. Murali 2018). The antipredation applications of these forms of hidden signals are not mutually exclusive and differentiated by behavioral aspects of how they are deployed, as well as their effects on predators.

\subsection{Brief introduction to deimatic displays}

Deimatic displays describe the deployment of a hidden signal while stationary in response to direct threat of predation (Umbers et al 2017). In some cases, deimatic displays may involve a chemically defended organism temporarily modulating the visibility of an aposematic signal, such as the conspicuous vestigial wing displays of some chemically defended phasmids and the hood displays seen in cobras (snakes from the genus Naja). The potential utility of a transiently hidden aposematic signal is intuitive. By only displaying warning colors when under direct threat, an organism may be able to avoid detection from both potential predators and prey, while 
retaining the benefits of aposematism when necessary (Song et al. 2020). Intriguingly, many relatively undefended organisms are also known to possess deimatic displays (Edmunds 1974). One possible explanation for this is Batesian mimicry. In much the same way that aposematic organisms may benefit from concealing their signals when not in use, Batesian mimics may also be able to obtain a best of both world's strategy of both crypsis and conspicuous signals (Kim et al. 2020). In addition to benefiting from resemblance to aposematic signals, many deimatic displays appear to resemble organisms that may pose a predation threat to the predators of the displaying organisms. Specifically, markings which resemble the eyes of predatory birds or snakes are seen on many deimatic displays including those of flower mantids (Mantidea), snake mimicking caterpillars of the genus Hemeroplanes (Sphingidae) and frogs of the genus Pleurodema (Edmunds 1974). In addition to the possible advantages of not displaying a conspicuous signal continuously, the effect of transiently visible eyespots may be enhanced by their sudden exposure. In fact, the sudden exposure of any conspicuous signal, even those that do not directly resemble specific threatening stimuli may generate a fitness benefit by startling a predator enough to buy time for escape (Kang et al 2017). This supposition is supported by the fact that selection has favored deimatic displays that do not appear to be mimetic in a number of unprotected organisms - most notably mantodea (Edmunds 1974).

Although, as stated above, the majority of research on antipredation signals has focused on those that are consistently visible, there have been a number of advances in our understanding of deimatic displays. Sargent (1978) for example, suggested and found some evidence that predator habituation may select for chromatic diversity in sympatric deimatic displays. More recently, Umbers \& Mappes (2015) found that naïve avian predators are more deterred by deimatic displays than those that have prior experience with such defenses. Kang et al. (2017) found that relatively large body size is necessary for putative deimatic displays in lepidoptera to effectively deter avian predators. Additionally, Kang et al. (2017) found that large erebidae moths are more likely to evolve contrasting hindwings compared to their smaller counterparts. The underlying mechanism that has resulted in large Erebidae moths being disproportionately prone to evolve deimatic displays is likely not specific to this group. The extent to which body size predicts the evolution of deimatic displays across insect taxa has yet to be tested. Likewise, experimental tests of the antipredation efficacy of deimatic displays has largely focused on avian predators. 
The capacity of deimatic displays (including eyespots) to deter ecologically relevant non-avian predators remains largely unknown (but see Prudic et al. 2015).

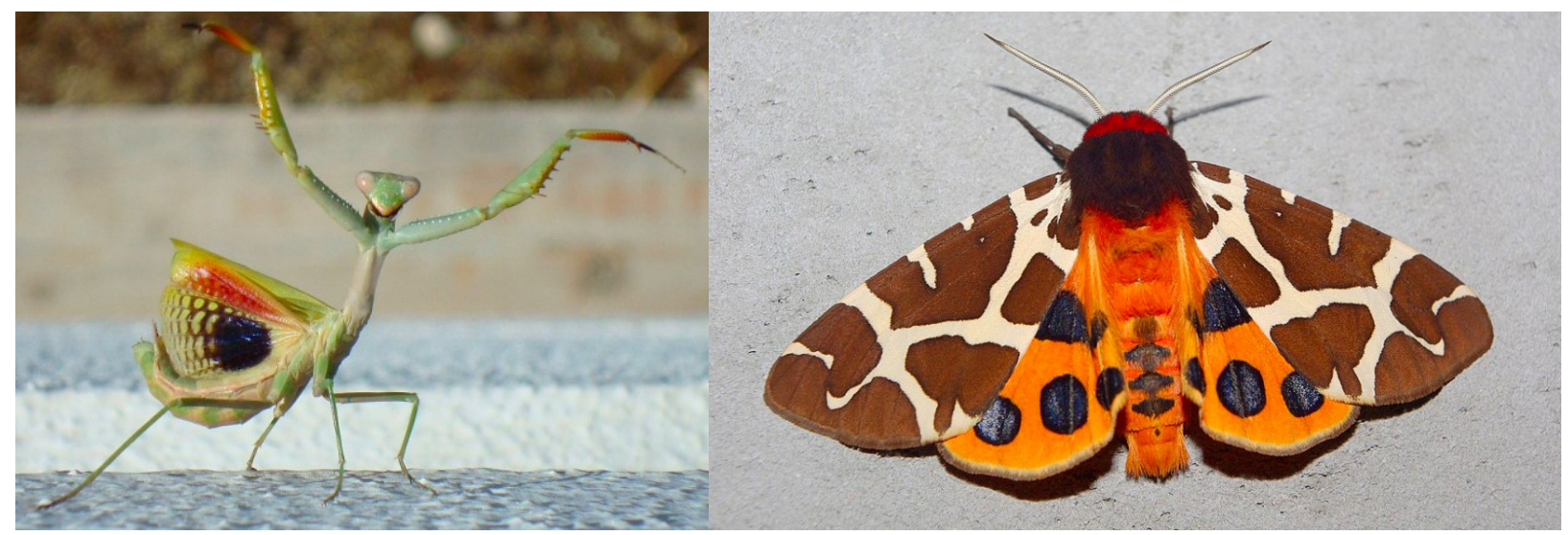

Figure 1.1 Examples of deimatic displays, Iris oratoria left, Arctia caja right.

\subsection{Brief introduction to flash displays}

Flash displays describe the sudden deployment of a hidden signal while fleeing, followed by the synchronized disappearance of the hidden signal and the cessation of movement (Edmunds 1974). Putative flash displays are taxonomically widespread. Examples include the tail flags of many Artiodactylas, the conspicuous hindwings seen in numerous insects, as well as conspicuous patches on the inner thighs of many hylid frogs and the rump patches of many birds that are only displayed when in flight. Like deimatic displays, flash displays may allow a chemically defended or mimetic organism to gain the benefit of both crypsis and conspicuous signals. This may be particularly advantageous while in motion because movement necessitates the abandonment of crypsis leaving an organism without a backup defense relatively vulnerable (Hall et al. 2013). The sudden disappearance of a flash display at the cessation of movement may function to confuse the predator as to the prey's resting appearance (with its flash display hidden), making detection more difficult (Cott 1940, Edmunds 1974, Loeffler-Henry et al. 2015). The presence of putative novel flash displays in numerus unprotected organisms suggests that flash displays do convey some fitness benefits beyond simply transient aposematism and mimicry.

Compared to deimatic displays, the literature on flash displays is relatively sparse. Naturalists and evolutionary biologists have speculated about the function of flash displays since at least 
1940 (Cott 1940). However as noted above, prior to work in this thesis, evidence of the adaptive significance of flash displays has remained elusive. Palleroni et al. (2005) found that pigeons with transiently visible conspicuous rump patches where less likely to be captured by falcons. However, the benefit appears to only be present when pigeons are in midflight suggesting a different mechanism from flash displays (Murali 2018). Establishing a "proof of concept" that flash displays can provide an anti-predation benefit is a prerequisite for further research on this topic. Once a "proof of concept" is established, outstanding questions about flash displays will include the following: What is the mechanism that causes them to yield an anti-predation benefit? Why, if they are effective in preventing attacks, are they selected for in some species but not others? And to what extent does their adaptive significance overlap with that of deimatic displays?
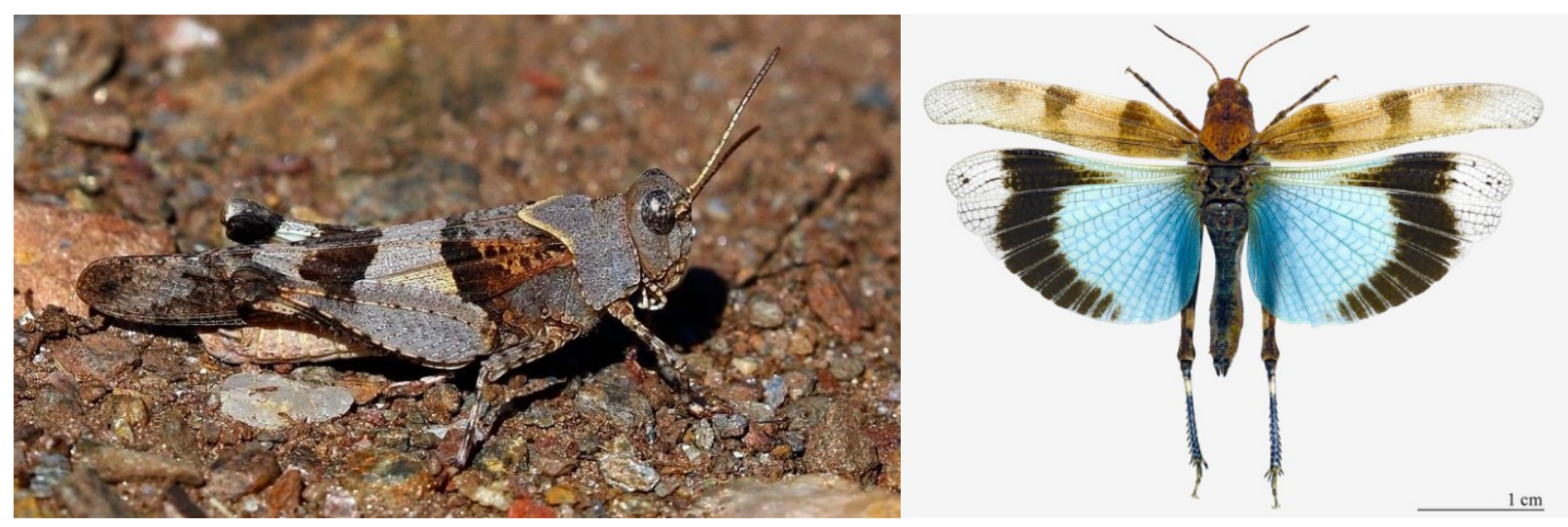

Figure 1.2 An example of a flash display Oedipoda caerulescens, cryptic resting appearance left, conspicuous appearance when in-flight right.

\subsection{Brief introduction to dynamic color change}

Recently it has been found that by rapidly alternating between two contrasting colors while in motion an organism may hinder capture attempts (Murali 2018, Murali et al. 2019, Murali \& Kodandaramaiah 2020). This mechanism has been postulated to result from the flash lag affect (Murali 2018, Nijhawan 2002). Notably a number of taxa (birds and insects with hidden contrasting signals) with putative flash displays have also been proposed to benefit from dynamic color change (Murali 2018, Cott 1940). While similar to the decoy function of flash displays, these two mechanisms may operate independently from one another. This is because the benefit of dynamic color change occurs while the prey is in motion, whereas the decoy 
function of flash displays is postulated to reduce the probability of capture after the prey has settled.

\subsection{Thesis overview}

The primary aim of my doctoral work was to answer two fundamental questions, 1 . how do hidden signals generate a fitness benefit, and 2 . what ecological circumstances are associated with their evolution? In order to address these questions, I have combined custom-built computer games and phylogenetic character analysis. The computer games that use humans as model predators have allowed us to simulate hidden signals while manipulating specific variables. The phylogenetic character analysis has allowed us to evaluate and test specific null hypotheses as to what ecological circumstances are associated with the evolution of flash displays. By combining these two complementary approaches, I have been able to evaluate a variety of hypotheses regarding the evolution of flash displays. First and foremost, I simply wished to test whether flash displays are capable of yielding a survival benefit for the reasons postulated.

Having tested whether flash displays can confer a "survival" benefit to computer generated prey, I next tested the hypothesis that elevated predation pressure is correlated with the evolution of flash displays and deimatic displays. In insects, large body size is associated with increased risk

of predation. This is because large insects are inherently more conspicuous and offer predators a greater caloric reward (Mänd et al, 2007). Therefore, I tested whether the evolution of hidden signals is correlated with body size in insects

Behavioral experiments suggest that selection from avian predators has contributed to the evolution of hidden signals. However, questions remain. In particular, it is unclear whether insect predators are deterred by deimatic displays, whether hidden or permanently displayed. Here I test whether predation by mantids is in any way inhibited when prey have permanently displayed eyespots.

Finally, it is unclear if the mechanism that drives the anti-predation benefit of flash displays is a visual illusion like the flash lag effect, analogous to dynamic color change, or the decoy effect, a 
cognitive illusion, as proposed by Cott (1940). To test if the decoy effect plays a role in the antipredation benefit of flash displays it is necessary to establish if the predator's ignorance of the preys resting color influences the antipredation benefit experienced by flashing prey?

This thesis will be concluded with a discussion in which I will summarize my thoughts on the collective implications of the previous 4 data chapters and some notes on possible future directions of hidden signal research.

\subsection{References}

Bates, H. W. 1862 Contributions to an insect fauna of the Amazon valley (Lepidoptera: Heliconidae). Trans. Linn. Soc. 23, 495-566. (doi:10.1111/j.1096-3642.1860.tb00146.x)

Caro T, Raees H, Stankowich T. 2020 Flash behavior in mammals? Behav. Ecol. Sociobiol. 74, 1 - 7. (doi:10.1007/s00265-020-2819-0)

Cott HB. 1940 Adaptive coloration in animals. London, UK: Methuen.

Edmunds M. 1974. Defence in animals: a survey of anti-predator defences. New York (USA): Longman Publishing Group.

Hall JR, Cuthill IC, Baddeley R, Shohet AJ, Scott- Samuel NE. 2013 Camouflage, detection and identification of moving targets. Proc. R. Soc. B 280, 20130064. (doi:10.1098/rspb.2013.0064)

Kang C, Zahiri R, Sherratt TN. 2017 Body size affects the evolution of hidden colour signals in moths. Proc. R. Soc. B 284, 20171287. (doi:10.1098/rspb. 2017.1287)

Kim Y, Hwang Y, Bae S, Sherratt TN, An J, Choi SW, Miller JC, Kang C. 2020 Prey with hidden colour defences benefit from their similarity to aposematic signals: Survival value of hidden colour defences. Proc. R. Soc. B Biol. Sci. 287. (doi:10.1098/rspb.2020.1894)

Nijhawan R. 2002 Neural delays, visual motion and the flash-lag effect. Trends Cogn. Sci. 6, 387-393. (doi:10.1016/S1364-6613(02)01963-0)

Mänd T, Tammaru T, Mappes J. 2007 Size dependent predation risk in cryptic and conspicuous insects. Evol. Ecol. 21, 485- 498. (doi:10.1007/ s10682-006-9130-z)

Maynard-Smith, J. \& Harper, D. 2003 Animal signals. Oxford, UK: Oxford University Press. 
Müller, F. 1879 Ituna and Thyrida: a remarkable case of mimicry in butterflies. Proc. Entomol. Soc. Lond. 1879, 20-29.

Murali G. 2018 Now you see me, now you don't: dynamic flash coloration as an antipredator strategy in motion. Anim. Behav. 142, 207 - 220. (doi:10. 1016/j.anbehav.2018.06.017)

Murali G, Kumari K, Kodandaramaiah U. 2019 Dynamic colour change and the confusion effect against predation. Sci. Rep. 9, 274. (doi:10.1038/ s41598-018-36541-7)

Murali G, Kodandaramaiah U. 2020 Size and unpredictable movement together affect the effectiveness of dynamic flash coloration. Anim. Behav. 162, 87-93.

(doi:10.1016/j.anbehav.2020.02.002)

Palleroni A, Miller CT, Hauser M, Marler P. 2005 Prey plumage adaptation against falcon attack. Nature 434, 973 - 974. (doi:10.1038/434973b)

Poulton, E. B. 1890 The colours of animals: their meaning and use. Especially considered in the case of insects. The international scientific series, 2nd edn. London, UK: Kegan Paul, Trench Trübner, \& Co.

Ruxton GD, William AL, Sherratt TN, Speed MP. 2018 Avoiding attack: the evolutionary ecology of crypsis, warning signals, and mimicry, 2nd edn. New York, NY: Oxford University Press.

Sargent TD. 1978 On the maintenance of stability in hindwing diversity among moths of the genus Catocala (Lepidoptera: Noctuidae). Evolution 32, 424 - 434. (doi:10.2307/2407609)

Song W, Lee SI, Jablonski PG. 2020 Evolution of switchable aposematism: Insights from individual-based simulations. PeerJ. (doi:10.7717/peerj.8915)

Umbers KDL, Bona SD, White TE, Lehtonen J, Mappes J, Endler JA. 2017 Deimatism: a neglected component of antipredator defence. Biol Lett. 13, 20160936.

(doi:10.1098/rsbl.2016.0936)

Umbers KDL, Mappes J. 2015 Postattack deimatic display in the mountain katydid, Acripeza reticulata. Anim. Behav. 100, 68 - 73. (doi:10.1016/j.anbehav. 2014.11.009) 


\section{Chapter 2: Flash behavior increases prey survival}

Karl Loeffler-Henry ${ }^{1}$, Changku Kang ${ }^{1 *}$, Yolanda Yip ${ }^{1}$, Tim Caro $^{2}$, Thomas N Sherratt ${ }^{1}$

${ }^{1}$ Department of Biology, Carleton University, Ottawa, ON, Canada

${ }^{2}$ Department of Wildlife, Fish and Conservation Biology and Center for Population Biology, University of California, Davis, CA, USA

*Corresponding author

Published in Behavioral Ecology (2018) 29: 528-533

Reproduced here in whole in accordance with Elsevier terms and conditions. 


\subsection{Abstract}

Flash behavior, in which otherwise cryptic prey exhibit conspicuous coloration or noise when fleeing from potential predators, has been postulated to hinder location of prey once they become stationary. Here, using artificial computer-generated prey and humans as visual predators, we show that human subjects are more likely to abandon their search for prey that flash, compared to continuously cryptic fleeing controls. Survivorship of flashing prey was an additional $20 \%$ higher than the survivorship of continuously cryptic prey, depending on the background against which it was depicted. This survivorship advantage was consistent regardless of whether prey showed flash colors continuously or intermittently during flight. The advantage over continuously cryptic prey was highest when the flashing prey was presented first. Likewise, the more search areas containing no prey that the volunteers had initially viewed, the more likely they were to give up when there was a cryptic prey present. Collectively, these 3 findings indicate that volunteers inferred the flashing prey was absent from the search area when they failed to see a prey in the same form as they saw it move. Our results demonstrate first proof of concept: flash behavior, widely seen in taxa from insects to mammals, is an effective antipredator escape mechanism. 


\subsection{Introduction}

Flash behavior describes the way in which an otherwise cryptic prey suddenly reveals a conspicuous patch of color or emits noise during movement after disturbance and then hides the patch or ceases to make a sound on stopping (Cott 1940; Edmunds 1974; Edmunds 2008). Examples of patches of color that are only displayed when fleeing include the bright hindwings (underwings) of noctuid and sphingid moths, and the proximal portions of the hindwings of cicadas (Hemiptera), grasshoppers (Orthoptera), and stick insects (Phasmatodea) (Cott 1940; Edmunds 1974). Such insects are cryptic at rest, but conspicuous in flight. Before flight and shortly after coming to rest following escape, these individuals fold their brightly colored hindwings beneath their cryptic forewings. Flash behavior exhibited during movement is also seen in many vertebrate taxa including frogs (Williams et al. 2000), some even-toed ungulates (Artiodactyla) (Caro et al. 2004) and rabbits and hares (Leporidae) (Stoner et al. 2003).

At present, the adaptive significance of this putative antipredator defense is unknown. Cott (1940) noted that it seems "to confuse or misdirect an enemy in the pursuit of prey" (p. 376), stressing that it is the "sudden disappearance of color combined with the equally sudden suspension of movement which tends to mislead the eye and to render the animal's exact whereabouts on alighting all the more difficult to detect". Edmunds (1974) similarly suggested that the predator "may be caused to hesitate by the sudden movement and appearance of the bright color ... and it may follow this color and be deceived by its sudden disappearance into assuming the prey has vanished whereas in reality the prey has come to rest in its normal cryptic posture with the colored structures hidden." As such, flash colors could serve to initially startle a would-be predator while the prey is on the move and/or hinder the predator's search if it follows the color rather than the organism (Edmunds 2008). These hypotheses are entirely plausible, but, as yet as far as we are aware, there is no evidence that flash behavior has evolved for these reasons. Here, we conduct experiments to test the second component of the above explanations, namely that flash behavior hinders subsequent search for potential prey.

Before describing the experiments, we first need to clarify precisely what we mean by flash behavior because it has been used rather broadly to represent almost any conspicuous display of color. Naturally, we focus here on the role of flash color as an anti-predator defense, rather than for mate attraction (see for example Lloyd 1971; Schultz and Fincke 2009; Ballantyne and 
Lambkin 2013). In that context, flash coloration is a term that has been used to describe startle ("deimatic") displays produced by stationary organisms in response to the approach or contact by a predator, thereby slowing or halting attack (Umbers and Mappes 2015; Kang et al. 2016; Umbers et al. 2017). While the sudden appearance of something previously hidden could serve to intimidate or distract predators, whether the prey is stationary or mobile (Olofsson et al. 2012; Kang et al. 2017), the second hypothesized protective mechanism associated with flash behavior is different: it involves hindering subsequent search for previously mobile prey. By contrast, deimatic displays do not involve a search-hindering affect. Flash coloration is occasionally used to refer to conspicuous signals that are easily seen during flight, such as the black flank stripe of the Thomson's gazelle Eudorcas thomsoniii, thought to amplify stotting, thus informing the predator that the prey is difficult to catch (Caro and Stankowich 2010). However, the signal is not hidden once the prey has stopped, so it is unlikely to have evolved to hinder search, and we do not consider this further.

Flash coloration in mobile prey has 2 forms: a continuous display of a conspicuous patch during flight, or an intermittent display. Continuous flash behavior has been described in many taxa including cryptic Herennia ornatissima spiders showing their red ventrum while descending rapidly on a thread from their webs (Anonymous 1945), in Oedipoda grasshoppers showing bright red lateral surfaces as they fly away from a disturbance (Edmunds 2008), in dull colored shorebirds showing their white backs, rumps or tails when fleeing en masse (Del Brooke 1998), and in white-tailed deer Oedicolus virginianus tail-flagging (Caro et al. 1995). Intermittent flashing is seen in some lepidoptera as they beat their wings (Edmunds 2008) and in some leporids such as the black-tailed jackrabbit Lepus californicus showing its black tail during flight (Kamler and Ballard 2006). Whether continuous and intermittent flashes serve different functions is unclear, so our experiments investigated the properties of both forms of display.

Flash colors could protect the prey by affecting predator psychology. As Cott (1940) and Edmunds (2008) suggested, flash colors displayed during movement may deceive visual predators about the subsequent location of the prey at rest. Additionally (or alternatively), flash colors may confuse predators about the resting colors of prey. Because fleeing prey allow predators to observe the prey momentarily, predators may formulate a transient "search image" based on flash colors (Tinbergen 1960; Langley 1996), although strictly speaking search image 
formation applies only to cryptic prey (Lawrence and Allen 1983). It is possible that flash colors are the most salient feature of prey during fleeing, thus making predators perceive prey to be of a completely different color than their resting color. If true, predators will be more likely to give up their search for prey that have exhibited flash behavior than those that have not, believing them to have fled the scene if they do not readily detect them. In this study, we used computergenerated artificial prey and humans as visual predators, which is a useful and convenient system to test the adaptive significance of animal coloration, and specifically to test the hypothesis that flash behavior causes predators to abandon search for cryptic prey.

\subsection{Methods}

We recruited anonymous human volunteers and evaluated the responses of each participant to flash behavior using a custom-built computer-based game. Our volunteers were visitors (largely undergraduates) to the University Centre at Carleton University, Ottawa, Canada and both experiments were conducted from May to July 2017. Games were presented on a 23" LCD monitor (Dell ST-2310f). Prior to testing, we showed each participant a tutorial video about the game, but details of the hypothesis were not disclosed. Each game had 2 phases, namely "prey escape" and "search." Once each participant understood the nature of the game and was ready to play, the game was started.

At the start of the prey escape phase, a single square prey item $(375 \times 375$ twips, with the number of pixels $=$ twips $/ 15$ ) of given color was placed at a random position on a complex background image (grass or sand, dimensions $8172 \times 16,764$ twips, Figure 2.1 ). When a participant moved the mouse pointer on the background image within 20,000 twips of the prey (hence any movement of the mouse pointer into the background image), the prey moved to escape. Escape was to either the left or right side of the screen (whichever was the furthest to move). Prey movement was simulated as a directed random walk comprising of a rapid sequence of discrete steps in randomly drawn directions taken from a given distribution. The step size of the prey throughout was 600 twips, the step angle was chosen at random from an even distribution within $\pm 45^{\circ}$ from the horizontal, and the duration of wait before new step was 30 ms. 

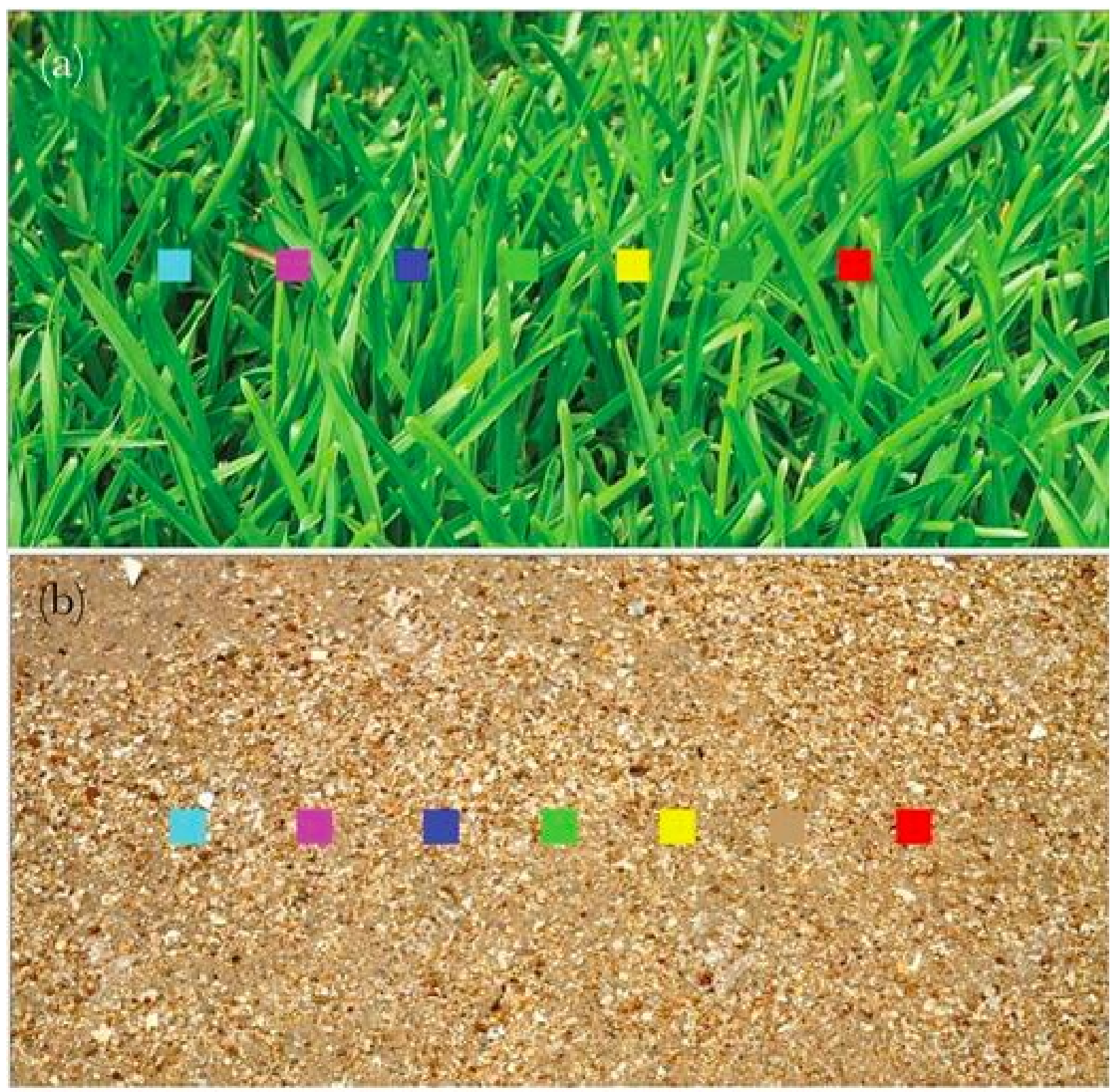

Figure 2.1 The prey (here shown together, although note that they were presented alone and in pseudo-random sequence to volunteers) displayed against the (a) grass and (b) sandy background. Individual prey were either cyan, magenta, blue, green, yellow, cryptic or red in color (left to right). Cryptic prey were presented only in the final 2 trials after presenting the prey with fixed conspicuous colors. These cryptic prey either kept their cryptic color when they moved, or they flashed red as they moved. Cryptic prey presented against the grass background had an red, green, blue values of each pixel $(\operatorname{RGB})$ of $(73,151,19)$ and an RGB of $(192,156,111)$ when presented against a sand background.

The prey (here shown together, although note that they were presented alone and in pseudorandom sequence to volunteers) displayed against the (a) grass and (b) sandy background. Individual prey were either cyan, magenta, blue, green, yellow, cryptic or red in color (left to 
right). Cryptic prey were presented only in the final 2 trials after presenting the prey with fixed conspicuous colors. These cryptic prey either kept their cryptic color when they moved, or they flashed red as they moved. Cryptic prey presented against the grass background had an red, green, blue values of each pixel (RGB) of $(73,151,19)$ and an RGB of $(192,156,111)$ when presented against a sand background.

These parameter settings allowed the participant to observe the retreating prey for $1-2 \mathrm{~s}$, depending on its starting position. Following the "escape" of prey, volunteers were asked to click a follow button, after which the search phase began. During search phase, the volunteers were shown an inverted version of the same background screen (to prevent prey being revealed through the contrasting otherwise identical images), with the same prey present at a new random location. The volunteers were asked to find the escaped prey and click on it (generating a pleasant sound and happy face when complete). In this phase, volunteers had 2 options: moving the mouse to the prey and clicking directly on it, or pressing a "give up" button to move on to the next prey if they could not find it (inferring that no prey was present in the screen).

Training and general experimental procedure

We presented 8 preys sequentially to each participant. The first 6 were considered as training prey and each of these was colored differently (magenta, cyan, red, green, yellow, and blue; see Figure 2.1), conspicuous against the grass or sand background and presented in a random order. The grass background was of lush green grass while the sandy background showed grains of light brown sand with tiny pebbles scattered on it. The grass background image was readily discriminable from the conspicuous green colored prey used in the training sessions. Crucially, all of these prey maintained the same color while moving (escape phase) and when sedentary (search phase).

For the first 6 prey types, there was a $25 \%$ probability that the prey would not be present in the search phase (i.e., the second screen). We used these blank "duds" in order to get the volunteers used to the fact that there can sometimes be no prey in a search screen after it had escaped (mimicking a rabbit disappearing down a hole, for example). When the prey was absent from the search screen, volunteers would inevitably press the "give up" button and the same color trial was entered again into the list of prey that had not yet been attacked, so that it could be presented 
again (in a random sequence of prey not yet searched for). See Supplementary Video S1 for a sample video.

After all 6 training prey were eventually attacked, volunteers were each presented with 2 treatment prey: a cryptic prey with continuous flash when it moved (continuous flash, CF) and a cryptic prey without flash when it moved (cryptic throughout, CR). The color of cryptic prey had mean R, G, and B values of the background image (Wyszecki and Stiles 1982), making it relatively hard to detect because of the background color matching between prey and background (Merilaita and Stevens 2011). CR prey displayed the cryptic color both when sedentary and when moving. CF prey showed the same cryptic color when sedentary, but exhibited a red color while moving; red is a common flash color found in insect prey thought to exhibit flash behavior (Edmunds 2008). CR prey were presented prior to CF prey for half of the volunteers and the order was reversed for the other half. The prey was always present in the search phase.

To test whether the results could be generalized across different background types, the experiment was repeated twice, once with a grass and once with a sandy background. Following the experiment, a noncomprehensive red/green color-blindness test was performed. Data from volunteers who demonstrated signs of color blindness $(n=5)$ were excluded from analysis. For each training and test image shown to each volunteer that was present on the search screen, we recorded 1) a binary response whether the participant attacked the prey or clicked the "give up" button and so moved on to the next image without finding the prey, and 2) the time spent on each image until either they detected the prey (detection time) or gave up searching (giving up time). There was no maximum cut-off time. A total of 120 volunteers judged to be non-color blind were tested ( 60 for each background). Each volunteer experienced only one type of background. Experiment 2: Intermittently flashing prey versus cryptic prey In this experiment, we tested whether intermittently displayed flash (hereafter, IF) color could increase survivorship of the prey. All conditions remained the same as in Experiment 1, except that we changed the nature of the flash behavior. Whenever a prey with flash behavior moved on the screen its color flickered (flickering rates: mean of 16.7 changes/seconds) between red and cryptic colors by randomly selecting red or cryptic at each step in the rapid random walk rather 
than constantly showing red color. Again, we tested 120 volunteers for this experiment (60 for each background).

Data analysis

In both experiments, our primary goal was to test whether cryptic prey with flash behavior had a survival advantage over cryptic prey without flash behavior. To test this, we fitted generalized (and general) linear mixed models to the data and compared 1) prey survivorship (binary response) and 2) prey searching time of volunteers hunting for cryptic and flashing prey (continuous response). The search time has 2 different endpoints: it indicates the time taken to detect the prey when the prey was detected (detection time) and it indicates the time taken until the volunteer gave up looking for the prey if the prey was not detected (giving up time). Thus, we separately analyzed detection time and giving up time. In each case, the search time response was $\log$ transformed to meet the assumptions of the fitted general linear model.

For Experiment 1, we treated prey type (CR or CF), background type (grass or sand), and the interaction between these 2 main effects as explanatory variables. We also included 1) the order of presentation of $\mathrm{CR}$ and $\mathrm{CF}$ as a fixed effect to control for any effect of presentation order, and 2) the interaction between presentation order and our color treatment as predictors, since the order that prey appeared first could have influenced the volunteers' performance in finding prey. Since "duds" appeared stochastically in the training, the number of "duds" that occurred during a trial varied among volunteers ranging from 0 to 9 duds (on average, volunteers experienced 1.9 duds while $19.1 \%$ of the tested individuals did not experience any duds). To estimate and control for any effect of duds, we additionally included the number of duds that appeared for each participant in the training sequence as a covariate. To account for possible differences among human volunteers, and ensure independence, the volunteer was treated as a random effect. The analysis of Experiment 2 proceeded in the same way, with prey type treatments now being CR and IF (intermittent flash).

To compare the effectiveness of CF prey with IF prey in reducing predation between experiments, we fitted 2 separate models using 1) survivorship (binomial), 2) giving up time (continuous), and 3) detection time (continuous) as response variables respectively (only one observation for each human was used in each analysis, so a random effect was not necessary to 
control for independence). Prey type (CF vs. IF), background type, the order of the presentation (whether flashing prey was presented prior to or after cryptic prey in each experiment), number of duds, and the interaction between background and prey type were included as explanatory variables. In all results, we present the model with the lowest Akaike Information Criterion (AIC) among competing candidate models. The analysis of deviance table for each analysis is shown in Supplementary Tables S1 and S2. All the analyses were conducted in R (R Core Team 2017) using "Ime4" package (Bates et al. 2015).

\subsection{Results}

Experiment 1: Continuously flashing prey versus cryptic prey

Survivorship of the CF prey was on average $19 \%$ higher than CR prey (Figure $2.2 \mathrm{a}, \chi^{2}{ }_{1}=$ $10.55, P=0.001$ ), and the overall survivorship of prey was significantly higher on a grass background than on a sandy background (Figure 2.2a, $\chi^{2} 1=6.78, P=0.009$ ). We also found a significant interaction effect between background and prey type (Figure 2.2a, $\chi^{2}{ }_{1}=25.63, P<$ 0.001 ) in that the survivorship advantage of the continuously flashing prey was stronger against grass compared to the sandy background. The overall trend of CF prey surviving better than $\mathrm{CR}$ prey was consistent between the 2 backgrounds. Interestingly, however, presentation order had a significant effect on prey survivorship (order effect, $\chi^{2}{ }_{1}=25.42, P<0.001$ ) and survivorship of CF prey higher when they were presented prior to CR prey rather than presented later (treatment $\times$ order interaction, $\left.\chi^{2}{ }_{1}=5.09, P=0.02\right)$. Volunteers were less likely to detect the prey as they experienced a greater number of duds $\left(\chi^{2}{ }_{1}=9.36, P=0.002\right)$. 
(a)
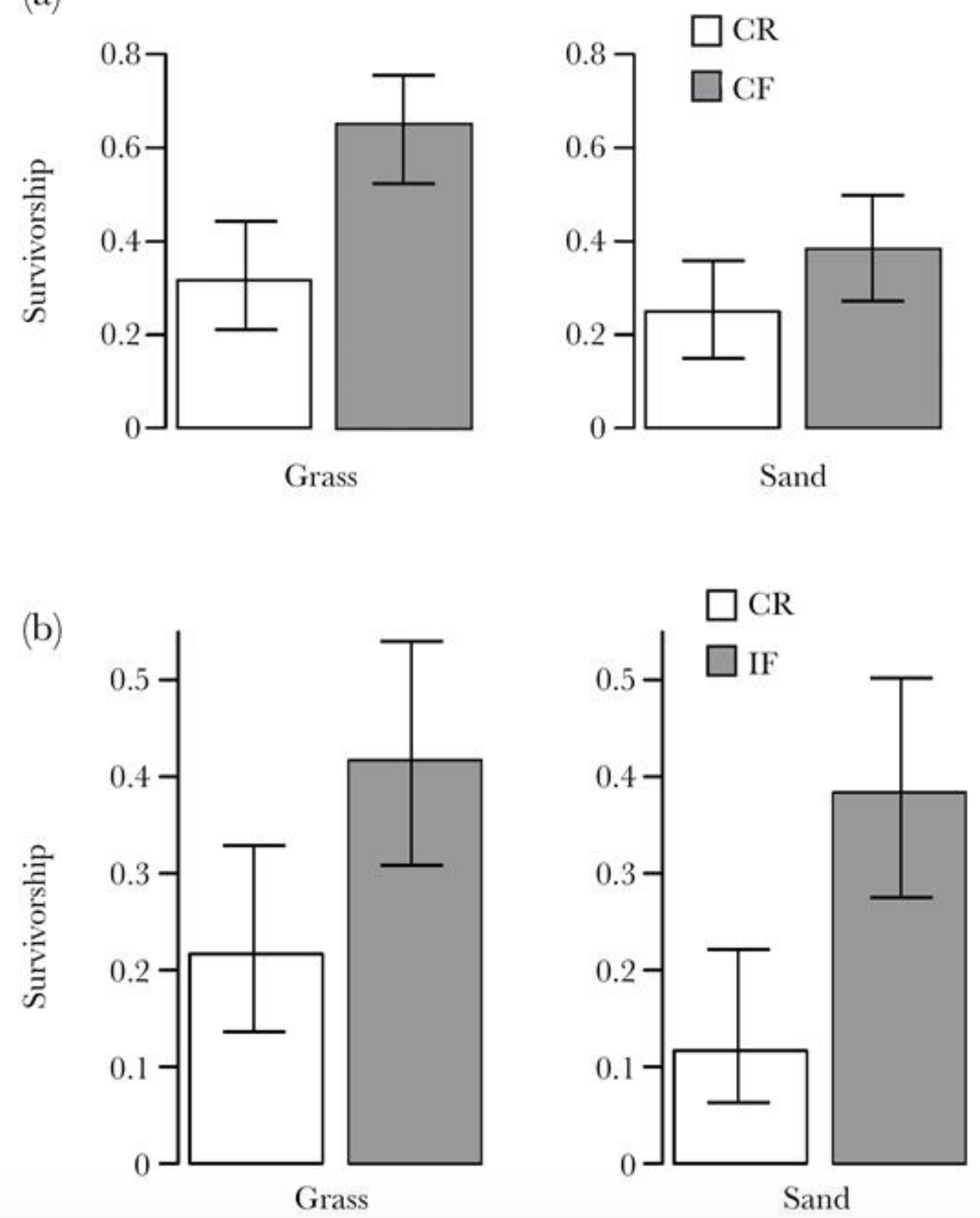

Figure 2.2 Comparisons of the survivorship of cryptic prey and flashing prey when presented against 2 different backgrounds (grass and sand). (a) shows the comparison between cryptic prey and continuously flashing prey in Experiment 1 while (b) shows the comparison between cryptic prey and intermittently flashing prey in Experiment 2. Bars represent the mean survivorships and error bars represent Wilson binomial 95\% confidence intervals. $\mathrm{CR}=$ cryptic prey; $\mathrm{CF}=$ continuously flashing prey; IF = intermittently flashing prey.

For those prey that were eventually detected, we found no effect of prey type (CF or CR) on detection time (Figure 2.3, $\chi^{2}{ }_{1}=0.81, P=0.37$ ), but volunteers spent longer trying to find prey on 
grass than on a sandy background $\left(\chi^{2}{ }_{1}=5.88, P=0.02\right)$. We found no interaction effect between prey type and background type on detection time $\left(\chi^{2}{ }_{1}=0.27, P=0.60\right)$, and no effect of presentation order effect $\left(\chi^{2}{ }_{1}=0.25, P=0.62\right)$ nor an interaction between order and treatment $\left(\chi^{2}{ }_{1}=0.54, P=0.46\right)$. The number of duds volunteers experienced did not affect detection time $\left(\chi^{2}{ }_{1}=0.001, P=0.97\right)$.

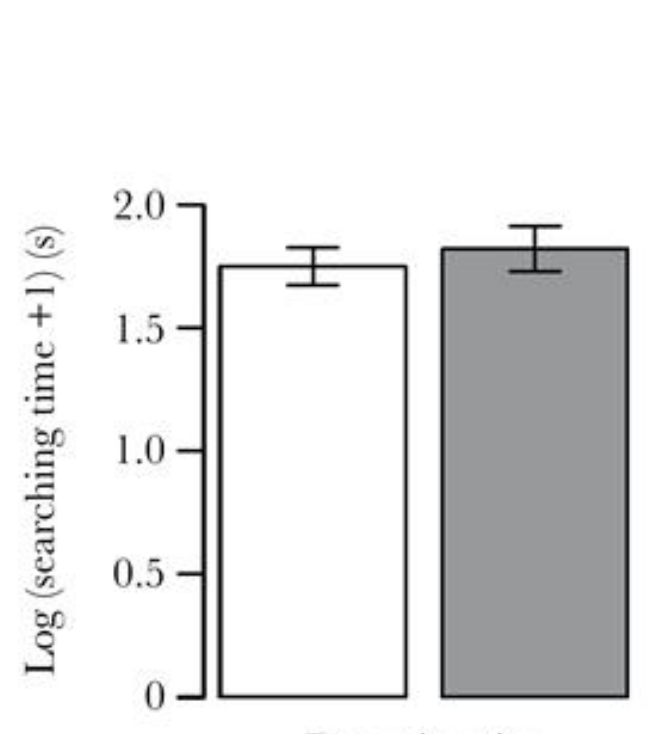

Detection time

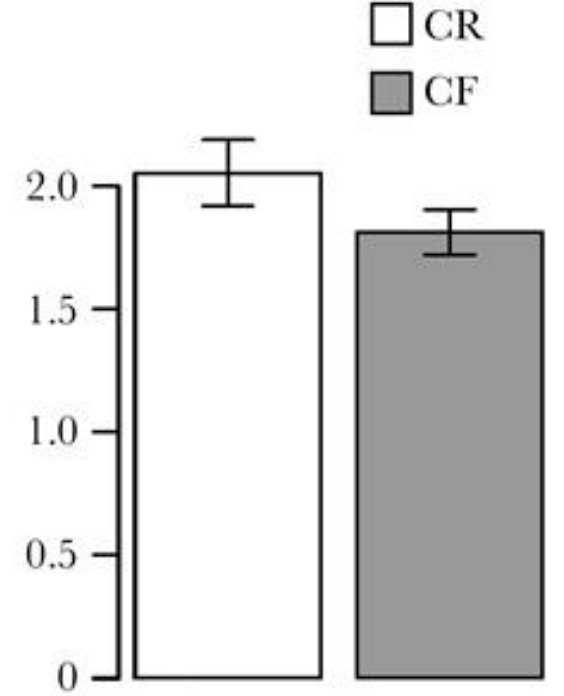

Giving up time

Figure 2.3 The log transformed detection time (when the prey was found) and giving up time (when volunteers stopped looking, inferring the prey was not present in the scene) for cryptic prey and continuously flashing prey in Experiment 1. Bars and error bars represent mean and standard error of the mean. $\mathrm{CR}=$ cryptic prey; $\mathrm{CF}=$ continuously flashing prey.

On the other hand, the giving up time was shorter for CF prey in comparison to CR prey (Figure 2.3, $\left.\chi^{2}{ }_{1}=9.92, P=0.002\right)$ and shorter on grass than on the sandy background $\left(\chi^{2}{ }_{1}=\right.$ 13.15, $P<0.001)$. The giving up time was also shorter for whichever prey was presented later (order effect: $\chi^{2}{ }_{1}=4.76, P=0.03$ ). We found no effect of the interaction between background and prey type on giving up time $\left(\chi^{2}{ }_{1}=0.88, P=0.35\right)$ nor evidence of an interaction between presentation order and treatment $\left(\chi^{2}{ }_{1}=0.30, P=0.58\right)$. For volunteers who experienced a greater frequency of duds, they gave up finding the prey earlier $\left(\chi^{2}{ }_{1}=13.95, P<0.001\right)$. 
Experiment 2: Intermittently flashing prey versus cryptic prey

Survivorship of IF prey was on average $23 \%$ higher than cryptic (CR) prey (Figure $2.2 \mathrm{~b}, \chi^{2}{ }_{1}=$ 13.44, $P<0.001)$, but here we found no effect of background type $\left(\chi^{2}{ }_{1}=1.69, P=0.19\right)$ and there was no evidence of an interaction between background and prey type $\left(\chi^{2}{ }_{1}=0.99, P=0.32\right)$ on prey survivorship. As before, the survivorship of both CR and IF prey were higher when they were presented prior to the other $\left(\chi^{2}{ }_{1}=5.38, P=0.02\right)$, but we did not find significant effects of either the interaction between presentation order and treatment $\left(\chi^{2}{ }_{1}=1.74, P=0.19\right)$ nor the number of duds experienced $\left(\chi^{2}{ }_{1}=1.83, P=0.18\right)$.

In terms of search time, we did not find any effects of our explanatory variables on both detection time (all $P>0.3$ ) and giving up time (all $P>0.07$ ) except that volunteers gave up finding the prey earlier when they experienced more duds $\left(\chi^{2}{ }_{1}=9.39, P=0.002\right)$.

Continuously flashing prey versus intermittently flashing prey

We found no effect of flash type $\left(\chi^{2}{ }_{1}=3.27, P=0.07\right)$ nor an interaction between flash type and background $\left(\chi^{2}{ }_{1}=2.19, P=0.13\right)$ on prey survivorship, although there was a trend showing that prey survived better on grass background than on the sandy background overall $\left(\chi^{2}{ }_{1}=7.08, P=\right.$ 0.007). In both CF and IF prey, survivorship was higher when prey were presented before cryptic prey (order effect: $\chi^{2}{ }_{1}=17.41, P<0.001$ ). Prey survivorship was higher when volunteers experienced a greater number of duds for both CF and IF prey $\left(\chi^{2} 1=8.02, P=0.005\right)$.

In terms of searching time, we found no effects of background type, flashing type, the interaction between background and flashing type, and presentation order on either detection time or giving up time (all $P>0.06)$ except that volunteers gave up earlier $\left(\chi^{2}{ }_{1}=35.10, P<0.001\right)$ and detected prey earlier $\left(\chi^{2}{ }_{1}=5.84, P=0.02\right)$ as they experienced a greater number of duds

\subsection{Discussion}

Our results demonstrate that flash behavior gives artificial prey a survival advantage of approximately $20 \%$ (a $\sim 0.2$ increase in survivorship, depending on the background) compared to cryptic fleeing prey, whether the prey flashes continuously or intermittently. A related benefit of 
flash behavior is that human predators gave up searching for retreating prey that continually flashed earlier than for prey that remained cryptic throughout. This suggests that expectations of finding a prey that exhibited conspicuous colors previously were lower than if the prey had remained cryptic. However, we found no differences in the detection time between prey that were cryptic throughout and cryptic prey that flashed when they escaped. Our results collectively support the hypothesis that flash behavior protects the prey by sending "false information" about the prey's resting color (see also our analyses of the effects of duds below).

In relation to the background effect, grass backgrounds appeared to be difficult habitats in which to locate prey based on overall longer detection times and higher prey survivorship than on the sandy background. However, the background effect is only apparent for the continuously flashing prey, yet we found no differences in detection times or prey survivorship between the 2 backgrounds for intermittently flashing prey. This implies that visual background might have affected the evolution of different flashing types.

Conspicuousness of flash colors might play a role in the observed decrease in giving up time in the experiment 1 . Visual predators adaptively modify their search rate (i.e., the time spent looking for a given prey in a background) based on prey crypticity: if prey are more cryptic, predators spend more time focusing in a given area to find prey (Smith 1974; Gendron 1986). Our finding that human volunteers gave up earlier when searching for flashing prey, compared to when searching for cryptic prey, is consistent with the idea that flash behavior leads predators to anticipate conspicuous prey, and therefore spend less time searching for flashing prey. This effect consequently increases the flash-displaying prey's probability of survival (but note here that we could not find the same effect for intermittent flash colors). Nevertheless, the observation that intermittently and continuously flashing prey derived similar survivorship benefits suggests that it is not the on-and-off nature of the signal per se but its suppression in conjunction with ceasing movement that is key to being effective.

Our findings using human volunteers indicate that exhibiting conspicuous colors during flight either continuously or intermittently and then returning to crypsis on stopping or alighting provides clear antipredator benefits just as Cott (1940) and Edmunds (1974) anticipated. The mechanism(s) by which flash behavior increases survivorship seems to be that conspicuousness 
sets up an expectation that the prey will be conspicuous and therefore makes it more difficult to locate the now cryptic prey. There is some evidence that the expectations of our volunteers did indeed shape the survival of prey they search for. In particular, the survival advantage of both continuously and intermittently flashing prey was higher as human volunteers experienced more "duds" in their search phase. In effect, if the volunteers were used to finding prey all the time (an unlikely phenomenon in nature) then they would be more liable to continue until they found one. This interpretation is further supported by the evidence for an effect of presentation order on survivorship: when flashing prey were seen before cryptic prey then their survivorship was substantially higher because subjects were less aware that such prey could be highly cryptic. Therefore 3 sources of evidence, our 20\% improved survival, the importance of expectations produced by duds, and presentation order, together suggest that the predator expectations of what to find once the prey had settled were influenced by flash behavior. Our findings suggest that flash displaying prey may have evolved in situations in which 1) predators do not spend a long time in one spot to find a prey, and 2) predators search in complex environments where prey are more difficult to find (Dimitrova and Merilaita 2009).

An alternative or additional reason why flash behavior results in higher survivorship is that the predator may expect to see the animal continuing on its obvious trajectory and search ahead of where the prey has alighted. Given the discrete nature of our screen shots for fleeing and settling, this was not tested, however. Finally, as suggested by Edmunds (2008), it is possible that the color patch may be followed rather than the outline of the prey, making it difficult to discern its outline at rest.

The observation that flash behavior has greater advantages on backgrounds where prey are overall hardest to detect is not surprising - if prey camouflage is poor, then such prey would be detected whether or not they flash during escape. As such, flash behavior may be more likely to evolve in particular habitats where crypsis is likely to be effective. Edmunds (1974) also proposed that flash behavior is more likely to evolve in species which lack the stamina for a long chase after all if a prospective prey item could flee the vicinity entirely, then its appearance on retreat would be immaterial. Species that face selection from relatively fast and agile predators may also be more likely to evolve flash displays. This is because if the probability of out pacing 
a predator is low, alternative escape adaptations are likely to be particularly advantageous. Comparative analyses could explore these propositions.

While our experiments have focused on elucidating the possible role of flash behavior in hindering subsequent detection, there may be other benefits. In particular, anecdotal evidence suggests that escape mimicry occurs in some insect taxa, for example, the flight of the grasshopper Arphia conspersa mimics that of the palatable but difficult to catch pierid butterfly Colias eurytheme (see Balgooyen 1997). Likewise, it is possible that flash behavior has intimidatory and confusion effects, not dissimilar to deimatic displays in stationary prey. At present, however, our data show for the first time, that flash behavior can hinder predator search in a manner suggested by early scholars of anti-predator defenses. Displays may well exploit a conspicuous illusion to lower the probability of detection. Despite this advance, flash behavior continues to constitute a widespread yet largely unexplored antipredator defense.

\subsection{References}

Anonymous. 1945. Animal concealment and flash coloration. Nature. 155:232-233

Balgooyen TG. 1997. Evasive mimicry involving a butterfly model and grasshopper mimic. Am Mid INat. 137:183-187.

Ballantyne LA, Lambkin CL. 2013. Systematics and phylogenetics of Indo-Pacific Luciolinae fireflies (Coleoptera: Lampyridae) and the description of new genera. Zootaxa. 3653:1-162

Bates D, Mächler M, Bolker B, Walker S. 2015. Fitting Linear Mixed-Effects Models Using \{lme4\}. J Stat Softw. 67:1-48.

Caro TM, Graham CM, Stoner CJ, Vargas JK. 2004. Adaptive significance of antipredator behaviour in artiodactyls. Anim Behav. 67:205-228.

Caro TM, Lombardo L, Goldizen AW, Kelly M. 1995. Tail-flagging and other antipredator signals in white-tailed deer: new data and synthesis. Behav Ecol. 6:442-450.

Caro TM, Stankowich T. 2010. The function of contrasting pelage markings in artiodactyls. Behav Ecol. 21:78-84.

Cott HB. 1940. Adaptive coloration in animals. London (UK): Methuen.

Del Brooke M. 1998. Ecological factors influencing the occurrence of 'flash marks' in wading birds. Funct Ecol. 12:339-346. 
Dimitrova M, Merilaita S. 2009. Prey concealment: visual background complexity and prey contrast distribution. Behav Ecol. 1:176-181.

Edmunds M. 1974. Defence in animals: a survey of anti-predator defences. New York (USA): Longman Publishing Group.

Edmunds M. 2008. Flash colors. In: Capinera JL, editor. Encyclopedia of entomology. Dordrecht: Springer Netherlands. p. 1466.

Gendron RP. 1986. Searching for cryptic prey: evidence for optimal search rates and the formation of search images in quail. Anim Behav. 34:898-912.

Kamler JANF, Ballard WB. 2006. Ear flashing behavior of black-tailed jackrabbits (Lepus californicus). Am Midl Nat. 155:402-403.

Kang C, Moon H, Sherratt TN, Lee S-I, Jablonski PG. 2016. Multiple lines of anti-predator defence in the spotted lanternfly, Lycorma delicatula (Hemiptera: Fulgoridae). Biol J Linn Soc. 120:115-124.

Kang C, Zahiri R, Sherratt TN. 2017. Body size affects the evolution of hidden colour signals in moths. Proc R Soc Lond B. 284:20171287.

Langley CM. 1996. Search images: selective attention to specific visual features of prey. J Exp Psychol Anim Behav Process. 22:152-163.

Lawrence ES, Allen JA. 1983. On the term "search image”. Oikos. 40:313-314.

Lloyd JE. 1971. Bioluminescent communication in insects. Annu Rev Entomol. 16:97-122.

Loeffler-Henry K, Kang C, Yip Y, Caro T, Sherratt TN. 2018. Data from: flash behavior increases prey survival. Dryad Digital Repository. http://dx.doi.org/10.5061/dryad.g80d3j3

Merilaita S, Stevens M. 2011. Crypsis through background matching. In: Merilaita S, Stevens M. editors. Animal camouflage: mechanisms and functions. Cambridge (UK): Cambridge University Press. p. 17-33.

Olofsson M, Eriksson S, Jakobsson S, Wiklund C. 2012. Deimatic display in the European swallowtail butterfly as a secondary defence against attacks from great tits. PLoS One. 7:e47092.

R Core Team. 2017. R: a language and environment for statistical computing. Vienna (Austria): R foundation for Statistical Computing. http://www.R-project.org/.

Schultz TD, Fincke OM. 2009. Structural colours create a flashing cue for sexual recognition and male quality in a neotropical giant damselfly. Funct Ecol. 23:724-732.

Smith JNM. 1974. The food searching behaviour of two European thrushes. II. The adaptiveness of the search patterns. Behaviour. 49:1-61. 
Stoner CJ, Bininda-Emonds ORP, Caro T. 2003. The adaptive significance of coloration in lagomorphs. Biol J Linn Soc.W. 79:309-328.

Tinbergen L. 1960. The natural control of insects in pine woods. I. Factors influencing the intensity of predation by songbirds. Arch Nerl Zool. 13:265-343.

Umbers KDL, De Bona S, White TE, Lehtonen J, Mappes J, Endler JA. 2017. Deimatism: a neglected component of antipredator defence. Biol Lett. 13:20160936.

Umbers KDL, Mappes J. 2015. Postattack deimatic display in the mountain katydid, Acripeza reticulata. Anim Behav. 100:68-73.

Williams CR, BrodieJr. ED, Tyler MJ, Walker SJ. 2000. Antipredator mechanisms of Australian frogs. J Herpetol. 34:431-443.

Wyszecki G, Stiles WS. 1982. Color science. New Jersey: Wiley. 


\section{Chapter 3: Consistent Associations between Body Size and Hidden Contrasting Color Signals across a Range of Insect Taxa}

Karl Loeffler-Henry ${ }^{1}$, Changku Kang ${ }^{2 *}$, and Thomas N. Sherratt ${ }^{1}$

${ }^{1}$ Department of Biology, Carleton University, Ottawa, ON, Canada

${ }^{2}$ Department of Biosciences, Mokpo National University, Muan,

Jeollanamdo, 58554, South Korea

*Corresponding author

Published in The American Naturalist (2019) 194: 28 - 37

Reproduced here in whole in accordance with Elsevier terms and conditions. 


\subsection{Abstract}

While there have been a number of recent advances in our understanding of the evolution of animal color patterns, much of this work has focused on color patterns that are constantly displayed. How- ever, some animals hide functional color signals and display them only transiently through behavioral displays. These displays are widely employed as a secondary defense following detection when fleeing (flash display) or when stationary (deimatic display). Yet if displays of hidden colors are so effective in deterring predation, why have not all species evolved them? An earlier study suggested that the hidden antipredatory color signals in insects are more likely to have evolved in species with large size because either (or both) (i) large cryptic prey are more frequently detected and pursued or (ii) hidden color signals in large prey are more effective in deterring predation than in small prey. These arguments should apply universally to any prey that use hidden signals, so the association between large size and hidden contrasting color signals should be evident across diverse groups of prey. In this study, we tested this prediction in five different groups of insects. Using phylogenetically controlled analysis to elucidate the relationship between body size and color contrast between forewings and hind wings, we found evidence for the predicted size-color contrast associations in four different groups of insects, namely, Orthoptera, Phasmatidae, Mantidae, and Saturniidae, but not in Sphingidae. Collectively, our study indicates that body size plays an important role in explaining variation in the evolution of hidden contrasting color signals in insects. 


\subsection{Introduction}

Insects have evolved a variety of strategies to avoid predation, including the adoption of color patterns that hinder detection or recognition (crypsis and disruptive coloration), development of honest (aposematism and Müllerian mimicry) and dishonest (Batesian mimicry) signals of unprofitability, and the imitation of cues of no interest to the predator (masquerade; Edmunds 1974; Ruxton et al. 2018). Each of these well known antipredator strategies involves the color patterns that are always visible to a would be predator. However, some prey species have evolved color signals that are generally hid den from view and displayed only when under immediate predation threat (Umbers et al. 2015). For example, many moths may have conspicuous hind wings that are not visible when the moth is in its usual resting position, yet they are dis- played when the moth is touched (Sargent 1990).

Hidden color signals employed in antipredator defense are widely seen in insects, including the conspicuous hind wings of noctuid and sphingid moths (Lepidoptera), cicadas (Hemiptera), grasshoppers (Orthoptera), mantises (Mantodea), and stick insects (Phasmatodea; Cott 1940; Edmunds 1974). Other potential functions for these signals, such as enhancing attractiveness through sexual selection, are unlikely, as the behavioral displays of contrasting signals are seen in both sexes and typically arise only as a response to predation threat. To date, two related mechanisms by which these hidden signals protect prey have been demonstrated: deimatic display (also called startle display) and flash display (Umbers et al. 2015; Loeffler-Henry et al. 2018).

Deimatic display involves the sudden exposure of a hidden signal that induces a startle response or affects predator psychology/behavior in some way to inhibit its attack (Umbers et al. 2015; Umbers and Mappes 2016). This antipredator defense has been reported in several groups of insects, such as Lepidoptera and praying mantises (Edmunds 1972; Schlenoff 1985), and its survival benefits have been demonstrated in a few studies (Vaughan 1983; Ingalls 1993; Olofsson et al. 2012; Kang et al. 2017). Olofsson et al. (2012), for example, showed that the exposure of its brightly colored dorsal wing patterns to predators increased the survivorship of the swallowtail butterfly, Papilio machaon. More recently, Kang et al. (2017) has demonstrated that deimatic displays of artificial moths can protect the prey against avian predators. 
Flash display is an umbrella term that describes the exposure of bright colors while in motion but not while at rest (Edmunds 2008). There are at least four possible functions of flash display, and they are not mutually exclusive: (i) the exposure of bright colors in motion may serve to startle a predator; (ii) the sudden appearance and then disappearance of the bright color in conjunction with a cessation in motion may reduce the probability of the prey being subsequently detected (Loeffler-Henry et al. 2018); (iii) the display enhances the resemblance of the prey to another species that is less profitable to consume or pursue, thereby reducing the motivation of the predator to chase it; and (iv) the dynamically changing flash colors in motion reduce the probability of prey capture because the predator's eyes cannot readily adjust to differences in brightness between sun flecks and shady patches (Papageorgis 1975; Endler 1978) and/or because of a "flash lag" effect in which estimating the position of a moving color changing object becomes harder (Murali 2018).

Despite these potential benefits, hidden contrasting color signals (here defined as a visually contrasting color signal that is normally hidden by wings or other parts of the body, whether they form part of deimatic or flash display) are by no means universally adopted. This leads to the question of why hidden signals have been selected for in some insect species but not in others. Kang et al. (2017) showed that in the moth family Erebidae (Lepidoptera), hidden contrasting color signals have evolved primarily in larger species. Moreover, using a remote controlled robotic moth, they showed that this result could be understood at least in part on the basis that larger hidden signals are more effective in deterring predators than smaller signals. Hossie et al. (2015) similarly found that eyespots in larger caterpillars were more effective in deterring inspection by domestic chicks than eyespots in small caterpillars. Likewise, Bae et al. (2019) found that flash coloration produced a higher survival benefit in large mobile computergenerated prey than in small mobile prey.

Deimatic displays often involve the individual advertising its size, and one reason why large displaying insects may be more effective in deterring predation is because large animals represent more of a threat to natural predators, such as birds. Naturally, larger cryptic species might also require a backup defense more frequently because they may be more readily detected by predators and more frequently attacked by certain predators on encounter (Mänd et al. 2007; Remmel and Tammaru 2009; Hossie et al. 2015). Collectively, there- fore, there may be stronger 
selective pressure for a secondary defense in insects with large body size, at least where birds are important predators. Intriguingly, arthropod predators such as dragonflies preferentially attack small prey over large prey, most likely because their own small size places physical limitations on the size of prey that they can capture and subdue (Rashed et al. 2005; Duong et al. 2017). Indeed, using data from five separate field studies, Remmel et al. (2011) estimated that avian predation rates on folivorous larvae increase approximately 3.6 fold, while arthropod (including spiders) predation rates decrease approximately 4.9 fold as the size of prey doubled. In contrast to work on birds, it is currently unknown how and why arthropod predators react to conspicuous displays by insect prey, but there is evidence that predatory dragonflies show no color preferences when attacking small artificial prey (Duong et al. 2017).

Clearly the above arguments relating to the greater effectiveness and greater need for conspicuous displays in large prey when subject to predation by birds are relatively general and so apply to other groups of prey that use hidden contrasting color signals as an antipredator defense. In this study, we tested this idea and examined whether the evolutionary association between large size and the hidden contrasting color signals is found across different groups of insects.

\subsection{Methods}

We studied five different insect groups, namely, Orthoptera, Mantidae (Mantodea), Phasmatidae (Phasmatodea), Saturniidae (Lepidoptera), and Sphingidae (Lepidoptera), to test whether there is an evolutionary association between large size and hidden contrasting color signals across insects. These groups were chosen because (i) species-level molecular phylogenetic trees were available (Song et al. 2015 [Orthoptera]; Svenson and Whiting 2009 [Mantidae]; Buckley et al. 2009 [Phasmatidae]; Barber et al. 2015 [Saturniidae]; Kawahara et al. 2009 [Sphingidae]) and (ii) all groups included the species that are well known for possessing hidden contrasting color signals that are putatively used for antipredator purposes (Robinson 1968; Edmunds 1972; Schmidt 2009).

Image and Body Size Data Acquisition 
First, we extracted species names from the published phylogenetic trees. Body size data for each species were then collected from various sources, including published papers, field guides, and online sources (see "References for Body Size and Image Sources"). Since different body size indexes were available for different groups of insects, we used the most commonly used body size index for each taxon: body length (from the tip of the head to the end of the abdomen) for Orthoptera, Mantidae, and Phasmatidae and wingspan (distance from one wing tip to the other wing tip when both wings were spread) for Saturniidae and Sphingidae. Body size information was typically available as a range, so we used the midvalue of the range as a representative size of each species. Where separate sizes were given for males and females, we used the midvalue of the overall size range for each species and did not consider intraspecific sexual size differences due to the limited data availability. When body size information was not available directly from the literature, we searched for specimen photos with a scale bar and measured the body size from the photos using ImageJ (open source program, National Institutes of Health).

To extract data on the colors of each species, we collected three specimen images per species (whenever possible) from various online sources (see "References for Body Size and Image Sources"). For online images, we primarily searched BOLD (the Barcode of Life Data System; Ratnasingham and Hebert 2007) because of the credibility of the information and fine quality of specimen photos. One problem (among many) with using publicly available photos is that they were photographed under unknown lighting conditions that might have affected the colors in the photos. However, while this may have increased the noise (e.g., random errors) of measured color values, we have no reason to believe that the data are biased toward a certain relationship. Besides, we extracted the color contrast between forewings and hind wings "within" photos, and thus we consider that our data were less affected by the variation "among" photos.

\section{Classifying Each Species into Noncontrasting or Hidden Contrasting}

To determine whether each species possesses hidden contrasting color signals as objectively as possible, we used image analysis on the obtained images of specimens. First, we measured red, green, and blue (RGB) values of pixels of the insect forewings/hind wings in each image. When there were no dis- tinctive/contrasting color patches on the wings, we measured median RGB values of a whole wing area and used these values as representative colors of forewings/hind 
wings. When there were clearly contrasting color patches on forewings, we measured the RGB values of the "basal" color of wings that compose the largest area and used the measured RGB values as forewing color values. However, if there were clear color patches on hind wings, we measured the median RGB values of each patch first and used the area that showed the most contrasting color (among the colors present on hind wings) against their forewing colors because the hidden contrasting color signals can evolve/function even if the contrasting colors are present only in part of the hind wings (such as the contrasting eyespots of moth hind wings in fig. 3.3). Rarely, the hid- den contrasting color signals were found not on hind wings but on other parts of the body (e.g., Paradirphia lasiocampina, which has non-contrasting hind wings but a contrasting yellow-black banded abdomen). In this case, we measured the contrasting color on the abdomen rather than measuring hind wing colors. Next, we transformed the measured RGB values to Lab color space ( $\mathrm{L}$ indicates lightness, while the combinations of $\mathrm{a}$ and $\mathrm{b}$ determine hue and saturation, respectively) and calculated the Euclidean color distance between forewing and hind wing colors (or abdomen when abdomen color was used; Wyszecki and Stiles 1982). To classify each species into non-contrasting (those that do not have hidden contrasting color signals) or hidden contrasting groups, we employed k-means clustering analysis (k p 2) on the color distances (Hartigan and Wong 1979). Although this flexible thresholding method can remove subjectivity of the classification, one concern about using k-means clustering is that it divides the variables into two groups even if the variation of variables is trivial (e.g., even if all the analyzed species are essentially non-contrasting). To check whether this problem exists, we (i) visually inspected the distribution of contrast values (fig. 3.1) and (ii) scrutinized all images of each insect group to be certain that there were at least some species that showed hidden contrasting signals. On these crude visual inspections, we found at least several species for each taxon that were subjectively categorized as possessing hidden contrasting color signals.

In Orthoptera and Phasmatidae, many species showed wingless morphology and thus having hidden color signals on hind wings is physically impossible. We assigned wingless species to the non-contrasting group unless the ventral coloration was highly contrasting against dorsal coloration when visually inspected. Occasionally only one sex (usually female) was wingless. In these cases, we analyzed the color of the winged sex and analyzed whether the winged version of these species showed hidden contrasting color signals. To complement our image analysis 
approach, we also conducted trials with human volunteers (10 judges per species) in which subjects were asked to simply classify species based on the same set of images into either "contrasting" or "non- contrasting" by comparing the coloration of forewings and hind wings (ethical approval: Carleton University Animal Care Committee 109683). No instructions were provided as to what threshold contrast our volunteers should use. Using humans is clearly more subjective, but unlike our image analysis approach they provide an overall gestalt when seeking to classify complex color pattern differences. Reassuringly, the human derived scores for each species (i.e., number out of 10 who believed that the wings of a given species were contrasting) and the measured color contrast values (excluding wingless species) from image analysis were highly correlated (Kendall rank correlation, t p 0:48, P ! :001). In both image analysis based and human judgment based classifications, the species that had transparent or translucent hind wings were assigned to the non-contrasting group since it is very likely that transparent hind wings have not evolved for antipredator signaling. Since (i) both methods of scoring generate similar (although not identical) conclusions when controlling for phylogeny and (ii) the results from human classification depended in part on how many volunteers agreed on the classification, we present our results from the image analysis here and present a full analysis of the human scores in the appendix (available online).

Naturally, while photographs allow us to collate information on color pattern variability from a wide array of insect species, they are designed to portray only the component 

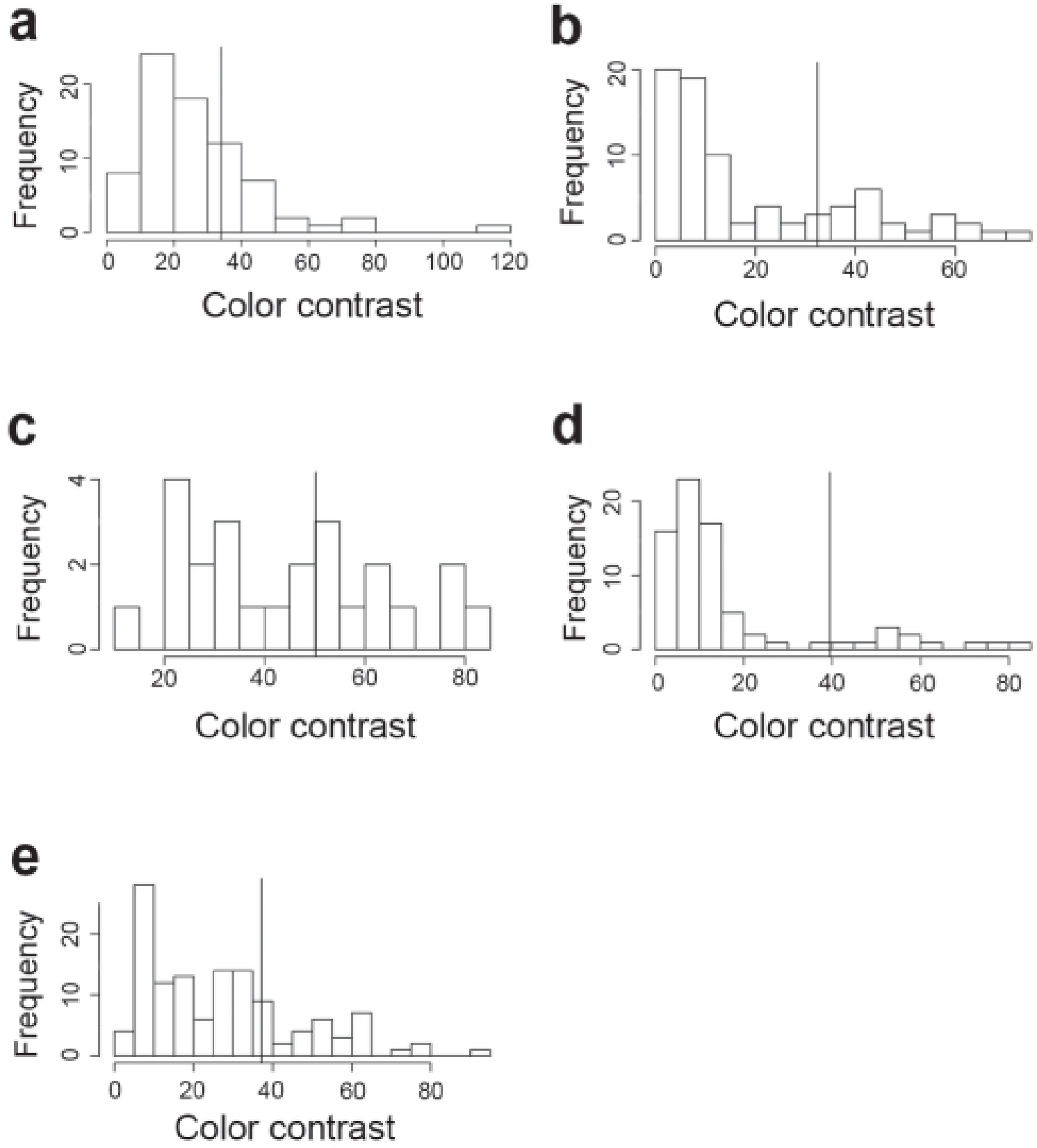

Figure 3.1 Histograms of estimated color contrast values using image analysis for each group: Orthoptera (a), Mantidae (b), Phasmatidae (c), Saturniidae (d), and Sphingidae (e). The vertical line in each histogram shows the threshold above which the species were considered to possess hidden contrasting color signals determined by k-means clustering.

of color variation that is visible to human eyes. An important drawback of having to rely on photographs is that natural predators such as birds are sensitive to wavelengths (mainly in the 
ultraviolet [UV]) that are not captured in normal photography. In particular, we note that RGB values have been developed for human vision and do not allow us to estimate the amount of contrast for species with UV in their hidden coloration. We return to this important point and the degree to which focusing only on visible colors may limit or bias our results in "Discussion."

Phylogenetic Analysis

Once we classified species into two distinct color groups (non- contrasting and hidden contrasting) for each taxon, we fitted models using phylogenetic generalized least squares (PGLS). This method allowed us to examine the relationship between body size and the presence of hidden contrasting color signals while accounting for the lack of independence due to shared evolutionary history. Prior to employing PGLS, each phylogenetic tree was pruned to contain only the species with known color contrast and body size. Body size was log trans- formed before analysis to ensure normality of residuals. The numbers of species analyzed were 128 species of Orthoptera (53 wingless), 80 of Mantidae, 49 of Phasmatidae (25 wing-less), 76 of Saturniidae, and 126 of Sphingidae. We ultrametricized each tree before running PGLS to timescale the tree relative to the genetic changes. We separately ran two different versions of PGLS assuming either Brownian motion or q6 Ornstein-Uhlenbeck character evolution models. We used nlme and phytools packages (Revell 2012) for PGLS and the ape package (Paradis et al. 2004) for tree ultrametricizing using R (R Foundation for Statistical Computing). Data underlying figures 2.1-2.3 have been deposited in the Dryad Digital Repository: https://dx.doi.org/10.5061/dryad.7g227bm (Loeffler- Henry et al. 2019).

\subsection{Results}

Overall, $21 \%$ of the surveyed species were categorized as having hidden contrasting color signals (21/128 for Orthoptera, 23/80 for Mantidae, 10/49 for Phasmatidae, 12/76 for Saturniidae, 31/126 for Sphingidae). Ornstein-Uhlenbeck models showed lower Akaike information criterion (AIC) values than Brownian motion models (DAIC 1 10) in all but Mantidae, where Brownian motion models showed slightly lower AIC 
Table 3.1 Results of phylogenetically controlled analysis

\begin{tabular}{lcccccc}
\hline Insect group & $N$ & Pagel's $\lambda$ & Coefficient & SE & $t$ & $P$ \\
\hline Orthoptera & 128 & .85 & .15 & .06 & 2.64 & $.009^{* *}$ \\
Mantidae & 80 & 1.06 & .09 & .04 & 2.15 & $.035^{*}$ \\
Phasmatidae & 49 & .46 & .17 & .07 & 2.33 & $.024^{*}$ \\
Saturniidae & 76 & .95 & .09 & .04 & 2.03 & $.046^{*}$ \\
Sphingidae & 126 & .85 & -.04 & .03 & -1.36 & .176 \\
\hline
\end{tabular}

Note: Positive coefficient values indicate that hidden contrasting color signals were associated with large size. Note that coefficients were estimated using log-transformed body size index as a response variable.

${ }^{*} P<.05$.

${ }^{* *} P<.01$.

than Ornstein-Uhlenbeck models (DAIC 1 10), but the results were consistent regardless of which character evolution models were used in all studied taxa. We therefore present the results of assuming an Ornstein-Uhlenbeck model of character evolution. PGLS indicated that there were statistically significant positive associations between body size and the presence of hidden contrasting color signals in all studied insect taxa (Orthoptera, Mantidae, Phasmatidae, Saturniidae) except in Sphingidae (table 3.1 for statistics; fig. 3.2 for the phylogenetically uncontrolled comparisons; fig. 3.3 for the phylogenetically controlled comparison; fig. A1, available online, for the plots placed in the context of a phylogeny). In Orthoptera, we found the same significant relationship even when wingless species were excluded from the analysis $(\mathrm{N} \mathrm{p}$ 75, t p 2:16, P p :03).

When we performed the same phylogenetically controlled tests of an association between body size and human based classification of our species into contrasting/noncontrasting, we found strong evidence of a positive association in Orthoptera and Phasmatidae, as above (see appendix). While trends were evident, we could not reject the null hypothesis of no association in the other three taxonomic groups.

\subsection{Discussion}

Our findings indicate that hidden contrasting color signals are more likely to be found in larger species in the majority of insect groups surveyed, at least based on our image analysis data. Our results based on human classification were more variable, but even here we found strong evidence for a positive 

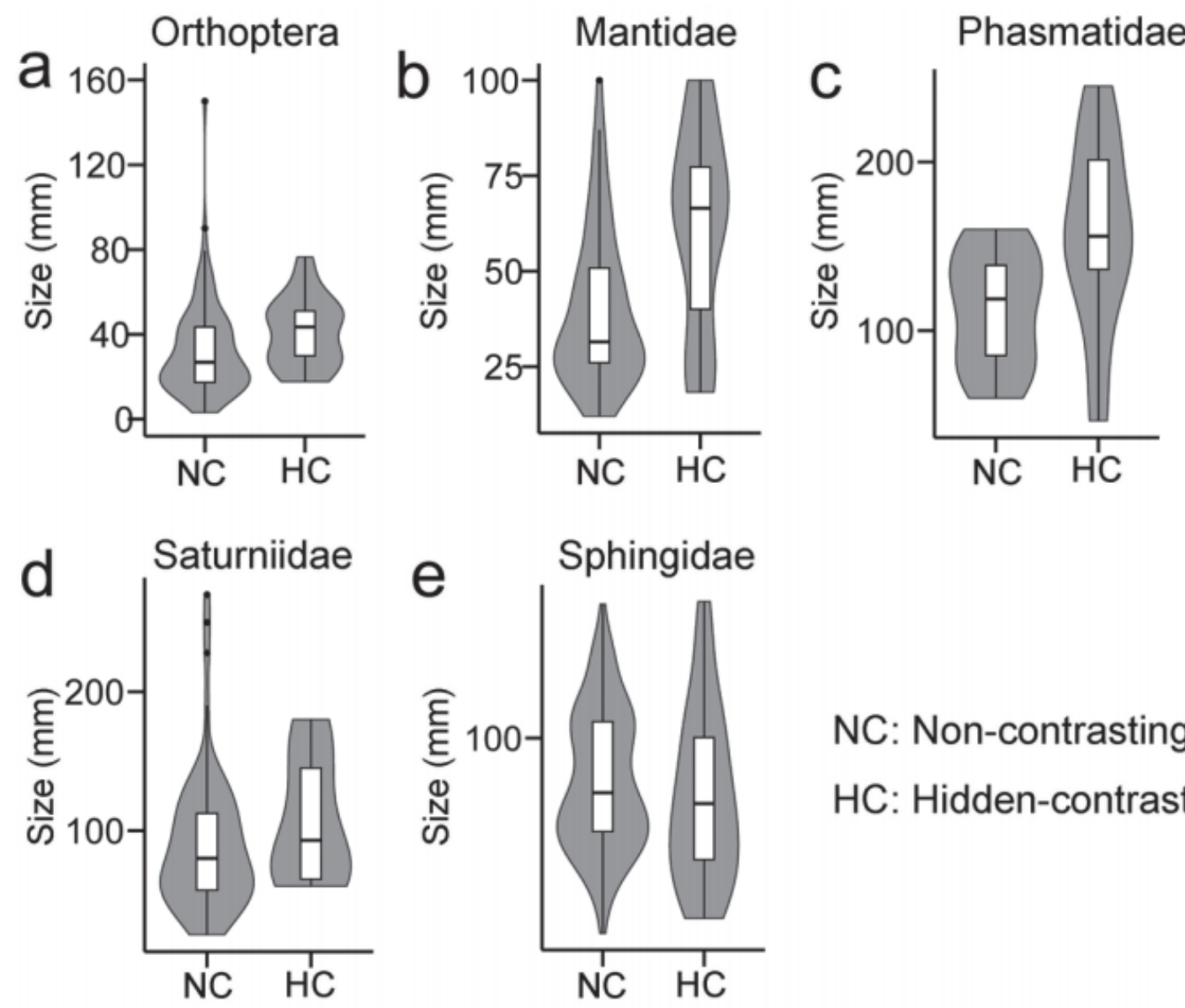

\author{
NC: Non-contrasting \\ HC: Hidden-contrasting
}

Figure 3.2 Each box-whisker plot shows the relationship between the presence of hidden contrasting color signals and body size for Orthoptera (a), Mantidae (b), Phasmatidae (c), Saturniidae (d), and Sphingidae (e) without controlling for phylogenetic relationships. Vertical lines in the middle indicate median values, boxes show interquartile ranges, whiskers show lowest/largest values, and dots show outliers. The numbers of species included in the analysis are 128 (a), 80 (b), 49 (c), 76 (d), and 126 (e).

association between body size and contrasting color signals in two of the five taxonomic groups considered (appendix). Together with the previous findings detailing the association within erebid moths (Kang et al. 2017), we now know that Orthoptera and Phasmatidae both exhibit the same positive association even when controlling for phylogeny, and there is conditional evidence that Mantidae and Saturniidae follow the same pattern. Our results therefore provide broad support for size-color contrast association in insects. Our results also provide an additional line of evidence that the evolution of insect defenses is mediated by body size (Penney et al. 2012; Hossie et al. 2015). Whether large size has driven the evolution of hidden color signals or vice versa is unclear, since the number of species analyzed for each taxa was not sufficient for 
estimating transition probabilities in this study. However, earlier estimates of transition rates in the Erebidae suggest that large non-contrasting species are more likely to evolve contrasting hind wings than vice versa and that small contrasting species are more likely to evolve noncontrasting hind wings than vice versa (Kang et al. 2017).
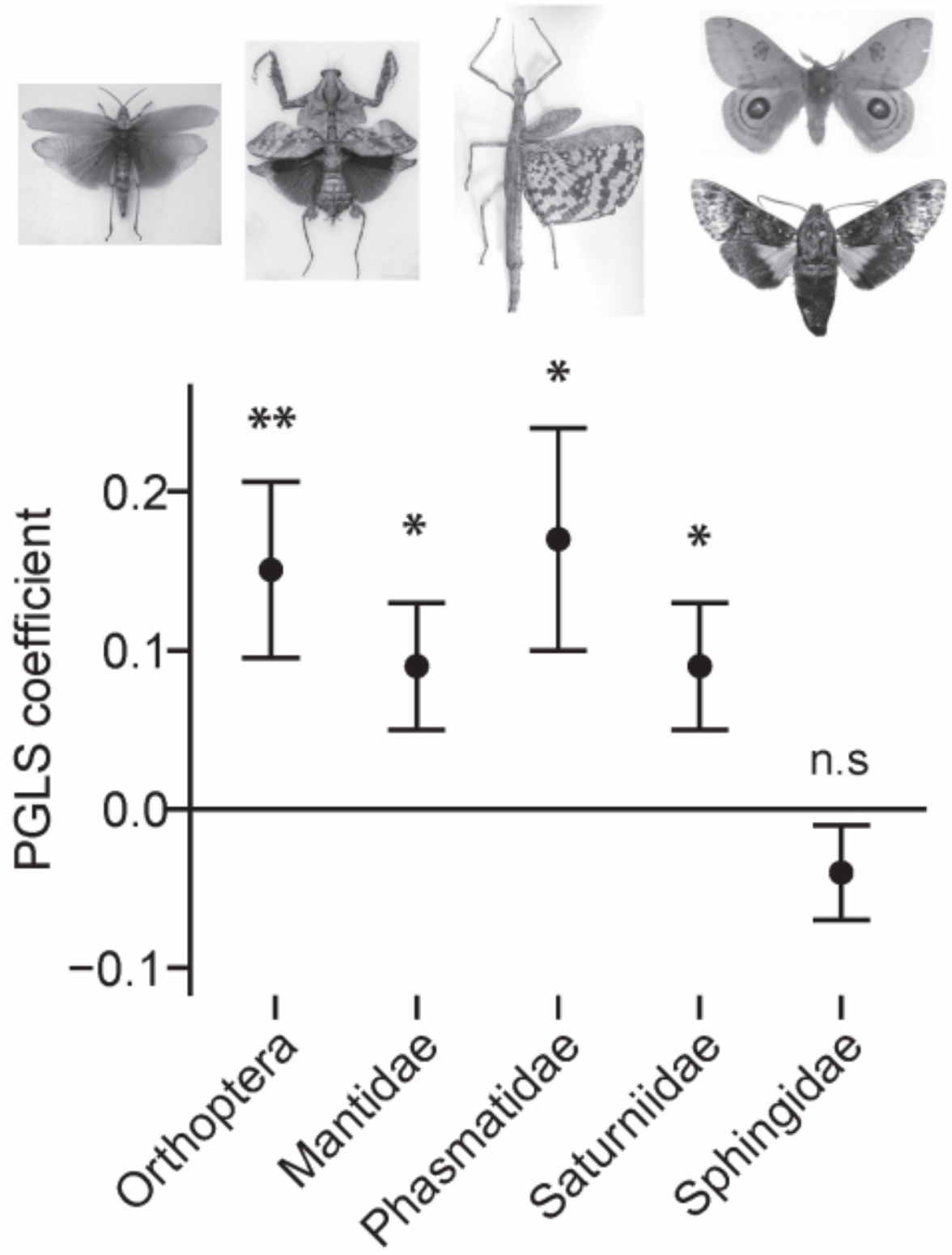

Figure 3.3 Coefficients and standard errors of the coefficients from the phylogenetic generalized least squares (PGLS) results. Positive values indicate that hidden contrasting color signals were associated with large size after controlling for phylogeny. See figure 3.2 for sample sizes. The photos show an example species in each group. From left to right, Phymateus morbillosus (photo credit: David Jackson), Deroplatys lobata (Edouard Hue), Phasma gigas (anonymous), Automeris io (upper, CBG Photography Group), Cautethia spuria (lower, Daniel H. Janzen). 
Our study has explored only morphological traits and has therefore overlooked behavioral traits (due to the limited behavioral data availability), which may play a significant role in the evolution of hidden signals. Although the specific function of these hidden color signals is still somewhat unclear and may vary within and among taxa, we consider predation as a main driver. Indeed, the behavioral display of hidden conspicuous signals to ward off predators has been observed in a number of taxa, including all of our studied taxa (Umbers and Mappes 2015 [Orthoptera]; Edmunds 1972 [Mantidae]; Robinson 1968 [Phasmatidae]; Blest 1957 [Saturniidae and Sphingidae]). For example, Catocala (underwing) moths are widely known to display their contrasting hind wings in response to imminent predation threat (Sargent 1978). Oedipodinae (band-winged) grasshoppers display their contrasting hind wings both (i) during escape by flying away and (ii) when attacked (Steiner 1981). The findings that both deimatic displays (Kang et al. 2017) and flash displays (Bae et al. 2019) are more effective in deterring predation in large species help explain the observed patterns and support the argument that body size mediates the evolution of contrasting hidden signals (Kang et al. 2017). Larger prey may be intrinsically more of a threat to small birds, and so they treat them with more caution (see also Hossie et al. 2015). Moreover, since they are intrinsically less cryptic, they may have more to gain from a secondary defense, such as fooling a predator into thinking they are a different color (flash display; Bae et al. 2019).

Another factor that might have affected the selective evolution of contrasting color signals in large species is that the species with different size may experience different types of predators. Predator-prey relationships are strongly influenced by body size differences, with predators preferentially attacking prey that are smaller than themselves (Brose et al. 2006). However, predators also have to meet their nutritional demands (Cohen et al. 1993). Therefore, larger insect species are more likely than smaller species to face selection to deal with vertebrate predators (e.g., birds), against which defensive displays of contrasting colors are known to be effective (Schlenoff 1985; Kang et al. 2017). Conversely, smaller species are more likely to face selection to avoid small invertebrate predators and parasitoids. We know very little about the effect of conspicuous displays on insect predators. It is possible that many arthropods would overlook contrasting color signals (Duong et al. 2017). 
Our study focused on forewing-hind wing contrast rather than conspicuousness, which is much more challenging to measure across a wide variety of species since it depends on the nature of their backgrounds. Nevertheless, the fact that all the studied species with contrasting hidden signals appeared to have cryptically colored forewings (e.g., brown, green, or grayish matching dead leaves, leaves, and tree bark, respectively) supports our argument that the display acts as a backup defense when the primary defense of crypsis fails. Besides aposematic species and mimetic species, both of which usually have vivid and conspicuous colors, most animals with color patterns that match their natural substrates are likely to be cryptic. It is therefore likely that the majority of hidden color signals that we have uncovered are exploited during the defensive displays in normally cryptic species.

Our color analysis that used images from digital cameras ignores the information in the UV region (300-400-nm wave- length region), which can be perceived by potential predators of our studied insect groups, including insects, spiders, and birds (Osorio and Vorobyev 2008). One potential drawback caused by this lack of UV information is that the species categorized as noncontrasting can actually look contrasting to UV sensitive predators if the wings differ in the UV range of the spectrum. Nevertheless, conspicuous/vivid colors such as yellow or orange on hind wings would be contrasting against cryptic forewings regardless of whether the hind wings reflect UV. Indeed, most of the UV colors are present on already conspicuous colors (in the camera-detectable color range), not on cryptic colors that resemble leaves or tree bark in many insects (Eguchi and MeyeRochow 1983), probably because natural substrates seldom reflect UV. In addition, many vertebrate and invertebrate predators have UV insensitive vision (with the peak sensitivity of short wavelength opsins lmax 1400 ; Osorio and Vorobyev 2008), so that the evolution of UV only contrasting color signals (that target only a specific type of predator) in insects is likely to be relatively rare. Thus, despite the above limitations, we expect our categorization of species into contrasting and non-contrasting on the basis of visible reflectance patterns to be relatively robust. Furthermore, considering both (i) the number of species we covered and (ii) the consistent results in most of the insect taxa, it seems highly likely that the association between large size and hidden contrasting colors is a real phenomenon.

Our results that the lepidopteran family Sphingidae (hawk moths) did not show any evidence of an evolutionary association between body size and the presence of hidden color signals is 
puzzling since this group is also known to exhibit conspicuous color/eyespots on hind wings that are often used in conjunction with defensive displays (Vallin et al. 2007). One explanation is that the evolution of hidden contrasting hind wings in this group has been mediated not only by defensive displays but also by other evolutionary factors that have operated in the opposite direction. One such possibility is mimicry. In some species of hawk moths, contrasting hind wings have been thought to confer a resemblance to bee species that are usually smaller than hawk moths, which might restrain the evolutionary change to larger size (Rothschild 1984). Clearly, further investigations are required to better understand the function and evolution of hidden contrasting color signals in this diverse group of Lepidoptera.

There have been considerable advances in the field of animal coloration research (Cuthill et al. 2017). However, our understanding of the evolution of color patterns that are dynamically displayed through behaviors is still poor, and there is a growing need to explore these dynamic color signals (Caro et al. 2016; Umbers et al. 2017). Our study provides the broadest evidence to date that the evolution of hidden color strategies is associated with the evolution of body size. We suggest that hidden contrasting color signals have evolved primarily in larger species because the antipredator strategies that use such color signals, such as deimatic and flash displays, are more effective when prey size is large and because large prey tend to need a backup defense more frequently than small prey.

\subsection{Acknowledgments}

We are grateful to H. Song, A. Kawahara, J. Breinholt, and G. Svenson for providing phylogenetic trees used for this study. This study was supported by the National Research Foundation of Korea (NRF 2018R1C1B5038317) and the Natural Sciences and Engineering Research Council of Canada.

\subsection{References}

Bae, S., D. Kim, T. N. Sherratt, T. Caro, and C. Kang. 2019. How size and conspicuousness affect the efficacy of flash coloration. Behavioral Ecology (forthcoming). 
Barber, J. R., B. C. Leavell, A. L. Keener, J. W. Breinholt, B. A. Chadwell, C. J. W. McClure, G. M. Hill, and A. Y. Kawahara. 2015. Moth tails divert bat attack: evolution of acoustic deflection. Proceedings of the National Academy of Sciences of the USA 112:2812-2816.

Blest, A. D. 1957. The evolution of protective displays in the Saturnioidea and Sphingidae (Lepidoptera). Behaviour 11:257-309.

Brose, U., T. Jonsson, E. L. Berlow, P. Warren, C. Banasek-Richter, L.-F. Bersier, J. L. Blanchard, et al. 2006. Consumer-resource body-size rela- tionships in natural food webs. Ecology 87:2411-2417.

Buckley, T. R., D. Attanayake, and S. Bradler. 2009. Extreme convergence in stick insect evolution: phylogenetic placement of the Lord Howe Island tree lobster. Proceedings of the Royal Society B 276: 1055-1062.

Caro, T., T. N. Sherratt, and M. Stevens. 2016. The ecology of multiple colour defences. Evolutionary Ecology 30:797-809.

Cohen, J. E., S. L. Pimm, P. Yodzis, and J. Saldaña. 1993. Body sizes of animal predators and animal prey in food webs. Journal of Animal Ecology 62:67-78.

Cott, H. B. 1940. Adaptive coloration in animals. Methuen, London. Cuthill, I. C., W. L. Allen, K. Arbuckle, B. Caspers, G. Chaplin, M. E. Hauber, G. E. Hill, et al. 2017. The biology of color. Science 357: eaan0221.

Duong, T. M., A. B. Gomez, and T. N. Sherratt. 2017. Response of adult dragonflies to artificial prey of different size and colour. PLoS ONE 12:e0179483.

Edmunds, M. 1972. Defensive behaviour in Ghanaian praying mantids. Zoological Journal of the Linnean Society 51:1-32.

Edmunds M. 1974. Defence in animals: a survey of anti-predator defences. Longman, New York.

Edmunds, M. 2008. Flash colors. Page 1466 in J. L. Capinera, ed. Encyclopedia of entomology. Springer, Dordrecht.

Eguchi, E., and V. B. Meyer-Rochow. 1983. Ultraviolet photography of forty-three species of Lepidoptera representing ten families. Annotationes Zoologicae Japonenses 56:10-18.

Endler, J. A. 1978. A predator's view of animal color patterns. Evolutionary Biology 11:319364. 
Hartigan, J. A., and M. A. Wong. 1979. Algorithm AS 136: a k-means clustering algorithm. Journal of the Royal Statistical Society C 28: 100-108.

Hossie, T. J., J. Skelhorn, J. W. Breinholt, A. Y. Kawahara, and T. N. Sherratt. 2015. Body size affects the evolution of eyespots in cater- pillars. Proceedings of the National Academy of Sciences of the USA 112:6664-6669.

Ingalls, V. 1993. Startle and habituation responses of blue jays (Cyanocitta cristata) in a laboratory simulation of anti-predator defenses of Catocala moths (Lepidoptera: Noctuidae). Behaviour 126:77-96.

Kang, C., R. Zahiri, and T. N. Sherratt. 2017. Body size affects the evolution of hidden colour signals in moths. Proceedings of the Royal Society B 284:20171287.

Kawahara, A. Y., A. A. Mignault, J. C. Regier, I. J. Kitching, and C. Mitter. 2009. Phylogeny and biogeography of hawkmoths (Lepi- doptera: Sphingidae): evidence from five nuclear genes. PLoS ONE 4:e5719.

Loeffler-Henry, K., C. Kang, and T. N. Sherratt. 2019. Data from: Consistent associations between body size and hidden contrasting color signals across a range of insect taxa. American Naturalist, Dryad Digital Repository, https://dx.doi.org/10.5061/dryad.7g227bm.

Loeffler-Henry, K., C. Kang, Y. Yip, T. Caro, and T. N. Sherratt. 2018. Flash behavior increases prey survival. Behavioral Ecology 29:528-533.

Mänd, T., T. Tammaru, and J. Mappes. 2007. Size dependent predation risk in cryptic and conspicuous insects. Evolutionary Ecology 21:485- 498.

Murali, G. 2018. Now you see me, now you don't: dynamic flash coloration as an antipredator strategy in motion. Animal Behaviour 142: 207-220.

Olofsson, M., S. Eriksson, S. Jakobsson, and C. Wiklund. 2012. Deimatic display in the European swallowtail butterfly as a secondary defence against attacks from great tits. PLoS ONE 7:e47092.

Osorio, D., and M. Vorobyev. 2008. A review of the evolution of animal colour vision and visual communication signals. Vision Research 48:2042-2051.

Papageorgis, C. 1975. Mimicry in Neotropical butterflies. American Scientist 63:522.

Paradis, E., J. Claude, and K. Strimmer. 2004. ape: analyses of phylogenetics and evolution in R language. Bioinformatics 20:289-290. Penney, H. D., C. Hassall, J. H. Skevington, K. R. Abbott, and T. N.

Sherratt. 2012. A comparative analysis of the evolution of imperfect mimicry. Nature 483:461464. 
Rashed, A., C. D. Beatty, M. R. Forbes, and T. N. Sherratt. 2005. Prey selection by dragonflies in relation to prey size and wasp-like colours and patterns. Animal Behaviour 70:1195-1202.

Ratnasingham, S., and P. D. N. Hebert. 2007. BOLD: the Barcode of Life Data System. Molecular Ecology Notes 7:355-364.

Remmel, T., J. Davison, and T. Tammaru. 2011. Quantifying predation on folivorous insect larvae: the perspective of life-history evolution. Biological Journal of the Linnean Society 104:1-18.

Remmel, T., and T. Tammaru. 2009. Size-dependent predation risk in tree-feeding insects with different colouration strategies: a field ex- periment. Journal of Animal Ecology 78:973-980.

Revell, L. J. 2012. phytools: an R package for phylogenetic comparative biology (and other things). Methods in Ecology and Evolution 3:217- 223.

Robinson, M. H. 1968. The defensive behavior of Pterinoxylus spinulosus Redtenbacher, a winged stick insect from Panama (Phasma- todea). Psyche 75:195-207.

Rothschild, M. 1984. Aide memoire mimicry. Ecological Entomology 9:311-319.

Ruxton, G. D., A. L. William, T. N. Sherratt, and M. P. Speed. 2018. Avoiding attack: the evolutionary ecology of crypsis, warning signals, and mimicry. 2nd ed. Oxford University Press, New York.

Sargent, T. D. 1978. On the maintenance of stability in hindwing diversity among moths of the genus Catocala (Lepidoptera: Noctuidae). Evolution 32:424-434.

Sargent, T. D. 1990. Startle as an anti-predator mechanism, with special reference to the underwing moths (Catocala). Pages 229-249 in D. L. Evans and J. O. Schmidt, eds. Insect defenses: adaptive mechanisms and strategies of prey and predators. State University of New York Press, Albany.

Schlenoff, D. H. 1985. The startle responses of blue jays to Catocala (Lepidoptera: Noctuidae) prey models. Animal Behaviour 33:1057- 1067.

Schmidt, J. O. 2009. Defensive behavior. Pages 252-257 in V. H. Resh and R. T. B. T. Cardé, eds. Encyclopedia of insects. 2nd ed. Academic Press, San Diego, CA.

Song, H., C. Amédégnato, M. M. Cigliano, L. Desutter-Grandcolas, S. W. Heads, Y. Huang, D. Otte, and M. F. Whiting. 2015. 300 million years of diversification: elucidating the patterns of orthopteran evo-lution based on comprehensive taxon and gene sampling. Cladistics 31:621-651.

Steiner, A. L. 1981. Anti-predator strategies. II. Grasshoppers (Or- thoptera, Acrididae) attacked by Prionyx parkeri and some Tachysphex wasps (Hymenoptera, Sphecinae and Larrinae): a descriptive study. Psyche 88:1-24. 
Svenson, J. G., and F. M. Whiting. 2009. Reconstructing the origins of praying mantises (Dictyoptera, Mantodea): the roles of Gondwanan vicariance and morphological convergence. Cladistics 25:468-514.

Umbers, K. D. L., S. De Bona, T. E. White, J. Lehtonen, J. Mappes, and J. A. Endler. 2017. Deimatism: a neglected component of anti- predator defence. Biology Letters 13:20160936.

Umbers, K. D. L., J. Lehtonen, and J. Mappes. 2015. Deimatic displays. Current Biology 25:R58-R59.

Umbers, K. D. L., and J. Mappes. 2015. Postattack deimatic display in the mountain katydid, Acripeza reticulata. Animal Behaviour 100:68- 73.

Umbers, K. D. L., and J. Mappes. 2016. Towards a tractable working hypothesis for deimatic displays. Animal Behaviour 113:e5-e7.

Vallin, A., S. Jakobsson, and C. Wiklund. 2007. “An eye for an eye?"- on the generality of the intimidating quality of eyespots in a butterfly and a hawkmoth. Behavioral Ecology and Sociobiology 61:1419-1424.

Vaughan, F. A. 1983. Startle responses of blue jays to visual stimuli presented during feeding. Animal Behaviour 31:385-396. 


\section{Chapter 4: Eyespots in large caterpillars deter insect predators}

\section{Key words}

Eyespots, insect predation, startle signal, anti-predation adaptation, Lepidoptera, praying mantid 


\subsection{Abstract}

Eyespots are one of the most taxonomically widespread anti-predation adaptations in the animal kingdom. A diverse array of predatory taxa including reptiles, mammals, fish and insects have been found to select for eyespots in their respective prey. Phylogenetic studies have found that the presence of eyespots in Lepidopteran caterpillars is associated with large body size, a result consistent with the observation that only eyespots in large caterpillars deter birds. However, we do not know whether predation from insects has contributed to selection for the observed association between eyespots and body size. Here we used a factorial experimental design to compare the survivorship of hawkmoth (Manduca quinquemaculata) larvae of two different sizes that had been manipulated to have eyespots (or not). These caterpillars were presented to Chinese mantids (Tenodera sinensis), a common arthropod predator. We found that eyespots yielded a relative benefit to large caterpillars and relative cost to small caterpillars. Our results suggest that predation from insects might have contributed to, or re-enforced, the observed association between eyespots and body size in Lepidopteran caterpillars. Future study involving other predatory insect taxa in the lab and field are necessary to confirm this assertion. 


\subsection{Introduction}

Many species have evolved conspicuous chromatic patterns ("eyespots") that appear to resemble vertebrate eyes (Edmunds 1974; Kodandaramaiah 2011; Monteiro 2015; Ruxton et al. 2018; Skelhorn et al. 2016). There are two broad explanations as to why selection by predators might drive the evolution of eyespots. In some taxa, eyespots may function to deceive a predator into thinking that a non-vital body part is the head and thereby deflect attacks to that body part (Kodandaramaiah et al. 2013; Olofsson et al. 2010 Prudic et al. 2015). Alternatively, or in addition, eyespots may deter predation through some form of intimidation (Kodandaramaiah et al. 2009; Olofsson et al. 2013). Although eyespots have been postulated to deter predation simply because of their conspicuous nature (Stevens 2005; Stevens et al., 2008; Stevens \& Ruxton 2014), recent behavioral experiments strongly suggest that predator mimicry dives their antipredation benefit (Blut et al. 2012; De Bona et al. 2015; Hossie \& Sherratt, 2014; Skelhorn et al. 2014)

Although eyespots are commonly associated with insect wings, they also occur in the immature stages of insects (e.g. Janzen et al. 2010; Prudic et al. 2015). The eyespots commonly observed on Lepidopteran caterpillars have long been believed to prevent predation via intimidation, rather than by deflecting attacks to non-vital body parts (Ruxton et al. 2018), not least because they frequently occur on or near the head (a vital body part) (Blest 1957). Recent field data using artificial caterpillar baits has provided empirical evidence that caterpillar eyespots do indeed serve to reduce predation rates in prey of this nature (Hossie \& Sherratt, 2012, 2013). Janzen et al. (2010) argued that for eyespots in caterpillars to effectively deter predation, predators must 
have an unlearned response to these eye-like stimuli. It is clear that some vertebrates do indeed have an unlearned response to eye-like stimuli (Hossie et al. 2015) but whether this extends to invertebrate predators is unknown. Interestingly, eyespots have been documented in caterpillar species that spend much of their larval phase in leaf shelters (Janzen et al. 2010). Since avian and other vertebrate predators are likely to predominantly search for prey on the surface of leaves, this raises the possibility that invertebrate predators also serve to select for eyespots in caterpillars.

One question in the study of the evolution of eyespots is that if they are such an effective antipredation defence why have they been selected for in some species but not others (Hossie et al. 2015)? A recent phylogenetic study demonstrated that there is an association between the presence of eyespots and body size in Sphingid caterpillars (Hossie et al. 2015). The crossspecies association between eyespots and body size is consistent with intra-specific observations which suggest that the development of eyespots often does not take place until later instars, when the caterpillar has achieved relatively large body size (Lederhouse, 1990). Analogous crossspecies associations have also been reported in "flash displays", in that species with hidden contrasting hindwings are also more likely to be larger (Kang et al., 2017; Loeffler-Henry et al., 2019).

Two non-mutually exclusive hypotheses have been proposed to explain the observed relationship between the evolution of eyespots and body size in insects. The first hypothesis is that large body size results in greater selective pressure for defence because such prey are not only more conspicuous (Remmel \& Tammaru, 2009), but also offer a greater caloric reward to predators. 
The second hypothesis is that eyespots (and startle signals in general) are more effective on larger insects because large organisms may be perceived by predators as more threatening (Hossie \& Sherratt 2014; Kang et al. 2017; Loeffler-Henry et al. 2019). Behavioral experiments using avian predators, both in the lab and in the field, support the second hypothesis (Hossie et al. 2015; Kang et al. 2017). This suggests that, like birds, insect predators likely select against eye spots in relatively small lepidoptera caterpillars. If the anti-predation benefits of eyespots in large prey is found to extend beyond avian predators, it would provide further evidence of selection more strongly favouring eyespots in large species.

Here we determined the fate of hawkmoth (Manduca quinquemaculata) larvae of two different sizes that had been manipulated to have (or not have) eyespots. These larvae were presented to the Chinese mantids (Tenodera sinensis) an arthropod predator. The primary aim of this experiment was to test whether eyespots on caterpillars are an effective deterrent to a visual arthropod predator. In addition however, we tested for evidence of an interaction between body size and eyespots, specifically whether eyespots provided a greater deterrent in larger individuals.

\subsection{Methods}

Chinese mantids (Tenodera sinensis) oothecae were purchased from a commercial natural insect control supplier (N.I.C; natural insect control) and raised in an VWR incubator at $27{ }^{\circ} \mathrm{C}$ with a photoperiod of 14 hours until final instar. Upon hatching, T. sinensis nymphs were raised in transparent plastic 0.95 liter cups. The floor of the cup was lined with a piece of wet filter paper 
for hydration and to facilitate the removal of frass. A wooden popsicle stick was placed in the cup at a $45^{\circ}$ angle to provide a surface for the $T$. sinensis to hang from when molting. $T$. sinensis nymphs were fed Drosophila melanogaster for their first two instars. By instar 3 they had outgrown D. melanogaster and were fed the larger Drosophila hydei until their fourth instar (L4). By L4 the T. sinensis were large enough to be fed house cricket (Acheta domesticus) nymphs and lesser wax moth (Achroia grisella) larvae, with the size of prey items that were offered continuing to increase as the $T$. sinensis grew. Once they reached their final (adult) instar they were removed from the incubator and maintained in the laboratory where experiments were also conducted at a room temperature of $23^{\circ} \mathrm{C}$ and photoperiod determined by the outdoor ambient light, approximately 14 hours L/10 hours dark. The adult $T$. sinensis (75-100mm long) were housed in larger enclosures constructed from two of the transparent 0.95 liter plastic cups placed one on top of the other, effectively doubling their volume. The bottom of the enclosure was once again lined with filter paper and the top had ventilation holes and a perch made of window screen glued to the top.

Two days prior to their first test, T. sinensis were fed darkling beetle ("superworm") Zophobas morio larvae to satiation. They were then fed nothing the next day. Experimental trials lasted seven days (a total of 4 days of testing, alternated with a total of 3 days without food). On each test day the mantids were first presented with a final instar larva of Tenebrio molitor that was not manipulated in any way ("treatment 0 "). Shortly after the mantid had finished consuming this mealworm, an individual of one of the test treatments, namely a five-spotted hawkmoth Manduca quinquemaculata caterpillar (purchased from PetSmart, Ottawa, Ontario) was presented. These hawkmoth caterpillars were one of two length classes (small: $33-47 \mathrm{~mm}$, large: 
61-74 mm) and either had two visible eyespots (white circles containing a smaller black circle, each painted with Sally Hansen 'insta-dry' nail polish) or did not (circles of identical dimensions, this time painted with clear Sally Hansen 'insta-dry' polish) - see Figure 4.1. To allow for (linear) allometry (see below), the eyespots on large caterpillars were larger than those on small caterpillars (large: white diameter $6 \mathrm{~mm}$, black diameter $3 \mathrm{~mm}$; small white diameter $4 \mathrm{~mm}$, black diameter $2 \mathrm{~mm}$ ). Upon seizing a test hawkmoth, the prey item was taken from the $T$. sinensis to prevent the ingestion of nail polish. After the treatment was taken away (or the experiment ended without attack) the T. sinensis was fed Z. morio larvae to the point of satiation. In between each test day, to increase motivation, the $T$. sinensis were not fed for a day. The precise order in which $T$. sinensis received each test treatment differed between blocks (Table 4.2). Each block consisted of 3 individuals (1 male and 2 females).

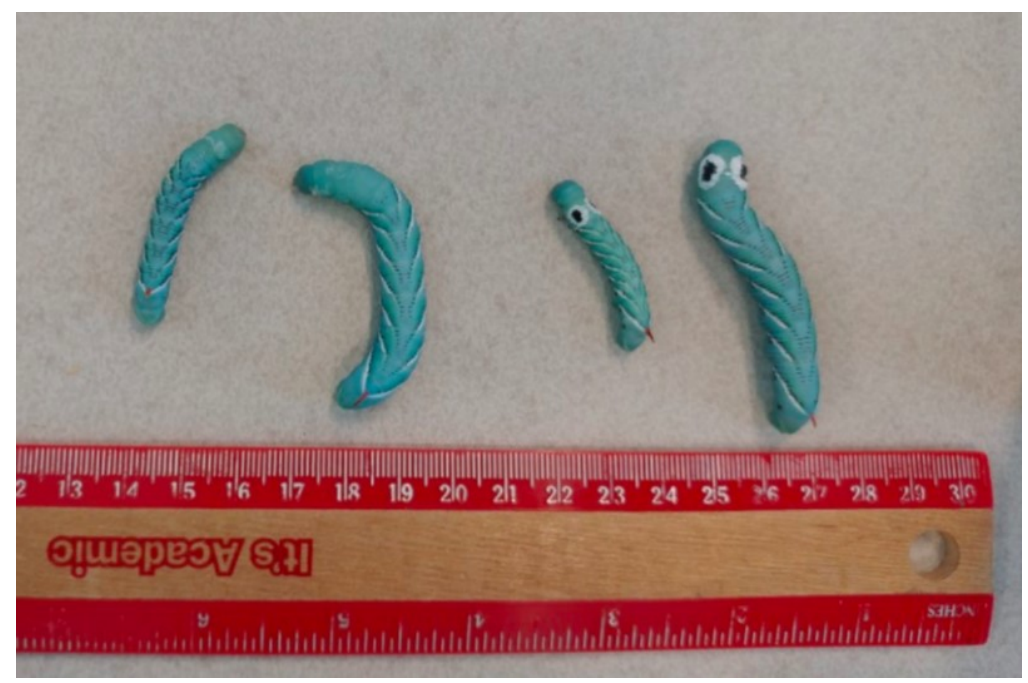

Figure 4.1 Manipulated live five-spotted hawkmoth M. quinquemaculata larva used in this experiment (from left to right: small no eyespots, large no eyespots, small with eyespots, large with eyespots). 
Trials took place in a 'blind' which was constructed from gray corrugated plastic and consisted of four sides allowing light to enter from the top while preventing the $T$. sinensis from seeing the researcher. The researcher observed the trial and recorded the results in real-time from a WebCam that was placed inside the trial blind. The larva of given size with and without eyespots (or mealworm control, see above), was placed in a 0.95 liter transparent plastic cup lined with filter paper. When the $T$. sinensis was resting on the screen perch in the original enclosure the top of the original enclosure was placed over the cup containing the treatment. The time at which the top cup containing the mantid was placed over the bottom cup containing the treatment marked the beginning of a given test. The duration of each test was 15 minutes. The time at which the $T$. sinensis's head passed a line on the back of the blind marking that it had traveled 6 $\mathrm{cm}$ from its original position on the perch and in the direction of the treatment was recorded (time to "first base"). The total time taken for $T$. sinensis to attack the prey offered was recorded and marked the end of the trial. If no prey were attacked within 15 minutes, then the test was terminated.

Note that in our experiment we applied large eyespots on large larva and small eyespots on small larva. A full exploration of the role of eyespots would have involved applying large eyespots on small larva and vice-versa (e.g. see Hossie et al. 2015). Nevertheless, eyespot size might be expected to scale allometrically with body length, so that larger caterpillars almost invariably have larger eyespots. To elucidate the nature of this allometry and place our experimental treatments in context, we determined the relationship between eyespot size and body size in ten different caterpillar species which all have eyespots (Papilio glaucus. Papilio troilus, Xylophanes tersa, Papilio rutulus, Xylophanes falco, Sphecodina abbottii, Papilio canadensis, 
Agrius cingulate, Papilio palamedes and Manduca sexta). Ten images of each of these ten species were obtained publicly available online images of caterpillars at a range of instars. The images necessarily required a reference scale bar to be present as well as a clear view of the eyespot. Based on the reference scale total body length of the caterpillar and the diameter of its eyespot were measured using Image $\mathrm{J}$.

Table 4.1 Factorial design showing treatment combinations of large and small five-spotted hawkmoth caterpillars with and without eyespots. Treatment 0 involved a presentation of mealworms.

\section{Presence of eyespots}

$$
\text { Eyespots No eyespot (clear) }
$$

$\begin{array}{llll}\text { Body size } & \text { Large } & \text { Treatment 1 } & \text { Treatment 2 } \\ & \text { Small } & \text { Treatment 3 } & \text { Treatment 4 }\end{array}$

Table 4.2 Treatment order over the four test days arranged in the four separate temporal blocks.

$\begin{array}{cccccc}\begin{array}{c}\text { Individual } \\ \text { mantid }\end{array} & \begin{array}{c}\text { Temporal } \\ \text { Block }\end{array} & \begin{array}{c}\text { Treatment } \\ \text { Test Day 1 }\end{array} & \begin{array}{c}\text { Treatment } \\ \text { Test Day 2 }\end{array} & \begin{array}{c}\text { Treatment } \\ \text { Test Day 3 }\end{array} & \begin{array}{c}\text { Treatment } \\ \text { Test Day 4 }\end{array} \\ 1 & 1 & 1 & 2 & 3 & 4 \\ 2 & 1 & 1 & 2 & 3 & 4 \\ 3 & 1 & 1 & 2 & 3 & 4 \\ 4 & 2 & 2 & 1 & 4 & 3 \\ 5 & 2 & 2 & 1 & 4 & 3 \\ 6 & 2 & 2 & 1 & 4 & 3 \\ 7 & 3 & 3 & 4 & 1 & 2 \\ 8 & 3 & 3 & 4 & 1 & 2 \\ 9 & 3 & 3 & 4 & 1 & 2 \\ 10 & 4 & 4 & 3 & 2 & 1 \\ 11 & 4 & 4 & 3 & 2 & 1 \\ 12 & 4 & 4 & 3 & 2 & 1\end{array}$

Statistical analysis 
The primary endpoint interest was the time taken for a mantid to attack the hawkmoth caterpillars of a given size class, with or without eyespots. Since attacks did not always occur within the 900 second observation period following release, then some of the data were effectively (right) censored. A survival ("time to event") analysis was therefore appropriate. Our primary predictors were caterpillar body size (large and small) and the presence/absence of eyespots (yes and no). As noted in the Introduction, we were also interested in testing for an interaction between body size and the presence/absence of eyespots on the attack time. Given that individual mantids were presented with all four possible treatments in one of four possible orders, we also fitted a block term to represent treatment order, with individual mantid nested within blocks (since mantids only experienced one treatment order). Both the block and individual mantid were considered as random effects (since their levels are effectively a subset drawn from a wider population of levels).

Our survival analysis necessarily involved fitting a Cox proportional hazards model with fixed effects as well as nested random effects. The mixed-effects survival analysis package COXME (Therneau, 2020) was used for this purpose (see also Therneau \& Grambsch 2012). We compared the fit of the full model (Surv $\sim$ Size*Eyespot $+(1 \mid$ Block /Individual)) with a series of simpler models lacking the interaction and main effects, maintaining the nested random effects and therefore consistent with the underlying design. Model comparison was via log likelihood ratio (LR) tests (to compare the goodness of fit of hierarchical models) and Akaike Information Criteria (AIC). Hazard ratios (based on exponents of estimated model parameters) for each body size/eyespot combination were determined against appropriate reference treatments. 
While the time taken to attack prey is indicative of the mantid's preparedness to attack prey, one can also ask whether the likelihood of being attacked over the entire experimental period differed between caterpillars with and without eyespots. To do this we fitted binary logistic models with the same Size*Eyespot interaction and nested random components (Block/Individual) using glmer from the lme4 package (Bates et al. 2015), assuming a binomial (attacked/not attacked) response. Unfortunately the fit of the full generalized linear mixed model with interaction was on the boundary of feasible parameter space ("singular fit") due to negligible variance associated with the random effects. Since the random components reflect the underlying design they were retained, but the results should be interpreted with caution.

We were also interested in whether the mantids show any change in the time taken to attack prey over consecutive presentations. Although we controlled for a block effect above, the most direct way to assess any change in hazard over day was to extract data on the attack times of mealworms (Tenebrio molitor) that were presented before each and every treatment. Here the fitted model for the attack times of mealworms was simply Surv $\sim$ Day $+(1 \mid$ Block/Individual $)$ and the importance of Day (first treated as a factor, then as a covariate) was evaluated by comparing similar models with and without Day. Although our primary endpoint was time to attack, to obtain a more complete understanding of the nature of the attack sequence and whether eyespots attract the attention of mantids from a distance, we fitted the same mixed effect survival models as above, with the times taken to reach "first base" in much the same way as we analyzed the time to attack. 
Finally, all the caterpillar species we examined showed clear allometry with eyespot length increasing with body length. To elucidate the nature of variation in eyespot length we fitted a simple ANCOVA model to our comparative data using glmer from the lme4 package (Bates et al. 2015), with species as a random effect and body size as a covariate. No phylogenetic comparisons were made, but it allowed us to quantitative place our experimental treatments in context against a range of lepidopteran larvae.

\subsection{Results}

On fitting the proportional hazard model, there was no evidence that the survival distribution of mealworms changed over time whether days were treated as a factor (LR tests, factor: $\mathrm{X}^{2}{ }_{3}=$ 2.963, $\mathrm{P}=0.397)$ or linear covariate $\left(\mathrm{X}^{2}{ }_{1}=0.429, \mathrm{P}=0.5126\right)$.

Our primary questions were (i) whether there was any evidence that the distribution of the time to attack differed between caterpillars of different sizes, and (ii) between caterpillars with and without eyespots, and (iii) whether there was any evidence of an interaction between these two factors. Comparing the full model containing interactions $(\mathrm{AIC}=219.8)$ with the main effects model $(\mathrm{AIC}=239.6)$, eyespots only model $(\mathrm{AIC}=238.2)$, size only model $(\mathrm{AIC}=237.7)$ and the intercept only model (AIC 236.2) each containing the Block and Individual as random factors, it was clear that the full model with interactions most parsimoniously explained the variation in attack times ( $\triangle \mathrm{AIC}$ from next-best fitting model $>16$ ). Deconstructing the full model using sequential log-likelihood ratio tests (analysis of deviance) indicated that body size alone does not explain significant variability in attack times over and above the null model $\left(\mathrm{X}^{2}{ }_{1}\right.$ $=0.542, \mathrm{P}=0.469)$ and neither does the presence/absence of eyespots alone $\left(\mathrm{X}^{2}{ }_{1}=0.010, \mathrm{P}=\right.$ 
0.920). However, the full model was a significantly better fit than both the null model $\left(\mathrm{X}^{2}{ }_{3}=\right.$ $21.85, \mathrm{P}<0.001)$ and the main effects model $\left(\mathrm{X}^{2}{ }_{1}=21.298, \mathrm{P}<0.001\right)$ and all models in between. Figure 4.2 shows the fitted survival plots. Having an eyespot reduces hazard in large caterpillars by a factor of $0.17(95 \%$ CI $0.051-0.567)$ yet by contrast, having an eyespot increases hazard in small caterpillars by a factor of 6.59 ( $95 \%$ CI 2.46-17.70).

The above results were consistent with a follow-up analysis based on whether the caterpillars were attacked or not in the observation period. Thus, the full fitted generalized linear mixed model with interactions had the lowest AIC ( $\triangle$ AIC from next best fitting model [= Eyespot only model] $>11.9$ ). Moreover, this interaction model explained significant variability over and above both the null model $\left(\mathrm{X}^{2}{ }_{3}=18.64, \mathrm{P}<0.001\right)$ and the main effects model $\left(\mathrm{X}^{2}{ }_{1}=14.93, \mathrm{P}<\right.$ 0.001). Eyespots in large caterpillars reduced attack rates during the experimental period from an overall mean of attack rate of $100 \%$ to $33.3 \%$ (LRT for fits of random effects logistic model comparing attacks on large caterpillars with and without eyespots $\mathrm{X}^{2}{ }_{1}=15.276, \mathrm{P}<0.001$ ). Eyespots in small caterpillars increased attack rates from an overall mean of $66.7 \%$ to $91.67 \%$, but this particular comparison was not significant (LRT for fits of random effects logistic model comparing attacks on small caterpillars with and without eyespots $\mathrm{X}^{2}{ }_{1}=2.403, \mathrm{P}=0.121$ ). 


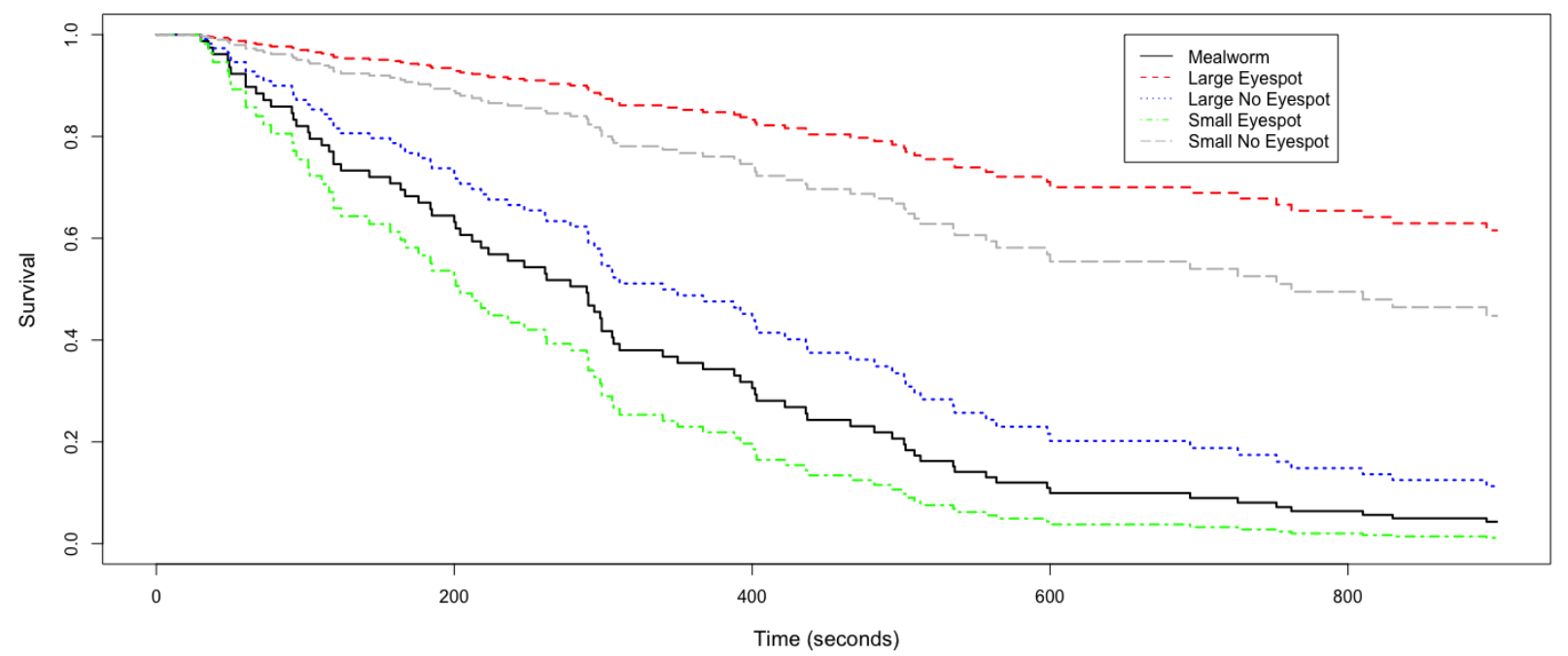

Figure 4.2 Survival plot of time taken for mantids to attack presented prey, following the fit of a Cox proportional hazards model. Small caterpillars with eyespots were most readily attacked while large caterpillars with eyespots were least readily attacked.

Intriguingly, when we fitted a survival model based on the time distribution to "first base", then a rather different pattern emerges from that of time to attack (Figure 4.3). Here the main effects model had the lowest AIC compared to all possible component models. The analysis of deviance following the fit of the full model indicates that the presence of eyespots explains significant variability in time to event over and above the null model $\left(\mathrm{X}^{2}{ }_{3}=31.48, \mathrm{P}<0.001\right)$ while the main effects model with eyespots and size explains even more variability above eyespots alone $\left(\mathrm{X}^{2}{ }_{1}=\right.$ 18.14, $\mathrm{P}<0.001)$. However, in this instance there was no evidence of a significant interaction effect that is able to explain additional variability over and above the main effects model $\left(\mathrm{X}^{2}{ }_{1}=\right.$ $1.64, \mathrm{P}=0.201)$. Being large increases the hazard by a factor of $8.16(95 \% \mathrm{CI} 2.66-25.04)$ while having eyespots increases the hazard of 26.86 (95\% CI 7.48-96.39). 
Finally, our allometric analysis clearly show that eyespots increase with increasing body size for all ten caterpillar species (Figure 4.3 fit of separate linear regressions shown) in that there is linear relationship between high spot size and body size in all species surveyed. Our experimental caterpillars had slightly larger eyespots than the other 10 species for their body size (see red dots), but the change in eyespot diameter is with increasing body length consistent with the allometric relationship seen in all the other caterpillar species( see figure 4.4).

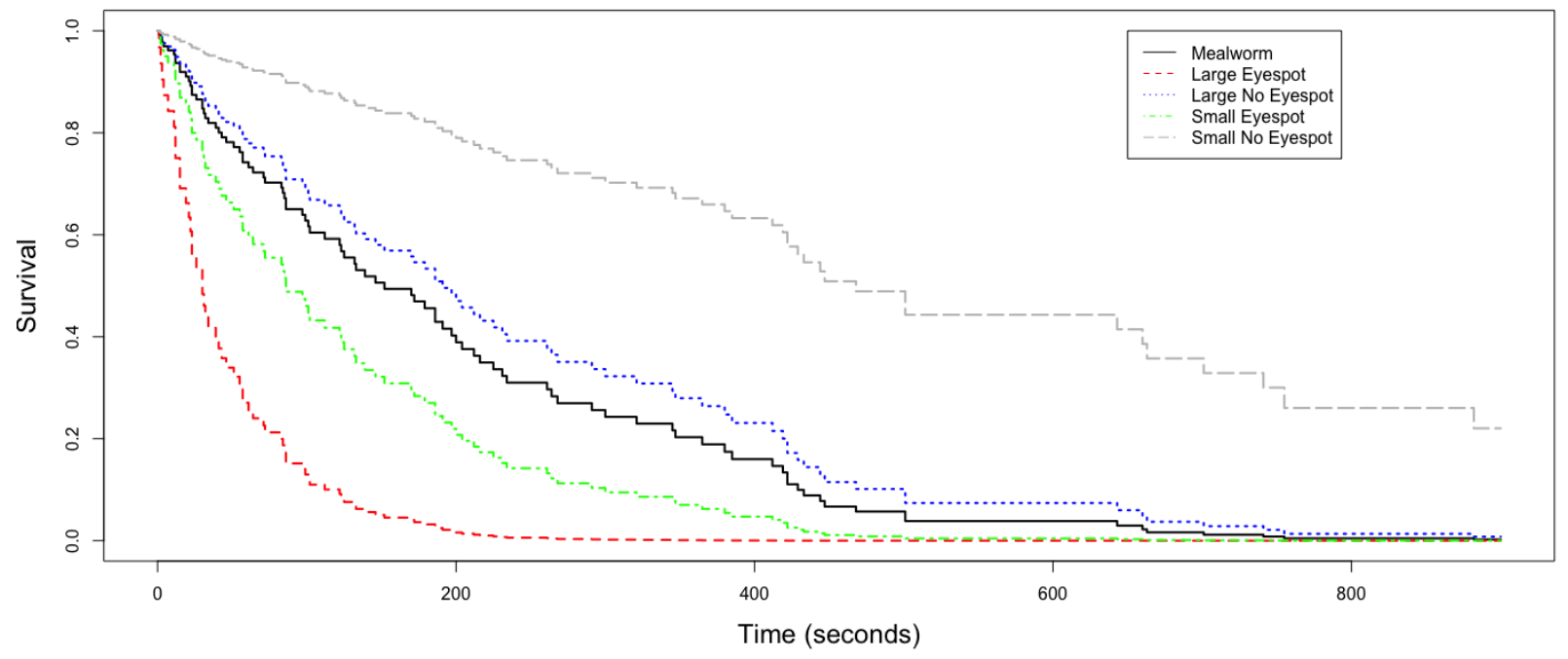

Figure 4.3 Survival plot of time taken by mantids to reach "first base" following presentation of caterpillars. Large caterpillars with eyespots most readily attracted mantid attention, while small caterpillars without eyespots attracted least attention. 


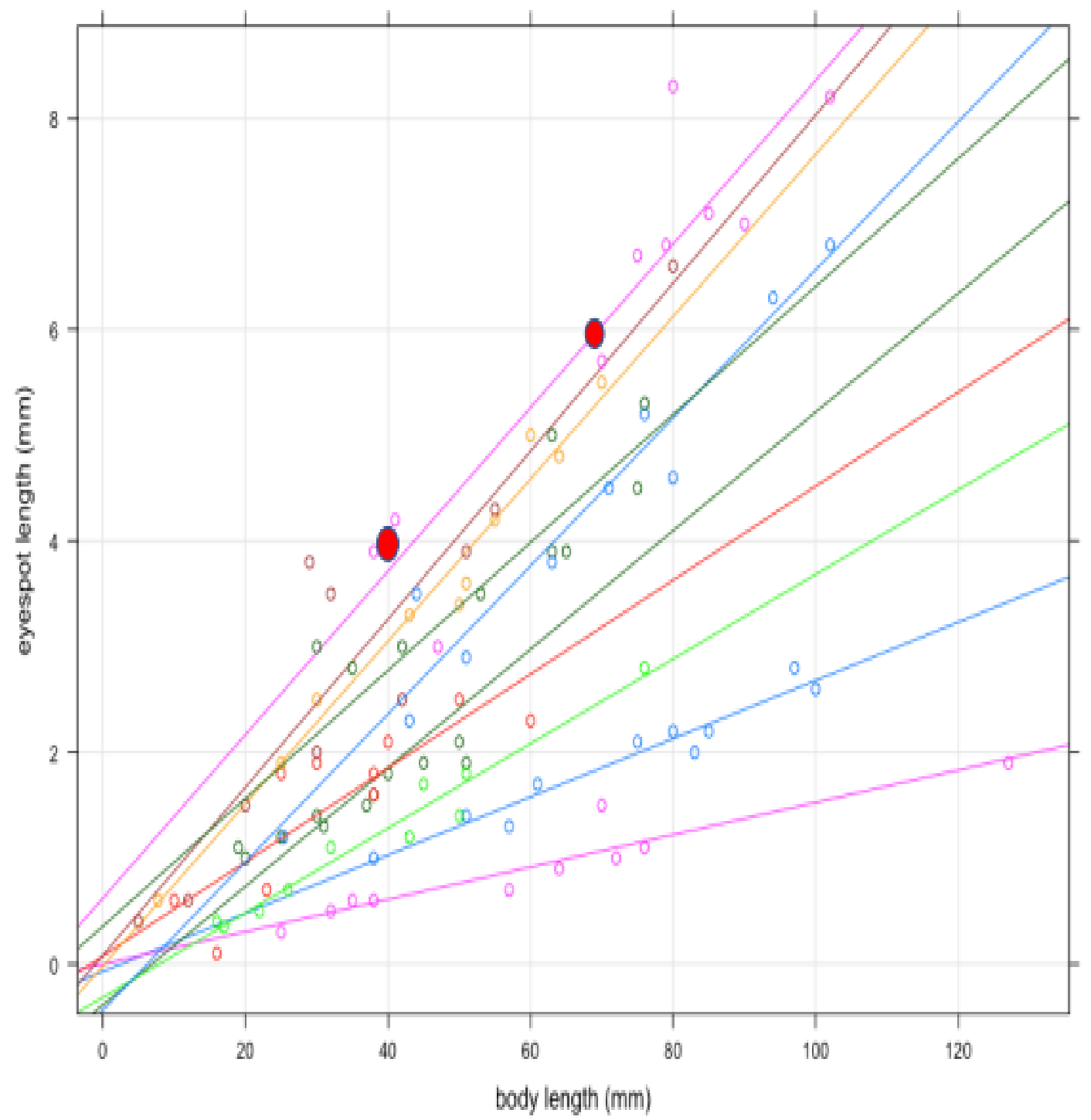

Agrius cingulata Manduca sexta Papilio canadensis Papilio glaucus Papilio palamedes Papilio rutulus Papilio troilus Sphecodina abbottii Xylophanes falco Xylophanes tersa

Figure 4.4 Intra-specific comparison of eyespot size and body size of caterpillars across 10 ontogenetic stages. The red dots show the eye spot and body sizes of the manipulated caterpillars used in this experiment. 


\subsection{Discussion}

Eyespots have attracted attention from naturalists and evolutionary biologists for over 150 years (Poulton 1890; Blest 1957; Skelhorn et al., 2016). In spite of our small sample size, we found strong evidence that eyespots on large hawkmoth larvae effectively deter predation by Chinese mantids relative to similar-sized larvae without eyespots. By contrast, we found evidence that small caterpillars without eyespots were less likely to be attacked than small caterpillars with eyespots. Phylogenetic analyses suggest that conspicuous anti-predator signals are disproportionately more likely in larger insect taxa (Hossie \& Sherratt 2014; Kang et al. 2017; Loeffler-Henry et al. 2019). This relationship was previously explained with the finding that conspicuous signals in large prey are more effective at deterring vertebrate predators than conspicuous signals in small prey. Here we provide evidence that these results also extend to invertebrate predators. Therefore, invertebrate predators might also contribute to the observed positive association between body size and eyespots in Sphingid caterpillars (Hossie et al. 2015). More broadly, our results provide support for the growing body of evidence suggesting that the evolution of antipredator adaptations is closely tied to other species traits, such as body size and habitat use (Hossie et al. 2015; Kang et al. 2012; Loeffler-Henry et al. 2018; Penney et al. 2012; Roslin et al. 2015).

While eyespots in large caterpillars slow down the rate at which they are attacked, one might ask whether a delay by a matter of seconds in attack provides any survival advantage. First, our fit of binary logistic models indicate that large caterpillars do indeed survive at a higher rate over the course of the experiment than similar-sized caterpillars without eyespots. Second, in our experiments the caterpillars were necessarily contained within a cup. However, under more 
natural conditions a delay in attack may give the larvae an opportunity to withdraw, escape (such as dropping to the ground) or deploy a backup defence.

It is worth noting that $T$. sinensis is native to east Asia and M. quinquemaculata is native to North America. Therefore we can rule out the possibility that some form of specific coevolutionary relationship between these two species may have influenced our results. Previous studies have found that mantids are capable of learning to avoid warningly coloured defended prey (Carle et al., 2018). Our finding that naïve mantids were wary of large caterpillars with eyespots at the outset, indicates that praying mantids have largely an innate rather than learned tendency to be cautious of large potential prey with eye-like stimuli. This wariness is readily understood. A large organism is inherently more likely to be able to harm the would-be predator, and the presence of eyespots may enhance the level of perceived risk. Thus, just as an innate response to eye-like markings might provide a harm-reducing benefit to vertebrate predators (Janzen et al. 2014; Hossie et al. 2015), it is likely to provide a similar benefit to would-be invertebrate predators.

While it is known that mantids attack and consume Lepidoptera caterpillars, the level of predation pressure they pose compared to avian and other vertebrate predators likely varies widely depending on habitat and species (Reitze \& Nentwig, 1991). The results of this study using adult mantids, together with studies using avian predators (Hossie et al. 2015), indicate that eyespots on small Lepidoptera are harmful for survival, most likely because eyespots in these cases increase the conspicuousness of the caterpillars without appearing too threatening. Indeed, our data on the time to first base support this conjecture, in that eyespots in both small 
and large caterpillars attract the interest and approach of mantids even if they are ultimately hesitant to attack the latter. These findings are consistent with the finding that small eye spots on adult lepidoptera wings attract attacks from mantids (Prudic et al. 2015). This naturally leads to the question as to why are eyespots observed on any small and early instar Lepidopteran caterpillars (Hossie \& Sherratt 2014)? A consideration of the relative size of predator and prey may be important. Unlike avian predators, who even at the earliest ontogenetic stages are large relative to virtually all insects, nearly all mantids start life under $10 \mathrm{~mm}$. Thus, even diminutive Lepidoptera larvae may benefit from eyespots if they are predominantly attacked by small invertebrates. Naturally this hypothesis could be readily tested. It is worth noting that Brose et al., (2006) found that the probability of predation on insects by vertebrate predators increased exponentially with increasing body size, while predation by invertebrates increased exponentially with decreasing body size (see also Duong et al., 2017). Therefore, it is likely that the primary selective force that has led to the evolution of eyespots in very small Lepidoptera caterpillars is predation by invertebrates.

As with most experiments, there are some caveats to consider. In particular, it is possible that mantids could see the markings even on caterpillars painted with transparent nail polish. Nevertheless, the fact that the mantids reacted differently to caterpillars with and without eyespots, strongly suggests that the predators discriminated between the two types of markings. For these reasons, a second control involving unmanipulated caterpillars would have been helpful. In addition, while this study has investigated the degree to which eyespots protect living caterpillars from attack by invertebrate predators, it took place in the lab environment with captive raised mantids. Future studies involving the presentation of manipulated caterpillars to 
wild mantids in the field may prove insightful. Likewise, we have presented only two classes of prey namely small and large caterpillars. Future studies examining the propensity of caterpillar eyespots to deter praying mantids might include size as a continuous variable, allowing one to identify the threshold body size at which eyespots are favoured for a given size class of invertebrate predators. Finally, while the large and small caterpillars we used had proportionately scaled eyespots similar to many Lepidoptera, it remains unclear if larger eyespots rather than larger body size might explain the benefit of eyespots experienced by our larger treatment group. Therefore, while it is possible that eyespot size and body size may affect predator behavior independent of one another, such effects are likely indistinguishable in nature.

Given their abundance, voraciousness and capacity to learn, researchers have long postulated a role for invertebrate predators in shaping warning signals and mimicry in other invertebrates (Bates 1862; Duong et al. 2017; Kauppinen \& Mappes 2003; O’Donnell 1996). Here we show that eyespots which have long been considered an important deterrent for avian predators may also serve to deter invertebrate predators although the size ranges of prey these selective pressures operate on is likely to be very different. 


\subsection{References}

Bates D., Maechler M., Bolker B., Walker S. (2015). Fitting Linear Mixed-Effects Models Using lme4. J Stat Software 67: 1-48.

Bates, H.W. (1862). Contributions to an insect fauna of the Amazon Valley: Lepidoptera Heliconidae. Trans Linn Soc Lond 25:495-566.

Blest, A. D. (1957). The function of eyespot patterns in the Lepidoptera. Behav 11: 209-256.

Blut C., Wilbrandt J., Fels D., Girgel E.I., Lunau K. (2012). The 'sparkle in fake eyes - the protective effect of mimic eyespots in lepidoptera. Entoml Exp Appl 143: 231-244. https://doi.org/10.1111/j.1570-7458.2012.01260.x

Brose U., Jonsson T., Berlow E.L., Warren P., Banasek-Richter C., Bersier L.-F., Blanchard J.L., Brey T., Carpenter S.R., Cattin Blandenier M.-F., Cushing L. Ali Dawah H., Dell T., Edwards F., Harper-Smith S., Jacob U., Ledger M.E., Martinez N.D., Memmott J., Mintenbeck K., Pinnegar J.K., Rall B.C., Rayner T.S., Reuman D.C., Ruess L., Ulrich W., Williams R.J., Woodward G., Cohen J.E. (2006). Consumer-resource body-size relationships in natural food webs. Ecology 87:2411-2417.

Carle T., Horiwaki R., Hurlbert A., Yamawaki Y. (2018). Aversive learning in the mantis (Tenodera aridifolia), a sit and wait predator. J Insect Behav 31:158-175.

De Bona S., Valkonen J.K., López-Sepulcre A., Mappes J. (2015). Predator mimicry, not conspicuousness, explains the efficacy of butterfly eyespots. P Roy Soc B-Biol Sci 282: 20150202. https://doi.org/10.1098/rspb.2015.0202 
Duong T.M., Gomez A.B., Sherratt T.N. (2017). Response of adult dragonflies to artificial prey of different size and colour. PLoSOne. https://doi.org/10.1371/journal.pone.0179483

Edmunds M. (1974). Defence in Animals: A Survey of Anti-Predator

Defences. Longman: Harlow, UK.

Hossie T.J., Sherratt T.N. (2012). Eyespots interact with body colour to protect caterpillar-like prey from avian predators. Anim Behav 84:167-173.

https://doi.org/10.1016/j.anbehav.2012.04.027

Hossie T.J., Sherratt T.N. (2013). Defensive posture and eyespots deter avian predators from attacking caterpillar models. Anim Behav 86:383-389.

https://doi.org/10.1016/j.anbehav.2013.05.029

Hossie T.J., Sherratt T.N. (2014). Does defensive posture increase mimetic fidelity of caterpillars with eyespots to their putative snake models? Curr Zool 60:76-89.

https://doi.org/10.1093/czoolo/60.1.76

Hossie T.J., Skelhorn J., Breinholt J.W., Kawahara A.Y., Sherratt T.N. (2015). Body size affects the evolution of eyespots in caterpillars. Proc Natl Acad Sci USA 112, $6664-6669$. doi:10.1073/pnas. 1415121112

Janzen D. H., Hallwachs W. \& Burns J. M. (2010). A tropical horde of counterfeit predator eyes. Proc Natl Acad Sci USA 107, 11659-11665

Kang C., Zahiri R., Sherratt T.N. (2017). Body size affects the evolution of hidden colour signals in moths. P Roy Soc B-Biol Sci 284:20171287.

Kauppinen J., Mappes J. (2003). Why are wasps so intimidating: field experiments on huntingdragonflies (Odonata:Aeshna grandis). Anim Behav 66:505-511.

doi:10.1006/anbe.2003.2225 
Kodandaramaiah U. (2011). The evolutionary significance of butterfly eyespots. Behav Ecol 22:1264-1271. doi.org/10.1093/beheco/arr123

Kodandaramaiah U., Lindenfors P., Tullberg B.S. (2013). Deflective and intimidating eyespots: a comparative study of eyespot size and position in Junonia butterflies. Ecol Evol 3: 4518-4524. doi: $10.1002 /$ ece 3.831

Kodandaramaiah U., Vallin A., Wiklund C. (2009) Fixed eyespot display in a butterfly thwarts attacking birds. Anim Behav 77: 1415-1419.

Lederhouse R.C. (1990). in Insect Defenses: Adaptive Mechanisms and Strategies of Prey and Predators, eds Evans DL, Schmidt JO (SUNY Press, Albany, NY), pp 175-189.

Loeffler-Henry K., Kang C., Sherratt T.N. (2019). Consistent associations between body size and hidden contrasting color signals across a range of insect taxa. Am Nat 194:28-37. doi: $10.1086 / 703535$

Monteiro, A. (2015). Origin, development, and evolution of butterfly eyespots. Ann Rev Ent 60:253-271.

O’Donnell S. (1996). Dragonflies (Gynacantha nervosa Rambur) avoid wasps (Polybia aequatorialis Zavattari and Mischocyttarus sp.) as prey. J Insect Behav 9:159-162.

Olofsson M., Vallin A., Jakobsson S., Wiklund C. (2010). Marginal eyespots on butterfly wings deflect bird attacks under low light intensities with UV wavelengths. PLoS ONE 5:e10798. doi: 10.1371/journal.pone.0010798.

Olofsson M., Løvlie H., Tibblin J., Sven Jakobsson S., Wiklund C. (2013). Eyespot display in the peacock butterfly triggers antipredator behaviors in naïve adult fowl. Behav Ecol 24:305331. 
Poulton EB (1890). The Colours of Animals: Their Meaning and Use, Especially Considered in the Case of Insects. K. Paul, Trench, Trübner.

Penney H.D., Hassall C., Skevington J.H., Abbott K.R., Sherratt T.N. (2012). A comparative analysis of the evolution of imperfect mimicry. Nature 483: 461-464. doi: 10.1038/nature10961

Prudic, K. L., Stoehr, A. M., Wasik, B. R., \& Monteiro, A. (2014). Eyespots deflect predator attack increasing fitness and promoting the evolution of phenotypic plasticity. Proceedings of the Royal Society B: Biological Sciences, 282(1798). https://doi.org/10.1098/rspb.2014.1531

Reitze M., Nentwig W. (1991). Comparative investigations into the feeding ecology of six Mantodea species. Oecologia 86:568-574.

Remmel T., Tammaru T. (2009). Size-dependent predation risk in tree-feeding insects with different colouration strategies: A field experiment. J Anim Ecol 78:973-980. doi: $10.1111 /$ j.1365-2656.2009.01566.x

Roslin T., Hardwick B., Novotny V., Petry W.K., Andrew N.R., Asmus A., Barrio I.C., Basset Y., Boesing A.L., Bonebrake T.C., Cameron E.K., Dáttilo W., Donoso D.A., Drozd P., L. Gray C.L., Hik D.S., Hill S.J., Hopkins T., Huang S., Koane B., Laird-Hopkins B., Laukkanen L., Lewis O.T., Milne S., Mwesige I., Nakamura A., Nell C.S., Nichols E., Prokurat A., Sam K., Schmidt N.M., Slade A., Slade V., Suchanková A., Teder T., van Nouhuys S., Vandvik V., Weissflog A., Zhukovich V., Slade E.M. (2017). Higher predation risk for insect prey at low latitudes and elevations. Science 356:742-744. doi: 10.1126/science.aaj1631

Ruxton G.D., Allen W.L., Sherratt T.N., Speed M. (2018). Avoiding Attack: The Evolutionary Ecology of Crypsis, Aposematism and Mimicry. Oxford Univ Press. doi:10.1093/oso/9780199688678.001.0001

Skelhorn J., Dorrington G., Hossie T.J., Sherratt T.N. (2014). The position of eyespots and 
thickened segments influence their protective value to caterpillars. Behav Ecol 25:1417-1422. https://doi.org/10.1093/beheco/aru154

Skelhorn J., Holmes G.G., Hossie T.J., Sherratt T.N.(2016). Eyespots. Curr Biol 26:52-54.

Stevens M. (2005). The role of eyespots as anti-predator mechanisms, principally demonstrated in the Lepidoptera. Biol Rev Camb Philos Soc 80:573-588. doi:10.1017/S1464793105006810

Stevens M. Hardman, C.J., Stubbins C.L. (2008). Conspicuousness, not eye mimicry, makes "eyespots" effective antipredator signals. Behav Ecol 19:525-531.

https://doi.org/10.1093/beheco/arm162

Stevens M., \& Ruxton G.D. (2014). Do animal eyespots really mimic eyes? Curr Zool 60:26-36. https://doi.org/10.1093/czoolo/60.1.26

Therneau T.M. (2020). R package 'coxme'. Mixed effects Cox models. R package version 2.2-6

Therneau T.M. \& Grambsch P.M. (2012). Modeling Survival Data: Extending the Cox Model (Statistics for Biology and Health). Springer-Veriag: New York. 


\section{Chapter 5: The anti-predation benefit of flash displays is related to the distance at which the prey initiates its escape}

Karl Loeffler-Henry ${ }^{1}$, Changku Kang ${ }^{2}$, Thomas N. Sherratt ${ }^{1 *}$

${ }^{1}$ Department of Biology, Carleton University, Ottawa, K1S 5B6, ON, Canada

${ }^{2}$ Department of Biosciences, Mokpo National University, Muan,

Jeollanamdo, 58554, South Korea

${ }^{*}$ Corresponding author

In press, Proceedings of the Royal Society $b$ 


\subsection{Abstract}

Flash behaviour is widespread in the animal kingdom and describes the exposure of a hidden conspicuous signal as an animal flees from predators. Recent studies have demonstrated that the signal can enhance survivorship by leading pursuing predators into assuming the flasher is also conspicuous at rest. Naturally, this illusion will work best if potential predators are ignorant of the flasher's resting appearance, which could be achieved if the prey flees while the predator is relatively far away. To test this hypothesis, we compared the survival of flashing and nonflashing computer-generated prey with different flight initiation distances (FIDs) using humans as model predators. This experiment found that flash displays confer a survivorship advantage only to those prey with a long FID. A complementary phylogenetic analysis of Australian bird species supports these results: after controlling for body size, species with putative flashing signals had longer FIDs than those without. Species with putative flashing signals also tended to be larger, as demonstrated in other taxa. The anti-predation benefit of flash displays is therefore related to the nature of escape behaviour. Since birds with hidden signals tend to flee at a distance, the flash display here is unlikely to function by startling would-be predators. 


\subsection{Introduction}

Many species have evolved colour patterns that resemble their backgrounds to avoid being detected by predators [1]. However, even cryptic species occasionally need to move and this motion increases the chance that they will be seen and/or heard by predators [2]. One way in which a cryptic species may mitigate their increased detection risk during motion is through the adoption of a flash display. Flash displays involve the sudden exposure of a previously hidden conspicuous signal when the animal is moving, followed by its concealment when the movement ceases $[3,4]$. Putative examples of flash behaviour include the brightly coloured hindwing displays seen in many insect groups (notably orthoptera and lepidoptera [7]), the tail flagging behaviour of some Artiodactyla and Leporids [8,9], and the conspicuous rump and underwing coverlets of many otherwise cryptic bird species, all of which are revealed only in flight $[3,4]$. The combination of exposing a hidden signal and movement distinguishes flash behaviour from deimatic, (startle) displays which typically involve exposing previously hidden signals while stationary $[8,9]$.

While flash behaviour may serve to surprise any would-be predator [4] and make the flasher harder to catch while fleeing [10], an important benefit is that would-be predators are misled into anticipating the prey is always conspicuous in appearance, when it is not [3]. Specifically, if a predator encounters a conspicuous prey item that is in the process of fleeing, the predator may continue to search for the prey assuming the prey retains the same conspicuous appearance on settling, when in fact it has reverted to its cryptic state. Supposing the prey is no longer present, the predator may more readily give up its search. In support, a computer based experiment using humans as visual predators found that participants were indeed more likely to give up looking for prey that displayed conspicuous colours when in motion but cryptic colours when at rest, compared to those prey that had cryptic coloration both in motion and at rest [11].

Despite their widespread taxonomic distribution [3,7], flash displays have only recently begun to be investigated and relatively little is known about the factors that mediate their effectiveness. Several comparative studies have reported that putative flash displays are more likely to have 
evolved in larger species [7,12]. Motivated by these observations, a recent experiment with computer-generated prey demonstrated that flash behaviour resulted in a higher survival benefit in large prey compared to small prey, in part because smaller prey have high survivorship even without a flashing signal, leaving less room for an improvement [13]. Here we address another, perhaps more important, condition that may mediate the effectiveness of flash signals, namely the distance at which the signallers initiate their escape from an approaching predator.

When faced with an approaching predator, prey have to decide whether, and when, to flee [14]. If flashing prey do indeed gain an anti-predator benefit from misleading the predator into supposing they are always conspicuous, then the success of this illusion might depend on whether the predator has observed the prey in its resting state before disturbance. Naturally, if prey wait until a predator closely approaches, then the predator will have more opportunity to detect the prey and directly observe its transition from crypsis to conspicuousness. Under these conditions, the effectiveness of the flash display is likely to be significantly reduced. In this study we began by testing whether the distance from a predator at which a flashing prey starts to flee (and hence the degree of opportunity of predators to see them in their cryptic state) affects the effectiveness of the flash display in reducing subsequent detection.

The distance at which an animal initiates escape from a predator in the wild has been variously referred to as a "flight initiation distance" (FID), "escape initiation distance" or "flush distance". FIDs have been widely reported in the literature and found to vary across species within many taxonomic groups [15-19] at least in part as a consequence of inter-specific variation in predation risk, with species at higher predation risk tending to have longer flight initiation distances [2023]. Some consistent covariates with flight initiation distance within and among species have therefore been identified (e.g. [24]). Of particular relevance to this study, body mass explains considerable variation in FID among species, especially in birds with larger species having a longer mean FID [25]. Although the underlying reasons for this association are unclear, large species are potentially more vulnerable in that they may be more detectable from a distance, less agile and/or more profitable to pursue [26]. 
Having experimentally evaluated how the efficacy of flash displays varies with flight initiation distance, we next determined whether the presence of hidden conspicuous signals is associated with FID in birds through phylogenetic comparative analysis. Birds are an excellent group to investigate the relationship between flash displays and the FID because FID has been carefully documented in many bird species under standardised conditions [27]. Although flash displays in birds have not yet been systematically evaluated, many species have conspicuous patches that are only visible when they are flying, which putatively function as a flashing signal. As noted above, we predict that species with putative flashing signals would initiate their escape from a greater distance than the species without such signals since the illusion is likely to be more effective when would-be predators do not see their resting state.

\subsection{Methods}

Human predator experiment

To elucidate the relationship between flight initiation distance (FID) and the efficacy of flash displays, a computer experiment was conducted from February to March 2019 (see Electronic Supplementary Materials [ESM] for a demonstration video). The experiment involved 30 volunteers playing a simple computer game that was modified from Loeffler-Henry et al. [11]. Participants (largely undergraduates) were recruited as they were entering and leaving Carleton University MacOdrum library, Ottawa, Canada. The game was developed in Microsoft Visual Basic 6 and displayed on a Toshiba ${ }^{\circledR}$ Portégé laptop. Before the experiment began, we asked the volunteers to read scripted instructions explaining how to play the game. The details of our hypothesis were not disclosed to our participants. When the participant indicated that they had understood the nature of the game and were ready to play, the game started.

Each game comprised 12 trials, with square artificial prey $(400 \times 400$ twips; 15 twips $=1$ pixel $)$ presented against the same complex grass background (dimensions 12700 twips height $\times 8170$ twips width). Each trial had a fleeing stage followed by a settling stage. At the beginning of the 
fleeing stage, a prey was placed at a random location on the grass background. When participants moved the mouse pointer within a specified reactive distance (corresponding to a fight initiation distance) of the prey item, the prey item moved to either right or left (whichever side was further) in a directed random walk off the screen. This allowed the participants to see the fleeing prey for 1-2 seconds on the screen. After the prey item disappeared from sight, participants were invited to press a "follow" button which led to a new screen containing a mirror image of the previous background, often (but not always, see below) containing the same prey. The background was mirrored in this settling stage screen to prevent our volunteers locating the prey by contrasting an otherwise identical background image. On following the prey to the new area, our volunteers had two options: they could either capture the prey by moving their mouse pointer over it and clicking on it or, if they failed to find it and considered the prey were not present on the screen, they could press a "give-up looking" button. When participants found the prey or pressed the give-up looking button they were then presented with a "next prey" button which led them to the next trial (or the game was ended if this was the last prey to be presented).

The first 8 trials were used as the training phase to acclimate the participants to the game, while the last 4 trials were used for testing the efficacy of flash displays. The training phase and testing phases were essentially the same except that flashing prey (with conspicuous colours when they were moving yet cryptic colours when they settled) were presented only in the test phase. During the training phase, participants were exposed to eight prey of different colours (all readily detectable due to their high contrast against the grass background, see RGB values in Table S1 of the ESM) presented in random order. The colours of the prey were fixed throughout the fleeing and settling stage. The flight initiation distance of the training prey that prompted movement was the mouse moving within 500 twips of the centre of the prey (1.25 times of prey lengths and $\sim 6 \%$ of the background width), allowing all participants an opportunity to see the prey's resting colours before it moved. Five of the training prey (blue, yellow, cyan, magenta, and green) were present both in the fleeing and settling stages. The remaining three training prey (set as blue, magenta, and yellow) were only present in the fleeing stage but not in the settling stage, ultimately forcing participants to press the "give-up looking" button and move on to the next screen. We included these "dud" trials so that volunteers would get used to the possibility that 
sometimes a given prey item would not be present in the search area, and the volunteer would therefore not continue to search the background indefinitely [11]. This mimics the natural situation where a predator follows an escaping prey but searches in the wrong area where the prey is not present.

After the training phase, the testing phase began in which four treatment prey were presented in random order to each participant. These treatment prey followed a 2 × 2 factorial combination of "flashers" (cryptic when sedentary but red in motion during the fleeing stage) and "non-flashers" (always with cryptic colouration) with short and long flight initiation distances. Each participant was presented with all four treatment prey types. However, each participant only saw each treatment once and in a random order $\left(1^{\text {st }}-4^{\text {th }}\right)$. All treatment prey in the testing phase were visible in the settling stage so there were no "duds". The cryptic colour of prey had the R, G, and $B$ values of the mean grass background $(R=73, G=151, B=19)$. In the short flight initiation distance treatment, fleeing was initiated when the mouse pointer was within 500 twips of the prey (1.25 times of prey length), as in the training phase. Under these conditions it was highly likely that the predator would see the prey in its cryptic state before the prey moved. In the long flight initiation distance treatment, prey initiated fleeing immediately after any movement of the mouse pointer (when prey were within a nominal 50,000 twips of the mouse pointer, which was always the case whenever the new screen appeared). With their hands always on the mouse and viewing where they had just clicked to generate a new screen, our volunteer predators under this treatment had little opportunity to observe the prey item in its resting state before it fled.

Statistical analysis of experimental data

All analyses were conducted in $\mathrm{R}$ version 4.0.3 [28]. We first fitted a generalised linear mixed model to elucidate if and how the presence/absence of flashing signals, the prey's short/long flight initiation distance (both treated as fixed factors), their order of presentation (treated as a covariate given the approximate logit linearity and lower Akaike Information Criterion, AIC) and volunteer ID (random intercept) explain variation in whether a prey item in the testing phase was ultimately attacked or not (binomial response). We included an interaction term between the presence of flashing signals and the flight initiation distance in our logistic model because we 
predicted that the efficacy of flashing signals in reducing predation would depend on flight initiation distance. Model fitting was conducted using the 'glmer' function (assuming binomial error structure) of the 'Ime4' package [29]. The importance of predictors was evaluated by comparing models with and without specific terms using log likelihood ratio tests (LRT). Following evidence for a significant interaction between the use of hidden signals and the prey's flight initiation distance, the proportions of the four different prey types attacked ( 2 flash/non flash prey types with 2 flight initiation distances) were compared directly. To make such multiple unplanned comparisons while controlling for the Type I error rate, Tukey HSD tests were conducted using the 'glht' function of the 'multcomp' package [30].

To test whether the four treatment prey types differed in their time to attack in the settling stage, while allowing for the fact that some prey were not attacked (i.e. they were right censused at the time of giving up), we conducted a survival (time to event) analysis. Specifically, we fitted a mixed effect Cox-proportional hazards model using 'coxme' package [31]. Using time to attack as the response variable (including whether it was censused by giving up) the model structure was the same as above with the presence/absence of flash signals, the prey's flight initiation distance and their interaction as the primary factors of interest, the order of presentation as a covariate and volunteer ID as a random factor.

Phylogenetic analysis

Flight initiation distance and body size data acquisition

The flight initiation distance data for 63 Australian birds were taken from an earlier comprehensive review [27]. These data were originally collected by having a human observer approach birds according to a standardised protocol (explained briefly below). Given the propensity of individual birds to habituate to disturbance [32], the FID data were not collected in areas with frequent human traffic. Birds were located with binoculars or the naked eye and approached by researchers at a standard speed of one pace per second. The flight initiation distance estimate for each species was based on the mean FID from at least 25 separate individuals of that species, with initial approach started at a range of distances. Although the 
initial distance of approach may explain some variation in FID [27], there were no statistically significant differences in population mean starting distances among species so that each species mean reflects data gathered at a comparable array of start distances. Bird body mass data was obtained from [33].

\section{Classification of the presence of flash behaviour}

We collected three to five images of each bird species under different viewing angles, obtained from Google ${ }^{\circledR}$ image searches, restricting ourselves to images from websites in which the birds were identified using scientific names, and which appeared authoritative (based on our own experience with bird identification). Our most commonly used source was [34] but a full list of our sources can be found in our ESM Supplementary Data. Based on these images, each species was classified as to whether it had putative flashing signals. To generate the classification, we asked 30 independent assessors (undergraduate student volunteers) to classify each species based on the images provided. These assessors had no prior knowledge either of the birds' FIDs or of the hypothesis being tested. Before beginning their classification, the assessors were presented with instruction slides (see ESM Fig. S1) based on a classification of a series of images of nonAustralian birds. We then asked assessors to continue to categorise our Australian bird species as having, or not having, novel colours only visible when in flight (i.e. colours that are not present in their resting appearance as an indication of flash behaviour). For those bird species believed to be sexually dimorphic (nine bird species based on their species descriptions [38]), photos of both males and females were separately presented to the assessors. Despite variation in appearance, both sexes of the sexually dimorphic species were consistently classified in the same way as to whether or not they exhibited hidden signals (five of the nine dimorphic species were classed as having hidden signals; minimum agreement for a given ses/species across partcipants was 73.3\%). Since the FID data [27] we had for each bird species was not sex-specific and both sexes of sexually dimorphic species were classified in the same way, then these data were retained in our analysis. Assessment took place over Zoom ${ }^{\circledR}$ in 30 separate one-on-one sessions with volunteers in October 2020. To minimize and control for any effect that presentation order may have on the assessor's classification, we divided the assessors into three blocks with three 
separate random presentation orders of the species' images. Assessors were alternately assigned to one of the blocks based on the order in which the trials took place.

\section{Phylogenetical analysis}

We performed phylogenetically controlled analysis using both 1) the maximum clade credibility (MCC) tree (tree provided in Fig. S2), and 2) 1000 phylogenetic trees randomly sampled from the posterior distribution of a supertree obtained from birdtree.org using the Ericson backbone to account for the uncertainties in topology and branch length [36]. To elucidate the relationship between the mean adult body mass, the presence of putative flashing signals, and the mean FID of birds after controlling for their phylogeny, we fitted phylogenetic generalised linear squares (PGLS) models using all trees. In all cases, we set the mean FID of each species as the response variable. For explanatory variables, we used the presence/absence of putative flashing signals (either a binary or continuous predictor, see below for how we created this variable), the mean mass of each species, and the interaction between these two. Both the mean FID and mean mass were log-transformed to remove their left-skewness in distributions. We assumed a Brownian motion (BM) model of trait evolution [37]. Alternative models of trait evolution (specifically Pagel's $\lambda$ and Ornstein-Uhlenbeck models [38]), are known to work poorly in small trees $(<200$ species) and failed to estimate exact parameters in some of the trees [39]. Nevertheless, we compared the estimated parameters and the results of PGLS among different models (BM, Ornstein-Uhlenbeck, Pagel's $\lambda$ ) using subsets of trees and found that the inference did not differ, regardless of which models we assumed.

To generate a binary predictor variable as to whether each species possess putative flashing signals, we first calculated the proportion of volunteers who agreed on their classifications. Based on the consistency of classification, we generated the species classification variable in several different ways. First, we used 1) the modal (majority) classificatory response of volunteers for all species and then we increasingly restricted our analysis to 2) only those species for which more than $70 \%$ of volunteers agreed on their classifications, 3 ) only those species for which more than $80 \%$ agreed, 4) only those species for which more than $90 \%$ agreed and 5) only 
those species on which all (100\%) of our volunteers agreed on their classification. Each of these forms of classification retained 61 bird species (we removed the two species that the volunteers' responses were divided into half, to be conservative) of which 21 were classed as species with hidden signals, 55 species (of which 17 had hidden signals), 41 species (of which 13 had hidden signals), 24 species (of which 8 had hidden signals), and 10 species (5 with hidden signals). We performed PGLS on all variables that retained more than 20 species (i.e. all but $100 \%$ level of consistency). We appreciate that the uncertainty of classification may itself have biological meaning. To incorporate this uncertainty directly, we additionally fitted an analogous PGLS model, this time using the proportion of volunteers that classified a species as having hidden colour patches as a continuous predictor variable of the extent of flash.

To elucidate the strength of evidence for an association between body size and the presence of putative flashing signals as demonstrated in other taxa [32] we performed PGLS using logtransformed mean mass as a response variable and the presence of putative flashing signals as an explanatory variable (treated both in binary form, and as a continuous predictor as above).

\subsection{Results}

Human computer experiment

On fitting the generalized linear mixed model, there was evidence for an interaction between the prey item's flight initiation distance that triggered movement and the prey's colour when mobile on whether it was attacked or not (full model with and without interaction, LRT $\chi_{1}^{2}=5.34, \mathrm{P}=$ 0.028; see ESM Table S2 for a full separate main effect estimates and their interaction). When comparing the main effects model (i.e. the full model without interaction) with and without a given factor then both the reactive distance (LRT $\chi_{1}^{2}=4.79 \mathrm{P}=0.029$ ) and whether it flashed $\left(\mathrm{LRT} \chi_{1}^{2}=4.95, \mathrm{P}=0.026\right)$ explained significant variation in whether the prey was ultimately attacked, as did the order of presentation (LRT $\left.\chi_{1}{ }^{2}=7.35, \mathrm{P}=0.007\right)$ with the mean attack rate of all prey increasing over time. Collectively, flashers with long flight initiation distance survived at about twice the rate as non-flashers in the experiment (figure 5.1). Pairwise comparisons (see ESM Table S4 for all comparisons) showed that flashing prey with high flight initiation distance 
survived at a higher rate than all three alternative prey types (Tukey pairwise multiple comparisons, all three $\mathrm{P}_{\text {adj }}<0.04$ ), but no other pairwise comparison was significant (for the three remaining pairwise comparisons $\mathrm{P}_{\text {adj }}>0.98$ ).

Our survival analysis revealed borderline evidence of an interactive effect of flight initiation distance and whether it flashed, on time to attack (full model with and without interaction, LRT $\chi_{1}^{2}=3.64, \mathrm{P}=0.056$ ). When comparing the main effects model with and without a given factor then a model including reactive distance did not explain significant variability (LRT $\chi_{1}{ }^{2}=0.81, \mathrm{P}$ $=0.369$ ) but whether it flashed did explain significant variability in attack time (LRT $\chi_{1}^{2}=6.51$, $\mathrm{P}=0.01)$ as did the order of presentation (LRT $\left.\chi_{1}{ }^{2}=8.00, \mathrm{P}=0.005\right)$. Once again, prey that flashed only appeared to benefit from flashing if their flight initiation distance was long (figure 5.2). Thus, compared to flashing prey with a long flight initiation distance, flashing prey with a short flight initiation distance tended to be more vulnerable (hazard ratio $2.09,95 \%$ CI 0.998 4.377). Non-flashing prey were even more susceptible to being attacked than the flashing prey with long flight initiation distance (short flight initiation distance HR 2.539, 95\% CI 1.1735.497; long flight initiation distance HR 3.207, 95\% CI 1.511- 6.807). 


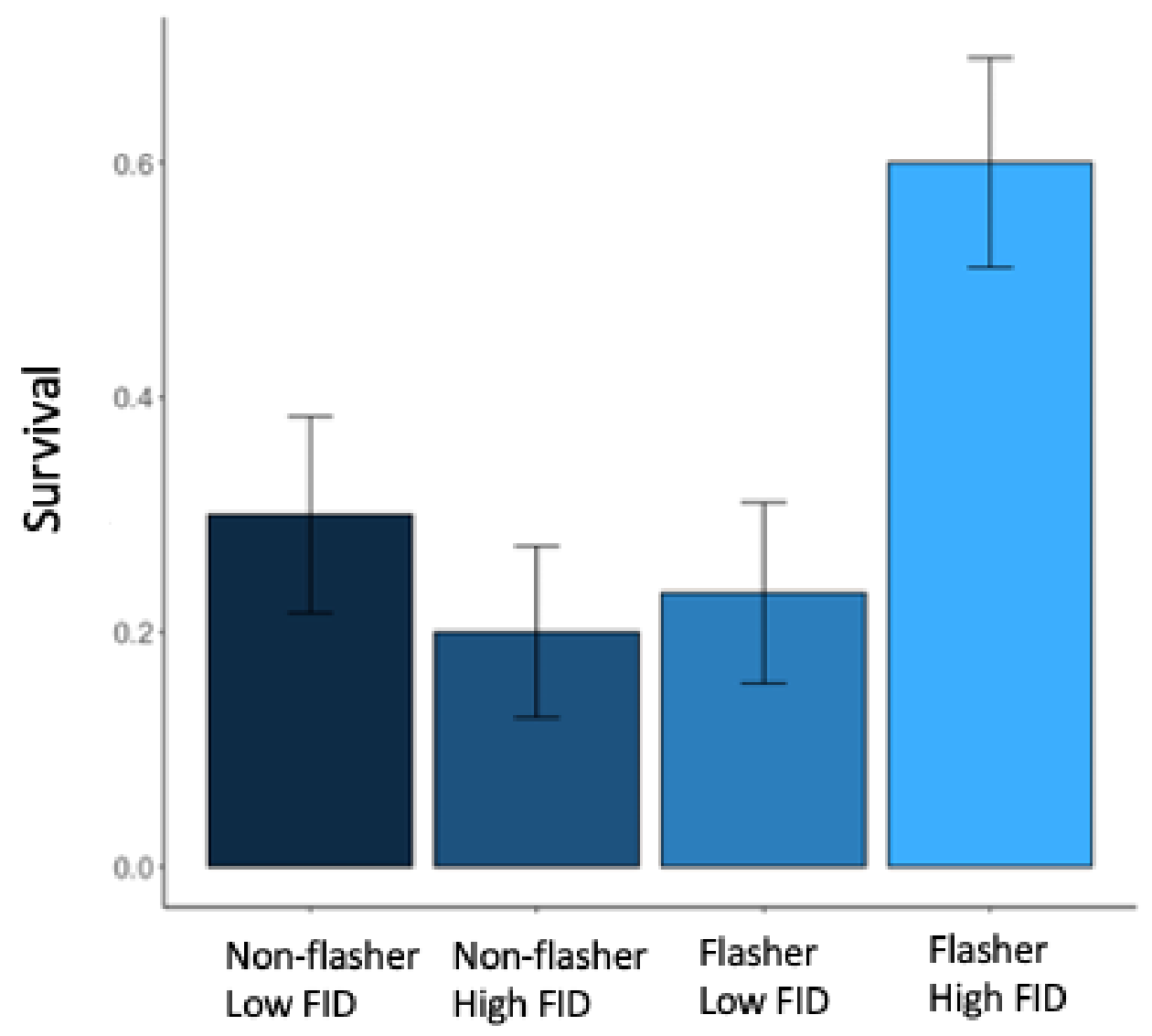

Figure 5.1 The mean proportion of each treatment prey type that survived once it had settled. The vertical error bars represent the 95\% Wilson binomial confidence intervals for these means. FID: flight initiation distance. 


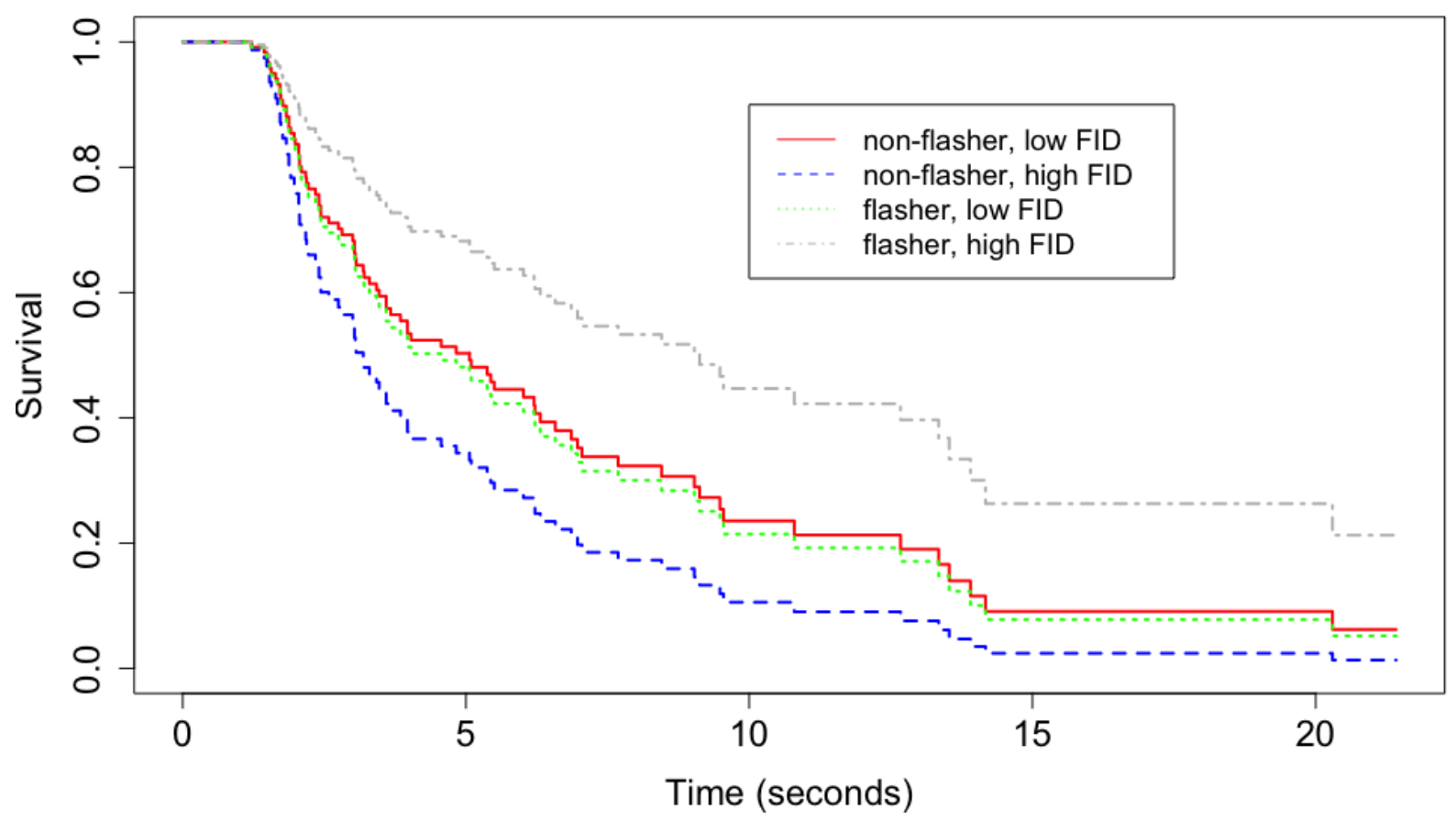

Figure 5.2 Distribution of the time taken by human volunteers to capture each of the four prey types. Those cases where the volunteer gave up searching were treated as censused at the time of giving up. Flashers with high flight initiation distances tended to survive the longest while nonflashers with high flight initiation distances tended to survive the shortest period of time.

\section{Phylogenetically controlled analysis}

Here, we present the results that used 1) the modal response of volunteers as a binary flash predictor and 2) the proportion of volunteers that classified a species as having putative flashing signals as a continuous flash predictor in the main results, since they retained almost all species we studied. The results that used other criteria did not differ qualitatively from these results and can be found in ESM (Fig. S3, Table S5). Although we iteratively performed PGLS analyses on 1000 trees, the $95 \%$ confidence limits of the estimated parameters and ranges of P-values from all trees were very narrow $( \pm 0.01$ range in P-values and \pm 0.04 range in all coefficients and result statistics; Fig. S4). Thus, we only present the results from the MCC tree which are essentially the same as the results from 1000 trees. 
The FID of birds was significantly higher in both larger species and those species that have putative flashing signals (Table 5.1, figures. 5.3,5.4). The interaction effect between body size and flashing signal presence on FID was non-significant. The results were consistent when we used the $70 \%$ agreed variable for the presence of hidden colour patches (ESM Table S5).

However, the effects of putative flashing signal presence became non-significant when we used both $80 \%$ and $90 \%$ agreed binary variables (ESM Table S5, Fig. S3, likely due to a reduction in statistical power or because the effect is driven by species with particularly ambiguous flash signals. The presence of putative flashing signals was also associated with larger size (coefficients $=0.25, t=2.18, \mathrm{P}$-value $=0.05$ ).

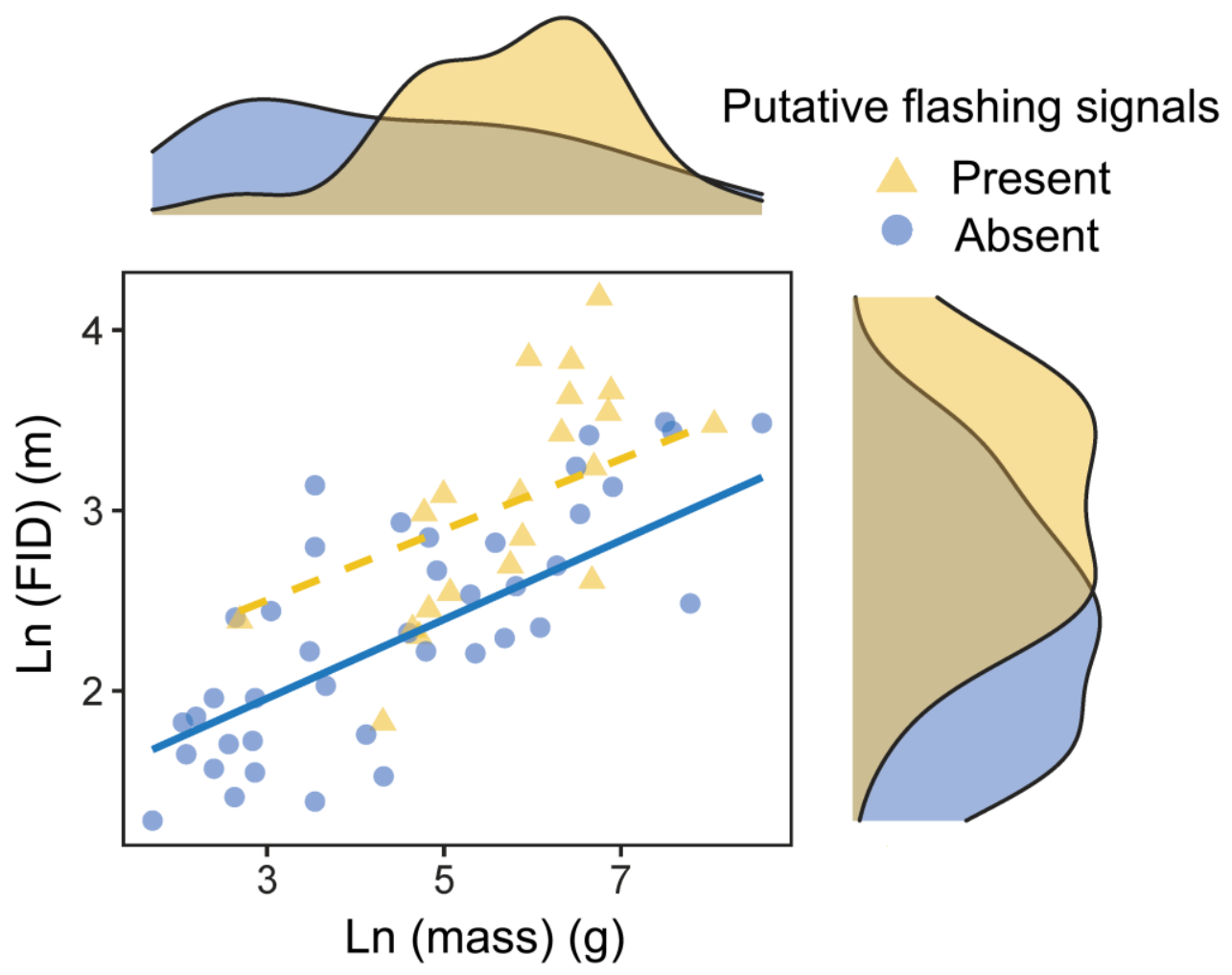

Figure 5.3 A scatterplot and density plots depicting the relationship between mean body mass, mean flight initiation distance (FID), and the presence of putative flashing signals in birds. We used the modal response of volunteers when classifying each species as having putative flashing signals or not $(N=61$ species) for plotting. The trend lines represent the predictions from the PGLS models using the maximum clade credibility tree. 

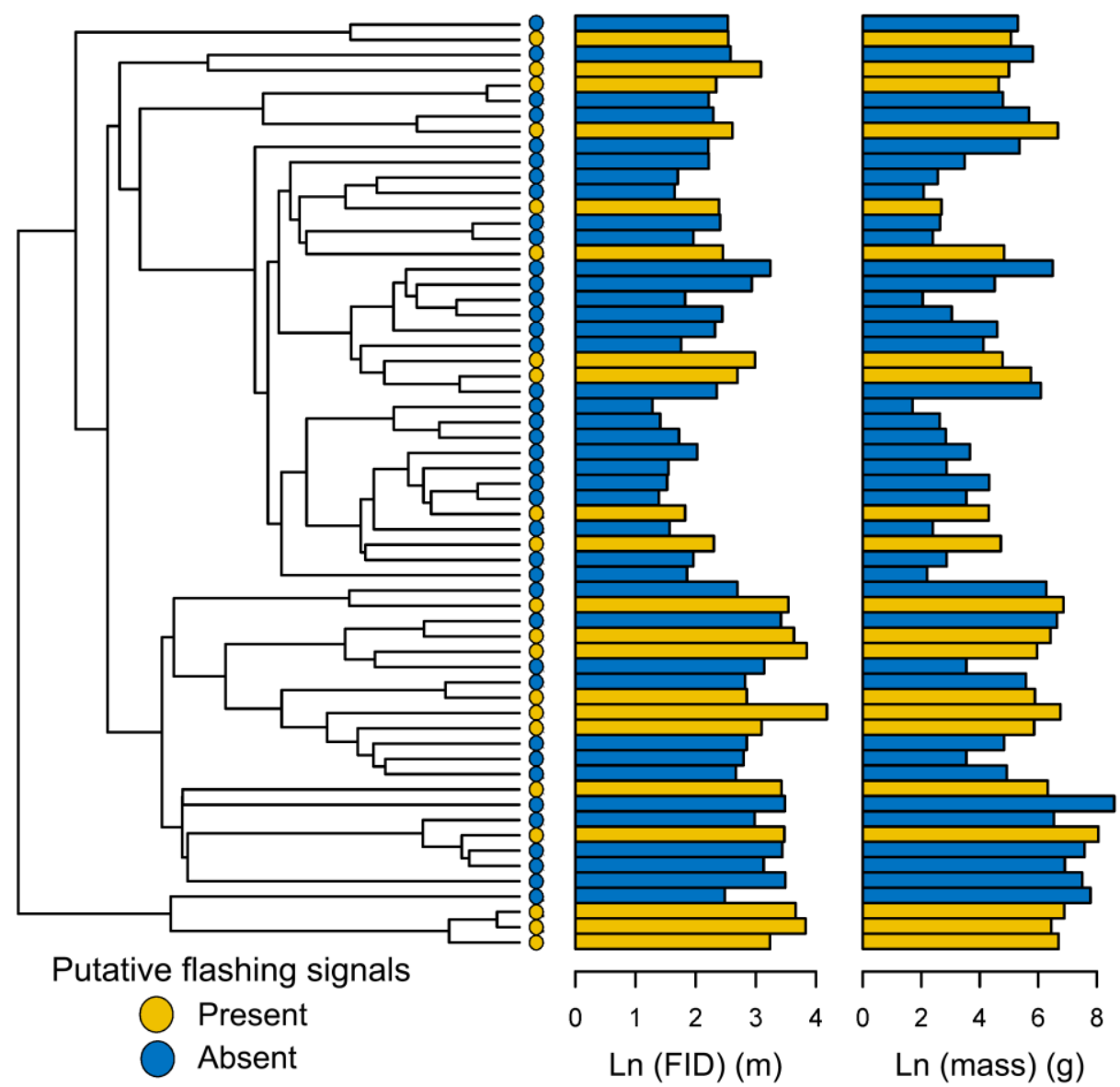

Figure 5.4 Mean body mass, mean flight initiation distance (FID) [both logged] and the presence of putative flashing signals of each species and their phylogenetic positions on the maximum clade credibility tree. 
Table 5.1 Results of PGLS models (assuming a Brownian motion model of trait evolution) predicting the flight initiation distance of birds using the maximum clade credibility tree.

\begin{tabular}{|c|c|c|c|c|}
\hline $\begin{array}{l}\text { The way that the } \\
\text { presence of } \\
\text { flashing signal was } \\
\text { inferred }\end{array}$ & Predictor of FID & Coefficient & $t$ & P-value \\
\hline \multirow{3}{*}{$\begin{array}{l}\text { The modal } \\
\text { response of } \\
\text { volunteers } \\
\text { ( } n=61 \text { species) }\end{array}$} & $\begin{array}{c}\text { Flashing signal } \\
\text { presence }\end{array}$ & 0.11 & 3.16 & 0.004 \\
\hline & Log (mass) & 0.21 & 5.39 & $<0.001$ \\
\hline & Interaction & 0.008 & 0.32 & 0.75 \\
\hline \multirow{3}{*}{$\begin{array}{l}\text { The proportion of } \\
\text { volunteers that } \\
\text { classified a species } \\
\text { as having flashing } \\
\text { signals } \\
\text { ( } n=63 \text { species) }\end{array}$} & $\begin{array}{l}\text { Flashing signal } \\
\text { presence }\end{array}$ & 0.40 & 3.70 & 0.001 \\
\hline & Log (mass) & 0.19 & 4.51 & $<0.001$ \\
\hline & Interaction & -0.05 & -0.86 & 0.42 \\
\hline
\end{tabular}

\subsection{Discussion}

Our human experiment showed that the survival benefit of flash behaviour in artificial prey was dependent on the prey having a relatively long flight initiation distance. Our complementary phylogenetic analysis was consistent with this inference, indicating that birds that have putative flashing signals tend to have a relatively longer flight initiation distance than those with no such signals, even after controlling for their body size. Collectively, our results demonstrate the importance of being undetected before fleeing in flashing prey and how this has shaped the evolutionary relationship between the employment of hidden signals and fleeing behaviour in birds. 
Our finding that the anti-predation benefit of flash behaviour is dependent on flight initiation distance provides additional mechanistic support for the hypothesis that flash behaviour serves as a decoy to deceive predators into assuming that the flasher is no longer present. In our human experiment, prey with longer flight initiation distances were unlikely to have been seen prior to their movement. For non-flashing prey that had cryptic colours throughout, the flight initiation distance appears to have been relatively inconsequential for its subsequent survivorship, because those prey were seen to be cryptic when in motion, so the searcher knew what to expect. By contrast, for those prey whose colour at rest differed from when in motion, not witnessing the prey item's original resting colour likely led participants to believe that the prey's "flash colour" was also its colour at rest. When the prey returned to its resting state, participants not seeing the colour they had previously associated with the prey likely assumed it was not present and gave up searching.

Although flashing and non-flashing prey with short flight initiation distances did not show significant survivorship differences in our game, in nature there may be some costs associated with flash displays which may favour non-flashing in these cases. Such costs might include possible metabolic costs involved in the generation of high contrast colours [40] and/or the potential for increased conspicuousness to predators by an incidental revealing of flash colours while at rest. Thus, flash displays may be selected against in species where their decoy function is rendered ineffective by a low FID.

It has previously been speculated that flash behavior may function to simultaneously mislead predators as to the prey's actual resting appearance, and function as a startle signal [3,4]. Our findings call this supposition into question. Startle signals deter predation by inducing a reflexive fear response that causes the predator to hesitate or flee, buying time for the prey to escape [9]. For a startle signal to induce such a response, the predator must perceive an imminent threat. If the startle signal is relatively far away, the perception of threat may be significantly reduced because real threats inherently become less dangerous with increasing distance. Given our finding that putative flash signals tend to be deployed when the predator is far away, it appears unlikely that the putative flash colours also serve as a startle. 
There are a variety of plausible alternate anti-predation mechanisms that may cause birds to evolve contrasting hidden signals $[10,41,42]$. Brooke [43] found that species of wader with flash marks are more likely to flock and proposed three inter-related predation-based explanations for the association namely: (a) it has evolved as a signal to conspecifics to flee (b) it generates a confusion effect in grouped prey (c) it serves to co-ordinate flight. Intriguingly, Mayer et al. [44] found groups of certain species of waterbird tend to have longer flight initiation distances than solitary conspecifics and proposed that this relationship is caused by groups of birds being more able to detect an approaching threat. The FID data we analyzed [27] was based on individual focal birds and we did not include group size or flocking tendency as a predictor in our phylogenetic model. Given the above, it is possible that flocking tendency may have co-evolved with flash signals to increase FID, but whether the decoy effect works at group level remains to be determined.

An additional plausible explanation for hidden signals is that the flashing colours of some birds function to reduce the likelihood of the signaller being captured during its pursuit $[10,42]$. In these cases, whether a bird is seen to have a different appearance at rest and in flight would be unimportant. While the association we observed between FID and flash displays can be readily directly explained on the basis of deception (see above), it remains possible that bird species that experience higher predation pressure face elevated selection for both hidden contrasting signals and relatively long FID independently. In some cases the hidden contrasting colors that we considered putative flash signals, may in fact operate as pursuit deterrent signals. Indeed, there is evidence that pursuit deterrent signals have coevolved with flight initiation distance some species of lizard [45-47]. Intriguingly, our phylogenetic analysis also revealed that larger species of bird are more likely to have hidden signals, just as larger species of insect are also more likely have hidden signals $[7,12,48]$. This likely reflects higher selective pressure to evolve a secondary defence on large species because of higher conspicuousness, and/or higher caloric profitability. However, there is evidence that flash behaviour may be more effective at deterring predation in large prey because smaller species are already hard to detect, thus selection to evolve a back-up defence is weaker in these species [13]. 
Other explanations for flash displays can be ruled out. In particular, while males and females of a given bird species sometimes differed in appearance in our data, they were consistently classified in the same way with respect to flash coloration. This indicates that sexual selection is not the basis of selection for hidden colour signals in birds. Indeed, it has similarly been noted that not a single instance of sexual variation in the presence of hidden signals was reported out of a sample of over 600 species of insects, spanning six clades [11,12]. Likewise, thermal regulatory factors also influence the evolution of animal colouration [49]. However, patches of colour only visible while in flight likely have a negligible effect on thermoregulation. Therefore, we consider it is unlikely that selection for thermally favourable coloration has confounded our results.

To our knowledge this is the first study to compare the flight initiation distances of species that display contrasting signals when fleeing (i.e. flashing) and those that do not. However, one potential limitation of the data used in our phylogenetic analysis is that the categorisation of birds as having or not having hidden contrasting colours was carried out in the human visual range, and not the visual range of ecologically relevant predators. The birds in this study are all native to Australia, which is largely devoid of native mammalian predators. Therefore, the dominant selective pressure likely to have shaped the evolution of anti-predation traits in our study species is predation by other birds, which may be better able than mammals to pursue escaping avian prey. Birds are known to perceive all colours within the human visual range as well as colours in the UV region ( $300-400 \mathrm{~nm}$ wavelength region that humans cannot perceive) [50], but recent studies suggest that birds and humans do not differ substantially in discriminating colour differences [51-52]. Therefore, all of the birds that we classified as contrasting (in visible range) would have contrasted to their avian predators as well. Some of the birds that we classified as non-contrasting may display some degree of contrast to avian predators especially when UV is associated. Given that flash coloration may function by drawing attention to the signaller, it seems unlikely that selection would favour UV-only signals for flash behaviour.

Flight initiation distances are important metrics of perceived risk and have long been documented by conservation biologists and ecologists. Our classification of birds was based on 
whether they reveal hidden colours when fleeing and we did not attempt to quantify their extent of crypsis at rest, which is background specific and varies with light conditions. It is currently unclear whether more conspicuous birds tend to compensate for their higher conspicuousness by fleeing at a greater distance. One study to address this question found no evidence that the flight initiation distances of birds was associated with their vividness of colour at rest [53]. However, Møller et al. [54] recently found that the mean FIDs of 12 bird species assessed to be "with camouflage" was significantly shorter than their matched 12 sister taxa without camouflage. Our finding of an association between flight initiation distance and exposure of hidden signals while fleeing would not be evident in the above analyses that are based simply on the extent of crypsis in resting plumage alone.

Our study highlights a co-evolutionary relationship between plumage colouration and flight initiation distance in birds and provides evidence for a plausible underlying mechanism. Many other taxonomic groups exhibit flash behaviour, including insects and mammals, and given the simplicity of the explanation it would be of interest to determine whether they show the same relationship. For example, Butler recorded the flight initiation distances of nine species of grasshopper [15]. While there are too few species for meaningful statistical comparisons, it is notable that all of the species with hidden contrasting colours (only visible in flight) had longer median FIDs than those without (ESM Fig. S5). Artiodactylas are another promising group to evaluate since many species display colours that are only visible when they flee, although the range of different ways of measuring FID makes cross-species comparisons challenging at this time [19].

\subsection{Acknowledgments}

We thank our human volunteers for their participation. We also wish to thank Michael Runtz for giving permission to recruit student volunteers from his natural history class for the bird classification work. Sebastiano De Bona and two anonymous referees provided a number of valuable suggestions which helped improve the clarity of our paper. 


\subsection{References}

1. Endler JA. 1984 Progressive background in moths, and a quantitative measure of crypsis. Biol. J. Linn. Soc. 22, 187 - 231. (doi:10.1111/j.1095-8312.1984.tb01677.x)

2. Hall JR, Cuthill IC, Baddeley R, Shohet AJ, Scott- Samuel NE. 2013 Camouflage, detection and identification of moving targets. Proc. R. Soc. B 280, 20130064.

(doi:10.1098/rspb.2013.0064)

3. Cott HB. 1940 Adaptive coloration in animals. London, UK: Methuen.

4. Edmunds M. 1974. Defence in animals: a survey of anti-predator defences. New York (USA): Longman Publishing Group.

5. Loeffler-Henry K, Kang C, Sherratt TN. 2019 Consistent associations between body size and hidden contrasting color signals across a range of insect taxa. Am. Nat. 194, $28-37$. (doi:10.1086/703535)

6. Caro T, Raees H, Stankowich T. 2020 Flash behavior in mammals? Behav. Ecol. Sociobiol. 74, 1 - 7. (doi:10.1007/s00265-020-2819-0)

7. Caro TM, Graham CM, Stoner CJ \& Vargas JK. 2004 Adaptive significance of antipredator behaviour in artiodactyls. Anim. Behav. 67, $205-228$.

(doi:10.1016/j.anbehav.2002.12.007)

8. Umbers KDL, Mappes J. 2015 Postattack deimatic display in the mountain katydid, Acripeza reticulata. Anim. Behav. 100, 68 - 73. (doi:10.1016/j.anbehav.2014.11.009)

9. Umbers KDL, De Bona S, White TE, Lehtonen J, Mappes J, Endler JA. 2017 Deimatism: a neglected component of antipredator defence. Biol Lett. 13, 20160936.

(doi:10.1098/rsbl.2016.0936)

10. Murali G. 2018 Now you see me, now you don't: dynamic flash coloration as an antipredator strategy in motion. Anim. Behav. 142, 207 - 220. (doi:10. 1016/j.anbehav.2018.06.017)

11. Loeffler-Henry K, Kang C, Yip Y, Caro T, Sherratt TN. 2018 Flash behavior increases prey survival. Behav. Ecol. 29, 528 - 533. (doi:10.1093/beheco/ary030)

12. Kang C, Zahiri R, Sherratt TN. 2017 Body size affects the evolution of hidden colour signals in moths. Proc. R. Soc. B 284, 20171287. (doi:10.1098/rspb.2017.1287)

13. Bae S, Kim D, Sherratt TN, Caro T, Kang C. 2019 How size and conspicuousness affect the efficacy of flash coloration. Behav. Ecol. 30, 697 - 702. (doi:10.1093/beheco/arz006)

14. Cooper Jr WE, Frederick WG. 2007 Optimal flight initiation distance. J. Theor. Biol. 244, 59 -67. (doi:10.1016/j.jtbi.2006.07.011) 
15. Butler EM. 2013 Species-specific escape behaviour in grasshoppers. Behaviour 150, 1531 1552. (doi:10.1163/1568539X-00003108)

16. Bell T, Harriss J, Ruzaini A, Fernando C, Guay PJ, Weston MA. 2019 Flight initiation distance in dragonflies is species-specific, positively related to starting distance and sometimes body length. Int. J. Odonatol. 22, 173 - 179. (doi:10.1080/13887890.2019.1668306)

17. Harbour D, Henson E, Boers C, Truman D, Fernando C, Guay PJ, Weston MA. 2019 Flight initiation distance in Lepidopterans is species-specific and positively related to starting distance. J. Asia. Pac. Entomol. 22, 41 - 43. (doi:10.1016/j.aspen.2018.11.015)

18. Bateman PW, Fleming PA. 2014 Switching to Plan B: changes in the escape tactics of two grasshopper species (Acrididae: Orthoptera) in response to repeated predatory approaches. Behav. Ecol. Sociobiol. 68, 457 - 465. (doi:10.1007/s00265-013-1660-0)

19. Stankowich T. 2008 Ungulate flight responses to human disturbance: a review and metaanalysis. Biol. Conserv. 141, 2159 - 2173. (doi:10.1016/j.biocon.2008.06.026)

20. Ydenberg RC, Dill LM. 1986 The economics of fleeing from predators. Adv. Stud. Behav. 16, 229 - 249. (doi:10.1016/S0065-3454(08)60192-8)

21. Cooper Jr WE, Frederick WG. 2007 Optimal flight initiation distance. J. Theor. Biol. 244, 59 - 67. (doi:10.1016/j.jtbi.2006.07.011)

22. Cooper WE, Pyron RA, Garland T. 2014 Island tameness: living on islands reduces flight initiation distance. Proc. R. Soc. B Biol. Sci. 281, 20133019. (doi:10.1098/rspb.2013.3019)

23. Stankowich T, Blumstein DT. 2005 Fear in animals: A meta-analysis and review of risk assessment. Proc. R. Soc. B Biol. Sci. 272, 2627-2634. (doi:10.1098/rspb.2005.3251)

24. Gotanda KM, Turgeon K, Kramer DL. 2009 Body size and reserve protection affect flight initiation distance in parrotfishes. Behav. Ecol. Sociobiol. 63, 1563 - 1572. (doi:10.1007/s00265009-0750-5)

25. Blumstein DT. 2006 Developing an evolutionary ecology of fear: how life history and natural history traits affect disturbance tolerance in birds. Anim. Behav. 21, $389-399$.

(doi:10.1016/j.anbehav.2005. 05.010)

26. Weston MA, McLeod EM, Blumstein DT, Guay PJ. 2012 A review of flight-initiation distances and their application to managing disturbance to Australian birds. Emu 112, 269- 286. (doi:10.1071/MU12026)

27. Blumstein DT. 2003 Flight-initiation distance in birds is dependent on intruder starting distance. J. Wildl. Manag. 67, 852 - 857. (doi:10.2307/3802692) 
28. R Core Team. 2018 R: a language and environment for statistical computing. R Foundation for Statistical Computing. See https:// www.R-project.org.

29. Bates D, Mächler M, Bolker BM, Walker SC. 2015 Fitting linear mixed-effects models using lme4. J. Stat. Softw. 67, 1 - 48. (doi:10.18637/jss.v067.i01)

30. Hothorn T, Bretz F, Westfall P, Heiberger R. 2008 Simultaneous inference in general parametric models. Biol. J. 50, 346-363. (doi: 10.1002/bimj.200810425)

31. Therneau MT. 2015 Package 'coxme'. Mixed Effects Cox Models.

32. Møller AP, Tryjanowski P, Diaz M, Kwiecinski Z, Indykiewicz P, Mitrus C, Golawski A, Polakowski M. 2016 Urban habitats and feeders both contribute to flight initiation distance reduction in birds. Behav. Ecol. 26, 861 - 865. (doi:10.1093/beheco/arv024)

33. Dunning, J. B. 1993 CRC handbook of avian body masses. London: CRC Press.

34. ebird | https://ebird.org/home (accessed on 2 February 2021).

35. Find a Bird | BirdLife. See https://birdlife.org.au/all-about-birds/australias-birds/find-a-bird (accessed on 2 February 2021).

36. Jetz W, Thomas GH, Joy JB, Hartmann K, Mooers AO. 2012 The global diversity of birds in space and time. Nature 491, 444 - 448. (doi:10.1038/nature11631)

37. Martins EP, Hansen TF. 1997 Phylogenies and the comparative method: a general approach to incorporating phylogenetic information into the analysis of interspecific data. Am. Nat.

149, 646 -667. (doi:10.1086/286013)

38. Revell LJ. 2010 Phylogenetic signal and linear regression on species data. Methods Ecol. Evol. 1, 319 - 329. (doi:10.1111/j.2041-210X.201000044.x)

39. Cooper N, Thomas GH, Venditti C, Meade A, Freckleton RP. 2016 A cautionary note on the use of Ornstein Uhlenbeck models in macroevolutionary studies. Biol. J. Linn. Soc. 118, 64 - 77. (doi:10.1111/bij.12701)

40. McGraw KJ, Hill GE, Parker RS. 2005. The physiological costs of being colourful: nutritional control of carotenoid utilization in the American goldfinch, Carduelis tristis. Anim. Behav. 69, 653-660. (doi: 10.1016/j.anbehav.2004.05.018)

41. Murali G, Kumari K, Kodandaramaiah U. 2019 Dynamic colour change and the confusion effect against predation. Sci. Rep. 9, 274. (doi:10.1038/s41598-018-36541-7)

42. Palleroni A, Miller CT, Hauser M, Marler P. 2005 Prey plumage adaptation against falcon attack. Nature 434, 973 - 974. (doi:10.1038/434973b) 
43. Brooke MDL. 1998 Ecological factors influencing the occurrence of 'flash marks' in wading birds. Funct. Ecol. 12, 339-346. (doi:10.1046/j.1365-2435.1998.00204.x)

44. Mayer M, Natusch D, Frank S. 2019 Water body type and group size affect the flight initiation distance of European waterbirds. PLoS One 14, e0219845.

(doi:10.1371/journal.pone.0219845)

45. Cooper WE. 2010 Pursuit deterrence varies with predation risks affecting escape behaviour in the lizard Callisaurus draconoides. Anim. Behav. 80, 249-256.

(doi:10.1016/j.anbehav.2010.04.025)

46. Cooper WE. 2007 Escape and its relationship to pursuit-deterrent signalling in the Cuban curly-tailed lizard Leiocephalus carinatus. Herpetologica. 63, 144-150. (doi:10.1655/0018083)

47. Cooper WE. 2011 Pursuit deterrence, predation risk, and escape in the lizard Callisaurus draconoides. Behav. Ecol. Sociobiol. 65, 1833-1841. (doi:10.1007/s00265-011-1191-5)

48. Emberts Z, Miller CW, Skojec C, Shepherd R, St. Mary CM. 2020 Leaf-footed bugs possess multiple hidden contrasting color signals, but only one is associated with increased body size. Ecol. Evol. 10, 8571 - 8578. (doi:10.1002/ece3.6468)

49. Cuthill IC et al. 2017 The biology of color. Science 357, 221. (doi:10.1126/science.aan0221)

50. Osorio D, Vorobyev M. 2008 A review of the evolution of animal colour vision and visual communication signals. Vision Res. 48, 2042 - 2051. (doi:10.1016/j.visres.2008.06.018)

51. Olsson P, Lind O, Kelber A. 2015 Bird colour vision: Behavioural thresholds reveal receptor noise. J. Exp. Biol. 218, 184 - 193. (doi:10.1242/jeb.111187)

52. Bergeron ZT, Fuller RC. 2018 Using human vision to detect variation in avian coloration: How bad is it? Am. Nat. 191, 269-276. (doi:10.1086/695282)

53. Hensley NM, Drury JP, Garland T, Blumstein DT. 2015 Vivid birds do not initiate flight sooner despite their potential conspicuousness. Curr. Zool. 61, 773-780. (doi:10.1093/czoolo/61.4.773)

54. Møller AP, Liang W, Samia DSM. 2019 Flight initiation distance, color and camouflage. Curr. Zool. 65, 535-540. (doi:10.1093/cz/zoz005)

55. Loeffler-Henry, K, Kang C, Sherratt TN. 2021. Data from: The anti-predation benefit of flash displays is related to the distance at which the prey initiates its escape. Dryad Digital Repositry (doi: 10.5061/dryad.79cnp5hvs) 


\section{Chapter 6 Discussion}

\subsubsection{Thesis contributions and conclusions}

Through the convergence of multiple independent lines of evidence, I believe that this thesis has advanced our current understanding of the evolutionary ecology of hidden signals. One of the primary aims of this work was to elucidate the adaptive significance of flash displays, a phenomenon that had previously not received controlled experimental investigation. Using a human computer experiment, I established a "proof of concept" that flash displays can yield a fitness benefit (Chapter 2). Furthermore, by demonstrating that the anti-predation benefit of flash displays is related to the predator's ignorance of the prey's static color, I have shed light on a novel mechanism that may explain how flash displays prevent attacks (Chapter 5).

The phylogenetic analyses in Chapters 3 and 5 support the findings of our human experiments. Since large insects are likely to be at higher predation risk than small insects (Remmel \& Tammaru 2009), our finding that body size is positively correlated with the evolution of hidden signals suggests that such traits do serve to prevent predation (Chapter 3). Likewise, our finding that birds with putative flash signals flee at a greater distance than those without, supports our findings from the human experiment. The consistency between the findings suggest that the human computer model system developed in this thesis is useful and effective at predicting the conditions under which selection will favor flash displays.

The finding that eye spots can be effective at deterring an insect predator suggests that selection from insects may have contributed to the evolution of deimatic displays (Chapter 4). This is because many deimatic displays feature eye-like markings. Moreover, our finding that body size influences the efficacy of eyespots in dissuading an insect predator is evidence that selection generated by insect predators likely contributed to the trend documented in Chapter 3 . This also suggests that the mechanism through which deimatic displays deter predation is by inducing a sense of threat and the predator, which may be perceived as more serious coming from a larger organism. 
Collectively the findings of this thesis provide compelling evidence that hidden signals can and do provide unique antipredation benefits via multiple mechanisms. Remaining questions about the evolutionary ecology of hidden signals include: 1 . In chemically defended organisms with hidden signals, how do hidden signals-specific antipredation mechanisms interact with aposematism to reduce predation? 2. To what extent has selection from insect predators influenced the evolution of hidden signals? and 3. In addition to relatively long flight initiation distance, what other adaptations may enhance the effectiveness of flash displays?

\subsubsection{Remarks on the role of natural verses sexual selection in the evolution of hidden signals}

Work in this thesis revealed a number of insights on the relative importance of sexual and natural selection in shaping hidden signals. Unlike sexual selection that can act on any trait regardless of its function or lack thereof, natural selection will only favor traits that have pragmatic utility (Andersson 1994). Therefore, it was first necessary to establish if hidden signals could generate a fitness benefit from natural selection alone. As stated above, Chapters 2 and 4 demonstrated that hidden signals can provide an anti-predation benefit. Having established that natural selection could act on hidden signals, the next step was to examine the possible role sexual selection may have played in shaping hidden signals. This was accomplished by testing for evidence of sexual dimorphism across numerous species, spanning a broad taxonomic breath. Although sexual dimorphism in not a necessary characteristic of sexually selected traits, one would expect that if sexual selection had shaped a trait there would be significant occurrence of sexual dimorphism within a large sample of species (Andersson 1994). Remarkably, within a sample of 458 insects in 5 clades and 63 birds there was not a single observed instance of sexual dimorphism with respect to the presence/absence of hidden signals.

Additionally, while there are a number of possible explanations for why selection from predators would preferentially favor hidden signals in large insects and birds, I am not aware of any reason why sexual selection would do so. Moreover, if the role of mate attraction signals is to increase conspicuousness in order to increase the probability of being seen by potential mates, one might expect selection of such signals to be stronger in small species that are inherently less 
conspicuous (Endler 1984). Likewise, I am not aware of a plausible explanation for why transiently visible mate attraction signals would co-evolve with relatively long FID in birds. Furthermore, many hindwing hidden signals in insects have eyespots that appear to be analogous to the eyespots seen in lepidoptera larvae. Given that these markings occur in both mature and non-reproductive ontogenetic stages and that we found them to be effective at preventing predation, natural selection appears to be the only plausible explanation for their evolution.

While it cannot be ruled out that sexual selection may have caused or contributed to the evolution of some hidden signals, the findings in this thesis provide robust evidence that natural selection is the primary driver of hidden signal evolution.

\subsubsection{Classification of hidden signals}

This thesis has illuminated valuable insights related to the classification of hidden signals. First and foremost, we found that flash displays only provide a clear anti-predation benefit if they are deployed while the predator is relatively far away. This indicates that contrary to previous supposition, the decoy function of flash displays and any possible intimidation or startle functions are likely mutually exclusive (Cott 1940, Edmunds 1974). Conversely, it is not implausible that some hidden signals that function to intimidate predators may be deployed when predators are relatively close and in synchrony with movement. Based on the previous behavioral differentiation between flash displays and deimatic displays, a defense of that nature would be considered a flash display. However, the mechanism via which such a display would prevent predation would be far more analogous to that of a stationary deimatic display than the decoy function of flash displays. Therefore, there may be some benefit in devising a classification scheme for hidden signals that not only takes into account behavioral aspects of how they are deployed but also the mechanism of how they prevent attacks.

Additionally, some diagnostic criteria between flash displays and dynamic color change were put forward. In order for the decoy effect of flash displays to function, the predator had to first be subjected to a training phase, where the expectation was built that prey would maintain consistent coloration both at rest and in motion. The dynamic color change effect however 
appears to require no such prior experience, suggesting that this illusion is visual rather than cognitive in nature (Murali 2018). Experiment 2 of Chapter 2 demonstrated that alternating colors while in motion in no way prohibits the decoy effect of flash displays. While it has not been directly tested, it stands to reason that returning to a cryptic state at the cessation of movement would similarly have no effect on the benefits of dynamic color change while in motion. Therefore, dynamic color change and the flash display decoy effect are likely complementary adaptations that can "cover each other's blind spots" with dynamic color change providing protection while in motion and the decoy effect inhibiting attacks after settlement. Intriguingly, selection may have favored both strategies in a number of organisms notably heliconius and nymphalid butterflies (personal observation).

Much as the classification of consistently visible antipredation signals is being continuously refined, there is likely significant room for improvement in how we differentiate between the various forms of hidden signals (Vane-Wright 1980, Jamie 2017, Loffler-Henry \& Sherratt 2021). The establishment of a consistent classification scheme for hidden signals would may be very useful in elucidating ecological relationships particular to different forms of hidden signal.

\subsubsection{The role of non-avian predators in selecting for hidden signals}

While avian predators are known to exert significant selective pressure on many hidden signal utilizing taxa, they are by no means the only ecologically relevant predators (Kang et al. 2017, Sargent 1978, Umbers et al. 2017). Specifically, insect predators are known to impose comparable, and in some environments, greater predation pressure on anti-predation signals using insect prey (Roslin et al. 2017). Our finding that eyespots on caterpillars can prevent attacks from an insect predator, together with the findings of Prudic et al, (2015) suggest that insects can impose selection for startle signals. While consistently visible eyespots are somewhat different from hidden signals, I argue that they likely deter predation through an analogous mechanism to many deimatic displays. This is because like deimatic displays eyespots function to make a relatively un-defended organism appear more intimidating either through resemblance to a threatening organism or by making the organism appear larger and more conspicuous (Hossie \& Sherratt 2013, Stevens et al. 2008). The fact that many hindwing hidden signals in 
insects actually feature eye-like markings supports this assertion. One key difference is that eyespots on caterpillars are often consistently visible whereas eyespot on deimatic displays are exposed transiently. While there is evidence that the sudden exposure of a previously hidden conspicuous or threatening stimuli may enhance its effect, it is difficult to envision a scenario under which consistent visibility of such markings would provide unique benefits. Therefore, I believe it is reasonable to assume that if eyespots on caterpillars can prevent attacks from an insect predator, similar markings on the hindwing deimatic displays of adult insects can do so as well.

The extent to which various insect and other non-avian predatory taxa are deterred by hidden signals remains unknown. However, our findings highlight the possibility that hidden signals may be effective at intimidating a range of arthropod predators.

\subsubsection{The role of body size in the evolution of antipredation adaptation}

In recent years body size has been demonstrated to be an important factor influencing the evolution of anti-predation signals in insects(Kang et al. 2017, Hossie et al. 2015, Penney et al. 2012). The findings of Chapter 3 and 5 have significantly contributed to this literature, providing the most taxonomically widespread support for the association between body size and evolution of anti-predation signals to date. The cause of this association remains somewhat ambiguous.

There is ample evidence that the mechanisms of many antipredation signals are more effective at deterring predation in large organisms. Large insects are also known to experience elevated predation risk (Remmel \& Tammaru 2009, Mänd et al. 2007). This suggests that they may face elevated selective pressure for secondary defenses. In support of the mechanistic explanation for the body size/antipredation signal association, a number of previous studies have demonstrated that avian predators select for anti-predation signals in large insects (Kang et al. 2017, Hossie et al. 2015). The findings of Chapter 4 indicate that this selective pattern extends to some insect predators as well. Likewise, Bae et al. (2019) found using a modified version of the computer game used in Chapter 2, that the decoy mechanism of flash displays is more effective in large prey. This appears to be the result of small prey being so difficult to find that they simply 
experience such high survival that there is little room to improve from any benefit of flash displays (Bae et al.2019).

In support of the selective pressure-based explanation for the body size/antipredation signal association, a recent phylogenetic study in mammals found no evidence of a body size/hidden signal association (Caro et al. 2020). Unlike insects, relatively large body size likely does not render mammals more vulnerable to predation. However, the mechanistic benefits afforded to hidden signals from large body size may still apply. Therefore, the body size/hidden signal association observed in some groups is likely the result of some interaction between the relatively elevated selective pressure and increased efficacy of these defenses in large species.

\subsection{Ongoing and future work}

\subsubsection{Hidden signals and aposematism}

A major aspect of the evolutionary ecology of hidden signals that has not been explored in this thesis is how the anti-predation benefits specific to hidden signals interact with the anti-predation mechanisms typically associated with consistently visible anti-predation signals e.g. aposematism, Mullerian mimicry etc. It is expected that the early evolutionary stages of aposematism may involve some fitness costs which inhibit its adoption. This is because predators will not have had the opportunity to learn and educate their young about the dangers of novel conspicuous phenotypes (Fisher 1930). A number of explanations including kin selection and the use of heterogeneous visual environments have been proposed to explain how novel conspicuous phenotypes could gain a foothold (Fisher 1930, Speed \& Ruxton 2005). However, one possible explanation that to my knowledge has not been widely discussed is that hidden signals may function as an evolutionary stepping-stone between crypsis and conspicuousness. It is plausible that the hidden signal-specific anti-predation benefits documented in this thesis may mitigate the costs of novel conspicuous phenotypes. This may allow aposematic individuals to reach a critical mass within the population, creating the necessary conditions for widespread predator education. 
In order to test this hypothesis, I have collected data on the presence/ absence of both consistently and transiently visible conspicuous signals in 1080 amphibian species. Preliminary phylogenetic analyses do suggest that hidden signals are indeed an intermediary step in the evolution of consistently visible aposematism.

\subsubsection{How insect predators contribute to the evolution of anti-predation signals globally}

Another question that remains open-ended is how important selection from insect predators is in shaping anti-predation signals in other insects. A recent global predation experiment found that the relative predation pressure exerted on caterpillars by insect predators is not homogeneous across latitudes, with attack rates increasing with proximity to the equator (Roslin et al. 2017).

In order to test if disparate levels of selection from insects has shaped latitudinal patterns in the evolution of antipredation signals, it must first be established whether insects select for hidden signals in any unique ways. One possibility is that insect predators impose unique patterns of selection on the basis of prey body size. While both birds and insects select for eyespots in relatively large caterpillars, this pattern is likely relative to the size of the predator. Because insects are generally smaller than birds, they may select for eyespots in relatively small caterpillars. To test this, wild caught yellow jacket wasps will be subjected to a series of binary choice experiments involving caterpillars of varying sizes that have been manipulated have, or not have eyespots. This experiment will be analogous to what the work done by Hossie et al. 2014 in evaluating the effect of caterpillar eyespots on avian predators. The aim of this experiment will be to obtain some insight as to the size threshold (if any) at which eyespots become effective at deterring insect predators.

Following this, a phylogenetic analysis will be performed to determine if small caterpillar species in equatorial latitudes are disproportionately more likely to have eyespots than those in more northern areas. This work will build on the findings of Hossie et al. 2014, who found that when geography is not taken into account the evolution of eyespots is associated with large body size in caterpillars. 


\subsubsection{Flash display mimicry}

The mechanism that leads to the anti-predation benefit of flash displays is likely dependent on the predator's ignorance of the preys resting color. If predators are repeatedly exposed to flash displays that have a distinctive appearance, they are likely to learn that the flash display's appearance is followed by the need to search for the preys resting appearance. A flash display that is not only conspicuous, but also resembles another organism that the predator has been exposed to, may reduce the likelihood that the predator will learn to associate the flash display with the resting appearance of the prey. A mimetic flash display may function to increase predator confusion provided that the predator has learned that the model will be absent if it appears to be absent. There are a number of putative examples of mimetic flash displays in nature including the Carolina locust (Dissosteira carolina) and the morning cloak (Nymphalis antiopa), the alfafa butterfly (Colias eurytheme) and the shorthorn grasshopper (Arphia conspersa), the midas blenny (Ecsenius midas) and the lyertailed anthid (Pseudanthias squamipinnis), and the mimic octopus (Thaumoctopus mimicus) and peacock flounder (Bothus mancus).

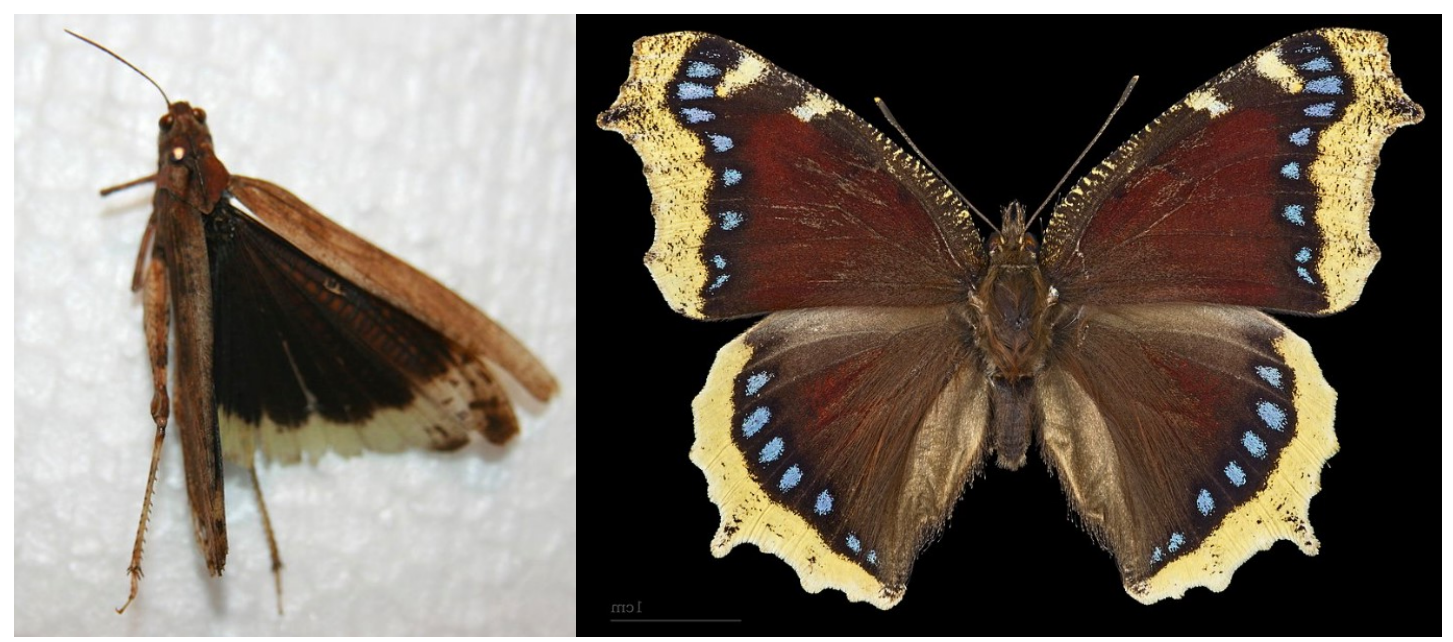

Figure 6.1, A putative example of the flash display mimicry, D. carolina left, $N$. antiopa right.

In order to test this hypothesis, we will once again use a modified version of the human computer game used in Chapter 2. Unlike previous iterations of the game the training phase will be absent. Instead, participants will experience four treatments (1. Consistently conspicuous, 2. 
Conspicuous flash display the same color as treatment 1,3. Conspicuous flash display a different color than treatment 1,4 . Consistently cryptic,) in repeating blocks. I predict that the antipredation benefit of flash displays will be enhanced by mimicry.

\subsection{Conclusion}

As a result of the research I have done through the duration of my doctoral studies I have reached a few fundamental conclusions. These are as follows. Hidden signals are a taxonomicallywidespread and ecologically important adaptation whose evolution is driven by predation. Moreover, hidden signals may prevent predation via multiple mechanisms. Hidden signals should be classified on the basis of the mechanism(s) that has led to them being selected for, which might involve an increase in the number of terms used to describe it. A diverse array of predators likely select for hidden signals and future research in this area should take into account whole predator guilds rather than just one model predator. Body size likely has some degree of influence on the evolution of hidden signals across most taxonomic groups and therefore should be taken into account when testing for any ecological or evolutionary relationships involving hidden signals. More research is required to further increase understanding of this previously neglected aspect an antipredation adaptation.

\subsection{References}

Andersson, M. 1994 Sexual selection. Princeton, NJ: Princeton University Press.

Bae S, Kim D, Sherratt TN, Caro T, Kang C. 2019 How size and conspicuousness affect the efficacy of flash coloration. Behav. Ecol. 30, 697 - 702. (doi:10. 1093/beheco/arz006)

Caro T, Raees H, Stankowich T. 2020 Flash behavior in mammals? Behav. Ecol. Sociobiol. 74, 1 - 7. (doi:10.1007/s00265-020-2819-0)

Cott HB. 1940 Adaptive coloration in animals. London, UK: Methuen.

Edmunds M. 1974. Defence in animals: a survey of anti-predator defences. New York (USA): Longman Publishing Group. 
Endler JA. 1984 Progressive background in moths, and a quantitative measure of crypsis. Biol. J. Linn. Soc. 22, 187 - 231. (doi:10.1111/j.1095-8312.1984. tb01677.x)

Fisher, R. A. 1930 The genetical theory of natural selection. Oxford: Clarendon Press.

Hossie TJ, Sherratt TN. 2013 Defensive posture and eyespots deter avian predators from attacking caterpillar models Anim. Behav. 86, 383 - 389. (doi:10.1016/j.anbehav.2013.05.029)

Hossie TJ, Skelhorn J, Breinholt JW, Kawahara AY, Sherratt TN. 2015 Body size affects the evolution of eyespots in caterpillars. Proc. Natl Acad. Sci. USA 112, $6664-6669$.

(doi:10.1073/pnas. 1415121112)

Jamie G. 2017 Signals, cues and the nature of mimicry. Proc. R. Soc. B 284, 20162080. (doi:10. 1098/rspb.2016.2080)

Kang C, Zahiri R, Sherratt TN. 2017 Body size affects the evolution of hidden colour signals in moths. Proc. R. Soc. B 284, 20171287. (doi:10.1098/rspb. 2017.1287)

Loeffler-Henry K, Sherratt TN. 2021 A case for mutualistic deceptive mimicry. Biol. J. Linn. Soc. (doi:10.1093/biolinnean/blaa219)

Mänd T, Tammaru T, Mappes J. 2007 Size dependent predation risk in cryptic and conspicuous insects. Evol. Ecol. 21, 485- 498. (doi:10.1007/ s10682-006-9130-z)

Murali G. 2018 Now you see me, now you don't: dynamic flash coloration as an antipredator strategy in motion. Anim. Behav. 142, 207 - 220. (doi:10. 1016/j.anbehav.2018.06.017)

Penney HD, Hassall C, Skevington JH, Abbott KR, Sherratt TN. 2012 A comparative analysis of the evolution of imperfect mimicry. Nature 483,461 - 464. (doi:10.1038/nature10961)

Prudic KL, Stoehr AM, Wasik BR, Monteiro A. 2015 Eyespots deflect predator attack increasing fitness and promoting the evolution of phenotypic plasticity. Proc. R. Soc. B 282, 20141531. (doi:10. 1098/rspb.2014.1531)

Remmel T, Tammaru T. 2009 Size-dependent predation risk in tree-feeding insects with different colouration strategies: A field experiment. J. Anim. Ecol. 78, 973-980. (doi:10.1111/j.13652656.2009.01566.x)

Roslin T et al. 2017 Higher predation risk for insect prey at low latitudes and elevations. Science 356, 742-744. (doi:10.1126/science.aaj1631)

Sargent TD. 1978 On the maintenance of stability in hindwing diversity among moths of the genus Catocala (Lepidoptera: Noctuidae). Evolution 32, 424 - 434. (doi:10.2307/2407609)

Speed, M. P. \& Ruxton, G. 2005 Aposematism: what should our starting point be? Proc. R. Soc. B 272, 431-438. (doi:10.1098/rspb.2004.2968.) 
Stevens M, Hardman J, Stubbins CL. 2008 Conspicuousness, not eye mimicry, makes 'eyespots' effective antipredator signals. Behav. Ecol. 19, 525 - 531. (doi:10.1093/beheco/arm162)

Umbers KDL, Bona SD, White TE, Lehtonen J, Mappes J, Endler JA. 2017 Deimatism: a neglected component of antipredator defence. Biol Lett. 13, 20160936.

(doi:10.1098/rsbl.2016.0936)

Vane-Wright, R. I. 1980 On the definition of mimicry. Biol. J. Linn. Soc. 13, $1-6$. (doi:10.1111/j.1095-8312. 1980.tb00066.x) 


\section{Appendix a}

\section{Supplementary materials for the paper Flash behavior increases prey survival}

Karl Loeffler-Henry, Changku Kang, Yolanda Yip, Tim Caro, Thomas N. Sherratt 
Supplementary table S1. Analysis of deviance table for the results of Experiment $1 .{ }^{*} \mathrm{P}<0.05, * *$ $\mathrm{P}<0.01, * * * \mathrm{P}<0.001$. The estimates of the lowest AIC model (i.e. the final model after backward model selection) are presented. If an explanatory variable was removed during the model selection procedure, we present the estimate values when the term was deleted. The removed terms are marked with (R). Likelihood ratio tests on the lowest AIC model with and without random effect (participants ID) showed that responses to the treatments varied between the participants for attack and detection but not for giving up time.

\begin{tabular}{|c|c|c|c|c|c|}
\hline $\begin{array}{l}\text { Response } \\
\text { variables }\end{array}$ & Explanatory variables & Estimate & D.f. & $\chi^{2}$ & $P\left(>\left|\chi^{2}\right|\right)$ \\
\hline \multirow{7}{*}{$\begin{array}{l}\text { Whether } \\
\text { the prey } \\
\text { was } \\
\text { attacked or } \\
\text { not }\end{array}$} & Intercept & 0.37 & 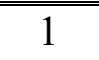 & & \\
\hline & Treatment & 17.22 & 1 & 10.55 & $0.001 * *$ \\
\hline & Background & -3.75 & 1 & 6.78 & $0.009 * *$ \\
\hline & Order & 9.67 & 1 & 25.42 & $<0.001 * * *$ \\
\hline & Treatment $*$ Background & 4.57 & 1 & 25.63 & $<0.001 * * *$ \\
\hline & Treatment $*$ Order & -7.58 & 1 & 5.09 & $0.02 *$ \\
\hline & Number of duds & -2.54 & 1 & 9.36 & $0.002 * *$ \\
\hline \multirow{7}{*}{$\begin{array}{l}\text { Detection } \\
\text { time }\end{array}$} & Intercept & 1.80 & 1 & & \\
\hline & Treatment (R) & -0.05 & 1 & 0.81 & 0.37 \\
\hline & Background & 0.14 & 1 & 5.88 & $0.02 *$ \\
\hline & $\operatorname{Order}(\mathrm{R})$ & 0.06 & 1 & 0.25 & 0.62 \\
\hline & Treatment $*$ Background $(\mathrm{R})$ & 0.03 & 1 & 0.27 & 0.60 \\
\hline & Treatment $*$ Order $(\mathrm{R})$ & 0.09 & 1 & 0.54 & 0.46 \\
\hline & Number of duds (R) & -0.001 & 1 & 0.001 & 0.97 \\
\hline \multirow{7}{*}{$\begin{array}{l}\text { Giving up } \\
\text { time }\end{array}$} & Intercept & 2.67 & 1 & & \\
\hline & Treatment & 0.19 & 1 & 9.92 & $0.002 * *$ \\
\hline & Background & 0.28 & 1 & 13.15 & $<0.001 * * *$ \\
\hline & Order & -0.26 & 1 & 4.76 & $0.03 *$ \\
\hline & Treatment $*$ Background $(\mathrm{R})$ & 0.06 & 1 & 0.88 & 0.35 \\
\hline & Treatment $*$ Order $(\mathrm{R})$ & -0.09 & 1 & 0.30 & 0.58 \\
\hline & Number of duds & -0.17 & 1 & 13.95 & $<0.001 * * *$ \\
\hline
\end{tabular}


Supplementary Table S2. Analysis of deviance table for the results of Experiment 2. $* \mathrm{P}<0.05$, ** $\mathrm{P}<0.01, * * * \mathrm{P}<0.001$. The estimates of the lowest AIC model (i.e. the final model after backward model selection) are presented. If an explanatory variable was removed during the model selection procedure, we present the estimate values when the term was deleted. The removed terms are marked with (R). Likelihood ratio tests on the model with and without random effect (participants ID) showed that responses to the treatments varied between the participants for all response variables.

\begin{tabular}{|c|c|c|c|c|c|}
\hline $\begin{array}{l}\text { Response } \\
\text { variables }\end{array}$ & Explanatory variables & Estimate & D.f. & $\chi^{2}$ & $P\left(>\left|\chi^{2}\right|\right)$ \\
\hline \multirow{7}{*}{$\begin{array}{l}\text { Whether } \\
\text { the prey } \\
\text { was } \\
\text { attacked or } \\
\text { not }\end{array}$} & Intercept & 0.81 & 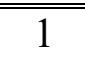 & & \\
\hline & Treatment & 1.06 & 1 & 13.44 & $<0.001 * * *$ \\
\hline & Background (R) & -0.41 & 1 & 1.69 & 0.19 \\
\hline & Order & 1.10 & 1 & 5.38 & $0.02 *$ \\
\hline & Treatment * Background (R) & -0.22 & 1 & 0.99 & 0.32 \\
\hline & Treatment $*$ Order $(\mathrm{R})$ & -0.90 & 1 & 1.74 & 0.19 \\
\hline & Number of duds & -0.30 & 1 & 1.83 & 0.18 \\
\hline \multirow{7}{*}{$\begin{array}{l}\text { Detection } \\
\text { time }\end{array}$} & Intercept & 1.75 & 1 & & \\
\hline & Treatment (R) & -0.00 & 1 & 0.00 & 0.93 \\
\hline & Background (R) & 0.07 & 1 & 1.50 & 0.22 \\
\hline & Order (R) & -0.09 & 1 & 0.91 & 0.34 \\
\hline & Treatment $*$ Background $(\mathrm{R})$ & -0.08 & 1 & 3.09 & 0.08 \\
\hline & Treatment $*$ Order $(\mathrm{R})$ & 0.16 & 1 & 2.02 & 0.16 \\
\hline & Number of duds (R) & -0.02 & 1 & 0.29 & 0.59 \\
\hline \multirow{7}{*}{$\begin{array}{l}\text { Giving up } \\
\text { time }\end{array}$} & Intercept & -0.19 & 1 & & \\
\hline & Treatment $(\mathrm{R})$ & 0.07 & 1 & 1.18 & 0.28 \\
\hline & Background (R) & -0.04 & 1 & 0.20 & 0.65 \\
\hline & Order (R) & -0.01 & 1 & 0.01 & 0.92 \\
\hline & Treatment $*$ Background $(\mathrm{R})$ & -0.03 & 1 & 0.20 & 0.66 \\
\hline & Treatment $*$ Order $(\mathrm{R})$ & -0.35 & 1 & 3.12 & 0.08 \\
\hline & Number of duds & -0.19 & 1 & 9.39 & $0.002 * *$ \\
\hline
\end{tabular}


Supplementary Table S3. Analysis of deviance table for the comparison between CF and IF prey. $* \mathrm{P}<0.05, * * \mathrm{P}<0.01, * * * \mathrm{P}<0.001$. The estimates of the lowest AIC model (i.e. the final model after backward model selection) are presented. If an explanatory variable was removed during the model selection procedure, we present the estimate values when the term was deleted. The removed terms are marked with $(\mathrm{R})$.

\begin{tabular}{|c|c|c|c|c|c|}
\hline $\begin{array}{l}\text { Response } \\
\text { variables }\end{array}$ & Explanatory variables & Estimate & D.f. & $\chi^{2}$ & $P\left(>\left|\chi^{2}\right|\right)$ \\
\hline \multirow{6}{*}{$\begin{array}{l}\text { Whether the } \\
\text { prey was } \\
\text { attacked or } \\
\text { not }\end{array}$} & Intercept & -1.07 & 1 & & \\
\hline & Treatment & -0.25 & 1 & 3.27 & 0.07 \\
\hline & Background & -0.32 & 1 & 7.08 & $0.007^{* *}$ \\
\hline & Treatment * Background & -0.25 & 1 & 2.19 & 0.13 \\
\hline & Order & 1.01 & 1 & 17.41 & $<0.001 * * *$ \\
\hline & Number of duds & -0.26 & 1 & 8.02 & $0.005^{* *}$ \\
\hline \multirow{6}{*}{$\begin{array}{l}\text { Detection } \\
\text { time }\end{array}$} & Intercept & 2.18 & 1 & & \\
\hline & Treatment & 0.04 & 1 & 0.50 & 0.48 \\
\hline & Background & 0.11 & 1 & 3.61 & 0.06 \\
\hline & Treatment $*$ Background & -0.02 & 1 & 0.08 & 0.78 \\
\hline & Order & -0.14 & 1 & 1.25 & 0.26 \\
\hline & Number of duds & -0.09 & 1 & 5.84 & $0.02 *$ \\
\hline \multirow{6}{*}{$\begin{array}{l}\text { Giving up } \\
\text { time }\end{array}$} & Intercept & 2.35 & 1 & & \\
\hline & Treatment & 0.05 & 1 & 1.81 & 0.18 \\
\hline & Background & 0.12 & 1 & 2.25 & 0.13 \\
\hline & Treatment * Background & -0.03 & 1 & 3.11 & 0.08 \\
\hline & Order (R) & 0.03 & 1 & 0.07 & 0.79 \\
\hline & Number of duds & -0.22 & 1 & 35.10 & $<0.001 * * *$ \\
\hline
\end{tabular}




\section{Appendix b}

\section{Supplemental Figure for Chapter 3}
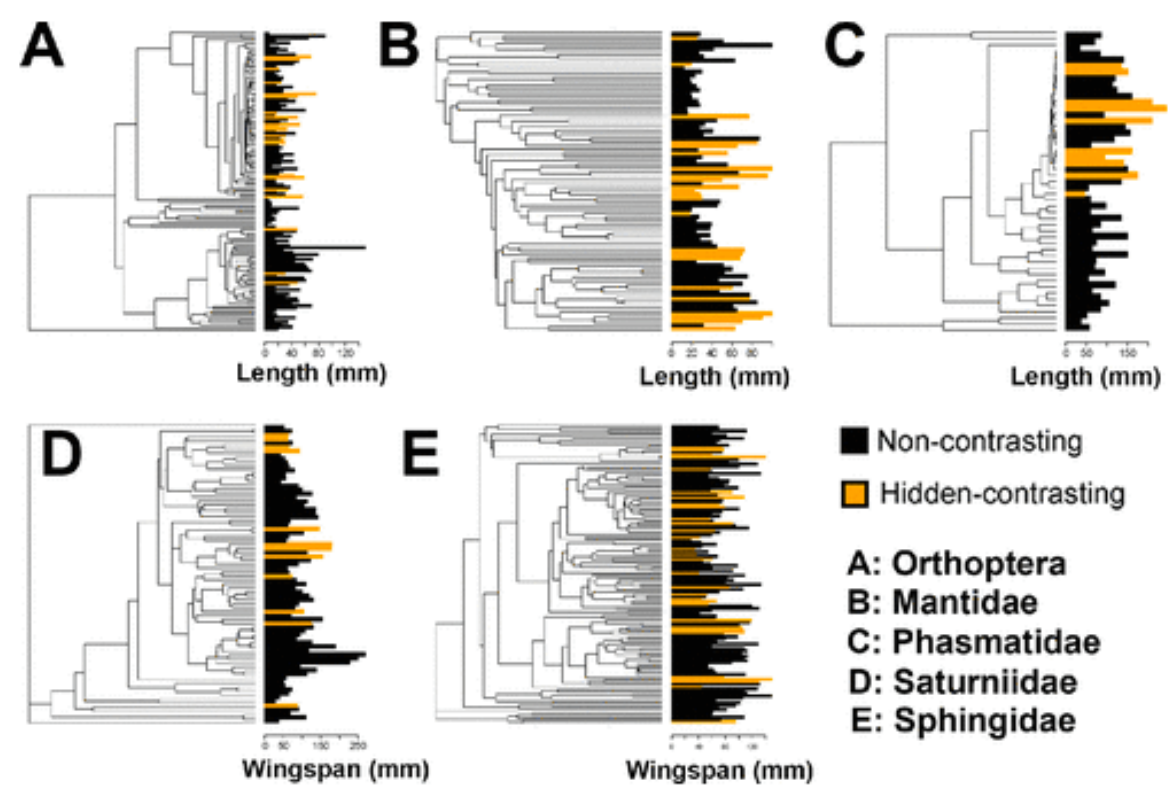

Non-contrasting

$\square$ Hidden-contrasting

A: Orthoptera

B: Mantidae

C: Phasmatidae

D: Saturniidae

E: Sphingidae

Coloration classification and body lengths of insect species used in this study placed in the context of a phylogeny. The trees show their phylogenetic relationships, while the barplot depicts the length (or wingspan) of each species. The colors of bars refer to the presence of hidden contrasting color signals in each species. 
Appendix C Supplementary Material for chapter 5

The anti-predation benefit of flash displays is related to the distance at which the prey initiates its escape

Karl Loeffler-Henry, Changku Kang \& Thomas N. Sherratt 
Table S1. RGB values of the prey used in the training and test flashing game. The cryptic green colour had the mean background R, G, B values.

\begin{tabular}{|l|l|l|l|}
\hline Colour & R & G & B \\
\hline Blue & 0 & 0 & 255 \\
\hline Green & 0 & 255 & 0 \\
\hline Cyan & 0 & 255 & 255 \\
\hline Red & 255 & 0 & 0 \\
\hline Magenta & 255 & 0 & 255 \\
\hline Yellow & 255 & 255 & 0 \\
\hline Cryptic green & 73 & 151 & 19 \\
\hline
\end{tabular}


Thank you for participating in our research!

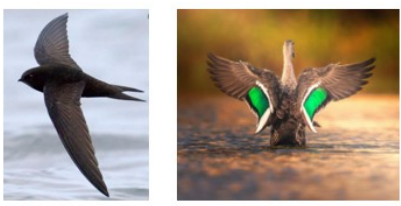

We ask you to categorize birds as those with "Hidden colours" (Y) or "No hidden colours" (N).

Birds with hidden colours ( $Y$ ) display novel colours when in flight compared to at rest.

Birds with no hidden colours ( $\mathrm{N}$ ) do not display any novel colours in flight compared to at rest.

The following slides of birds in flight and at rest will show some examples of the classification being applied.

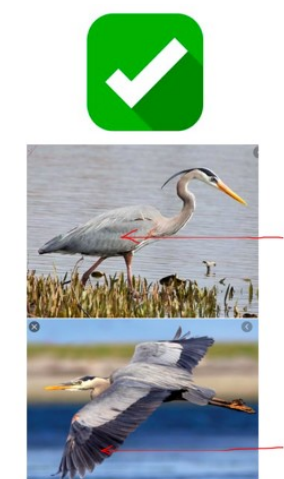

The wing feathers have a novel colour that is hidden in the resting position. Therefore this bird would be categorized as one with hidden colours (Y).
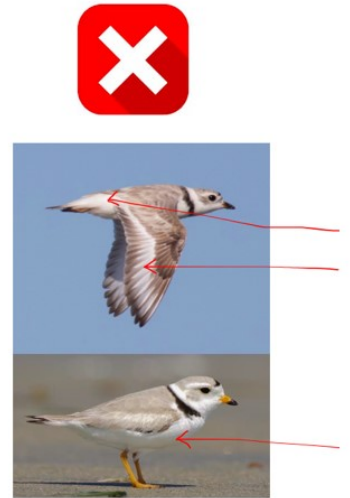

While the rump is white, this species has no novel colours only exposed when in flight. Therefore this bird would be classified as having no hidden colours (N).

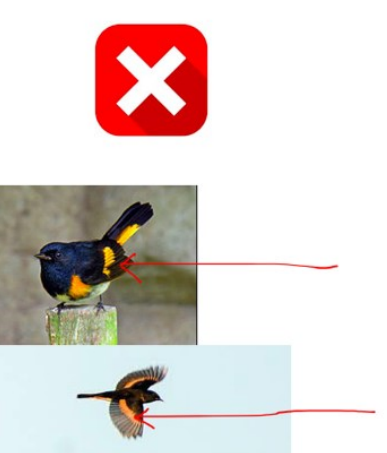

While the flight feathers are coloured, this species has no novel colours exposed when in flight. Therefore this bird would be classified as one with no hidden colours (N)

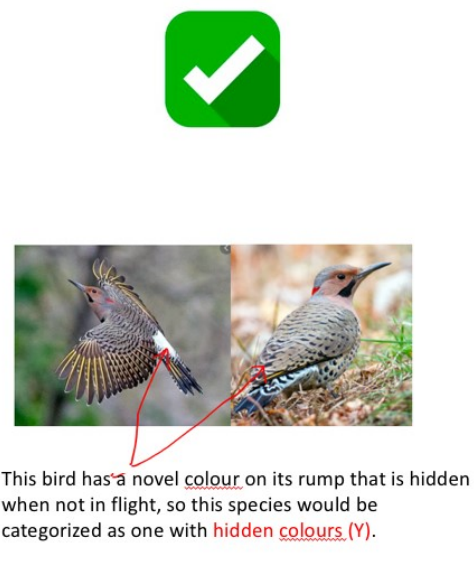

Figure S1. Instructions presented to the human volunteers prior to categorization of birds as "contrasting" and "non- contrasting". 


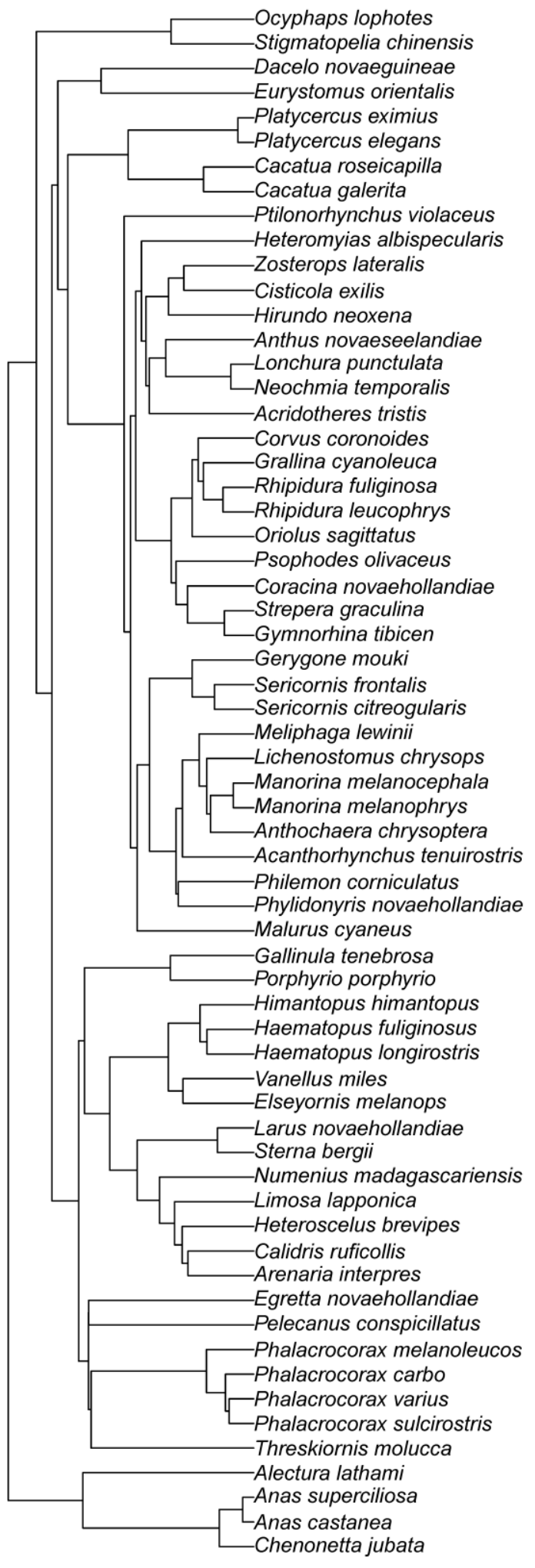

Figure S2. The maximum clade credibility tree of all analysed bird species. 

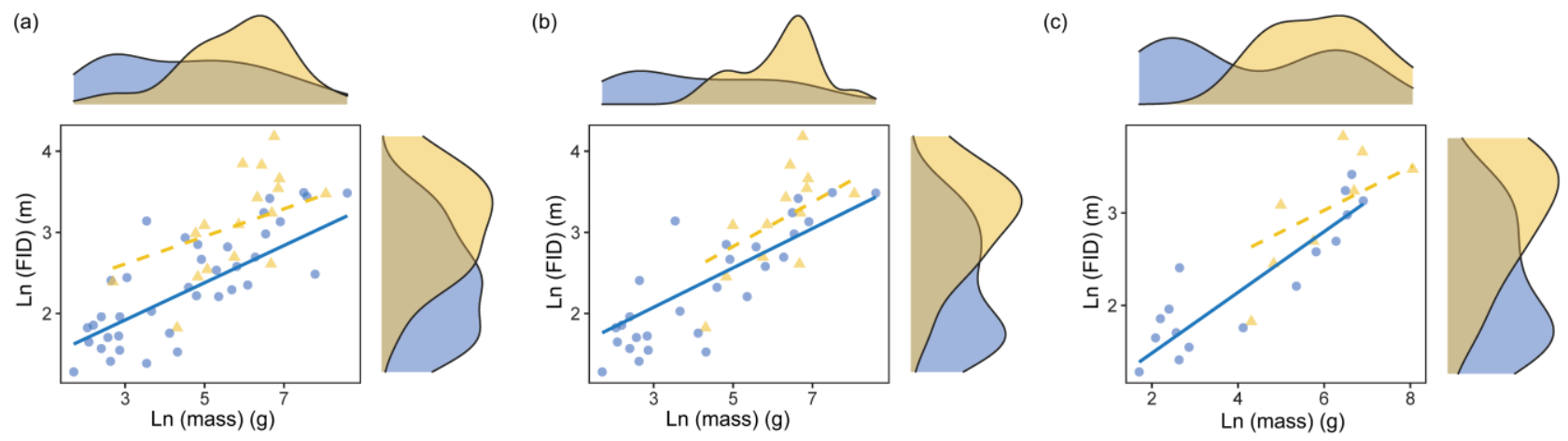

Figure S3. Scatterplots and density plots depicting the relationship between body mass, flight initiation distance (FID), and the presence of putative flashing signals in birds. To decide whether each species possess hidden colour patch, we created and used several binary variables:

(a) more than $70 \%$ of volunteers agreed on their classification ( $n=55$ species), (b) more than $80 \%$ agreed $(n=41)$, (c) more than $90 \%$ agreed $(n=24)$. The trend lines represent the predictions from the PGLS models using the maximum clade credibility tree. 
Table S2. Results of PGLS models (assuming a Brownian motion model of trait evolution) predicting the flight initiation distances of birds using the maximum clade credibility tree.

\begin{tabular}{|c|c|c|c|c|}
\hline $\begin{array}{c}\text { The way that the presence } \\
\text { of flashing signal was } \\
\text { inferred }\end{array}$ & Predictor & Coefficient & $t$ & P-value \\
\hline \multirow{3}{*}{$\begin{array}{l}\text { More than } 70 \% \text { volunteers } \\
\text { agreed on their } \\
\text { classifications ( } n=55 \\
\text { species) }\end{array}$} & Flashing signal presence & 0.14 & 2.91 & 0.007 \\
\hline & Log (mass) & 0.21 & 4.95 & $<0.001$ \\
\hline & Interaction & 0.01 & 0.32 & 0.55 \\
\hline \multirow{3}{*}{$\begin{array}{l}\text { More than } 80 \% \text { volunteers } \\
\text { agreed on their } \\
\text { classifications ( } n=41 \\
\text { species) }\end{array}$} & Flashing signal presence & 0.10 & 1.66 & 0.11 \\
\hline & Log (mass) & 0.22 & 4.51 & $<0.002$ \\
\hline & Interaction & 0 & -0.14 & 0.83 \\
\hline \multirow{3}{*}{$\begin{array}{l}\text { More than } 90 \% \text { volunteers } \\
\text { agreed on their } \\
\text { classifications } \\
\text { ( } n=24 \text { species })\end{array}$} & Flashing signal presence & 0.04 & 0.41 & 0.69 \\
\hline & Log (mass) & 0.26 & 3.65 & 0.002 \\
\hline & Interaction & 0.01 & 0.25 & 0.79 \\
\hline
\end{tabular}


Table S3. Results of PGLS models (assuming a Brownian motion model of trait evolution) revealing the slope of the relationship between log body mass and the presence of hidden colour patches.

\begin{tabular}{|c|c|c|c|}
\hline $\begin{array}{c}\text { The way that the } \\
\text { presence of flashing } \\
\text { signal was inferred }\end{array}$ & Coefficient & $t$ & P-value \\
\hline $70 \%$ agreed & 0.35 & 2.46 & 0.02 \\
\hline $80 \%$ agreed & 0.56 & 3.04 & 0.006 \\
\hline $90 \%$ agreed & 0.64 & 3.07 & 0.008 \\
\hline Proportion & 0.93 & 2.85 & 0.01 \\
\hline
\end{tabular}




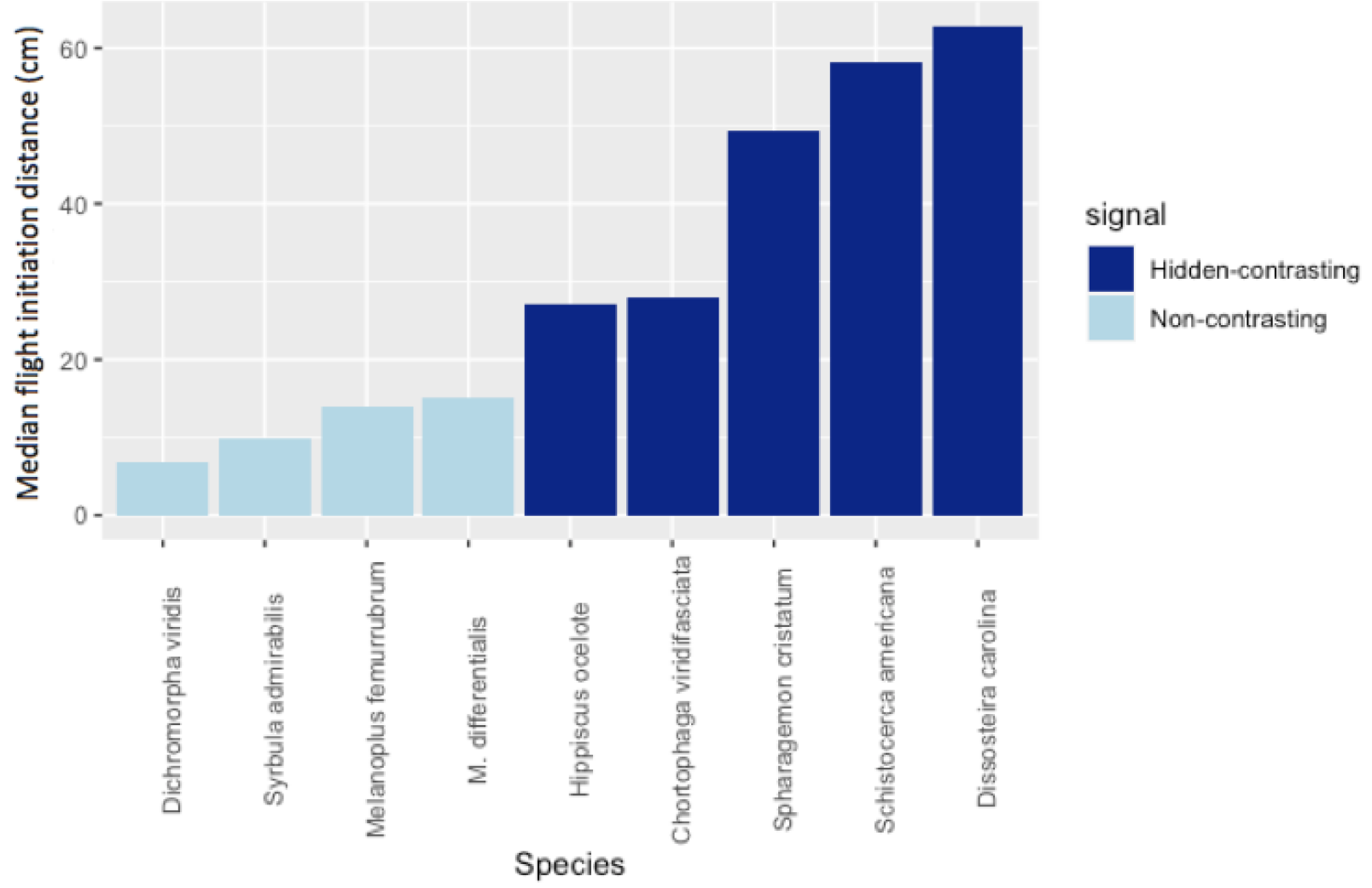

Figure S4. The median flight initiation distances $(\mathrm{cm})$ of orthoptera species with and without hidden contrasting hindwing flashing signals (as classified by KLH on the basis of the average contrast between the hindwing and forewing in the visible spectrum, measured using ImageJ). The flight initiation data were extracted from Figure 2 in Butler (2013) Behaviour 150, 15311552 [ref 15 in the main text]. 